Support Information

\title{
Upscaling Photoredox Cross-Coupling Reactions in Batch using Immersion-Well Reactors
}

\author{
Isabelle Grimm, ${ }^{+}$Simone T. Hauer, ${ }^{+}$Tim Schulte, ${ }^{+}$Gina Wycich, ${ }^{\dagger}$ Karl D. Collins, ${ }^{+}$Kai Lovis, ${ }^{\ddagger}$ Lisa \\ Candish*, \\ † Small Molecule Innovations, Bayer AG, Pharmaceuticals. Aprather Weg 18a, 42113 Wuppertal, Germany. \\ ₹ Chemical Development, Bayer AG, Pharmaceuticals. Friedrich-Ebert Straße 217, 42117 Wuppertal, Germany.
}

lisa.candish@bayer.com 


\section{Contents}

1. General information $\quad$ S3

2. Photoreactor specifications $\quad$ S3

3. Reaction set-up in IW reactors $\quad$ S6

4. $s p^{2} / s p^{3}$ Decarboxylative coupling reactions $\quad \mathrm{S7}$

5. $s p^{2} / s p^{3}$ Reductive coupling reactions $\quad \mathrm{S} 16$

$\begin{array}{ll}\text { 6. } s p^{3} / s p^{3} \text { Decarboxylative coupling reaction } & \text { S27 }\end{array}$

7. $s p^{2} / s p^{3}$ coupling of benzyl trifluoroborate $\quad$ S29

$\begin{array}{ll}\text { 8. Scale-up in IW side-loop reactors } & \text { S31 }\end{array}$

$\begin{array}{ll}\text { 8.1 Small base screen } & \text { S31 }\end{array}$

$8.240 \mathrm{mmol}$ scale reaction $\quad$ S32

$8.3400 \mathrm{mmol}$ scale reaction $\quad$ S34

9. Reactions up-scaled in round-bottom flasks $\quad$ S35

10. References $\quad$ S36

$\begin{array}{lr}\text { 11. NMR spectra } & \text { S37 }\end{array}$ 


\section{General information}

All chemicals were used as purchased. The photocatalyst was purchased from WuXi AppTec. Dry solvents were purchased from Acros as AcrosSeal ${ }^{\circledR}$, generally over molecular sieves, and were used as purchased. All chemicals were stored on the bench and used without pre-drying. Small-scale reactions were performed in sealed microwave vials $(10 \mathrm{~mL})$ and large-scale reactions were performed in immersion-well reactors. All glassware was used directly without drying.

Crude material was purified using silica gel column chromatography with Isolera ${ }^{\mathrm{TM}}$ from Biotage ${ }^{\circledR}$.

NMR spectra were recorded on a Bruker Avance DPX200, Bruker Avance DPX300, Bruker Avance DRX400 or Bruker Avance DRX500 instrument with a $1 \mathrm{H}$ dual Cryoprobe. ${ }^{1} \mathrm{H}$ NMR chemical shifts are given with respect to TMS or the solvent as internal standard. NMR peak forms are stated as they appear in the spectra, possible higher order effects have not been considered. The multiplicity is noted where it can be clearly defined: singulet $(\mathrm{s})$, doublet $(\mathrm{d})$, triplet $(\mathrm{t})$, multiplet $(\mathrm{m})$, quartet $(\mathrm{q})$; broad $(\mathrm{br})$. The data were processed using Bruker XWINNMR 3.5 and Topspin 1.3 software. NMR spectra were visualized using ACD/SpecManager (ACD/labs Release: 12.00, Product Version 12.5.

LM-MS spectrometry was performed on an Agilent MS Quad 6150;HPLC: Agilent 1290; Column: Waters Acquity UPLC HSS T3 $1.8 \mu \mathrm{m} 50 \times 2.1 \mathrm{~mm}$; eluent A: $1 \mathrm{~L}$ water $+0.25 \mathrm{~mL}$ formic acid, eluent B: $1 \mathrm{~L}$ acetonitrile $+0.25 \mathrm{~mL}$ formic acid; gradient: $0.0 \mathrm{~min} 90 \% \mathrm{~A} \rightarrow 0.3 \mathrm{~min} 90 \% \mathrm{~A} \rightarrow 1.7 \mathrm{~min} 5 \% \mathrm{~A} \rightarrow 3.0 \mathrm{~min} 5 \% \mathrm{~A}$; oven: $50{ }^{\circ} \mathrm{C}$; flow rate: $1.20 \mathrm{~mL} / \mathrm{min}$; UV-Detection: $205-305 \mathrm{~nm}$.

HRMS measurements were performed using either a Thermo Scientific FT-MS [System UHPLC+: Thermo Scientific UltiMate 3000; Column: Waters, HSST3, 2.1 x 75 mm, C18 $1.8 \mu \mathrm{m}$; Eluent A: 1 l Water + 0.01\% Formic acid; Eluent B: 1 l Acetonitrile + 0.01\% Formic acid; Gradient: 0.0 min 10\% B $\rightarrow 2.5 \mathrm{~min} 95 \%$ B $\rightarrow 3.5 \mathrm{~min} 95 \%$ B; Oven: $50^{\circ} \mathrm{C}$; Flow: $0.90 \mathrm{ml} / \mathrm{min}$; UV-Detection: $210 \mathrm{~nm} /$ Optimum Integration Path $210-300 \mathrm{~nm}$ ] or a TOF MS ES+.

The nickel catalyst ( $\mathrm{NiCl}_{2}$.DME) can cause rrespiratory sensitization (Category 1), H334.

\section{Photoreactor specifications}

Small-scale reactions were performed using EvoluChem ${ }^{\text {TM }}$ PhotoRedOx Box and PhotoRedOx Duo reactors from HepatoChem equipped with high powered LEDs from Kessil ${ }^{\circledR}\left(\mathrm{PR} 160, \lambda_{\max }=427 \mathrm{~nm}, 45 \mathrm{~W}\right.$ [input],).

(For more information about the Kessil high powered LEDs used in in this work see: https://www.kessil.com/photoreaction/PR160L.php)

Large-scale reactions were performed in immersion-well reactors purchased from Peschl Ultraviolet with blue LEDs (radiant flux $=27 \mathrm{~W}, \lambda_{\max }=460 \mathrm{~nm}$ ) (novaLIGHT TLED100-460, Article number 44295).

Table S1: Reactor volumes and optical path lengths of IW reactors.

\begin{tabular}{cc}
\hline volume (mL) & $\begin{array}{c}\text { optical path length } \\
\text { (mm) }\end{array}$ \\
\hline 150 & 6.5 \\
250 & 11 \\
350 & 14 \\
850 & 27 \\
\hline
\end{tabular}


Side-loop reactions were carried out in reactors purchased from Peschl Ultraviolet with blue LEDS (radiant flux $=47 \mathrm{~W}, \lambda_{\max }=420 \mathrm{~nm}$ ). (novaLIGHT TLED100-420, Article number 44294).

Table S2: Reactor volumes and optical path lengths of IW side-loop reactors.

\begin{tabular}{ccccc}
\hline $\begin{array}{c}\text { IW reactor } \\
\text { volume }(\mathbf{m L})\end{array}$ & $\begin{array}{c}\text { side-loop } \\
\text { volume }(\mathbf{m L})\end{array}$ & $\begin{array}{c}\text { optical path length } \\
\mathbf{( \mathbf { m m } )}\end{array}$ & $\begin{array}{c}\text { Pump flow rate } \\
\mathbf{( L / m L )}\end{array}$ & $\begin{array}{c}\text { Internal diameter } \\
\text { tubing }(\mathbf{m m})\end{array}$ \\
\hline 250 & 500 & 5 & 9 & 4 \\
1000 & 5000 & 10 & 10 & 12 \\
\hline
\end{tabular}

\section{Reaction temperature:}

The LED lamp used in the described reactions were cooled by recirculated chilled water to prevent potential overheating.

The temperature within the IW-reactor during reaction was measured for both the decarboxylative coupling and the reductive coupling at different time points of the reactions. The reaction temperatures were measured to be between $25-27^{\circ} \mathrm{C}$.

The temperature within the side-loop IW-reactor was maintained between $22-25^{\circ} \mathrm{C}$ using a thermostat.

\section{Safety note - preventing pressure build up in reactions that generate $\mathrm{CO}_{2}$.}

When performing reactions that generate gasses, such as $\mathrm{CO}_{2}$, one must take precautions to ensure that there is no pressure build up in the reactor. In the case of the IW reactors used in this study, the $\mathrm{CO}_{2}$ generated was liberated though the rubber seals where the immersion tube was inserted into the reaction flask (Figure S1).

This suggests that the reactor is not gas-tight, however, we did not observe that this was detrimental to the reaction in general. With other reactor designs, a gas-bubbler could be attached to facilitate release of any gases generated.
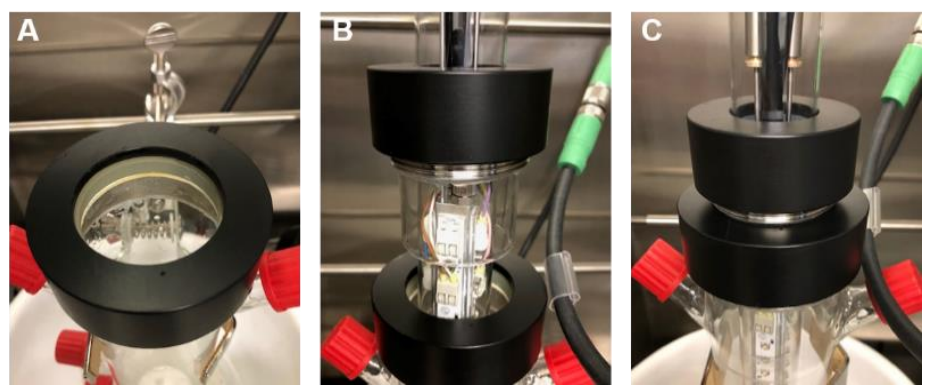

Figure S1: A. Rubber seal of the reactor vessel. B. Glass joint of immersion tube. C. Reactor vessel and immersion tube together. 


\section{Diagram of reactors}
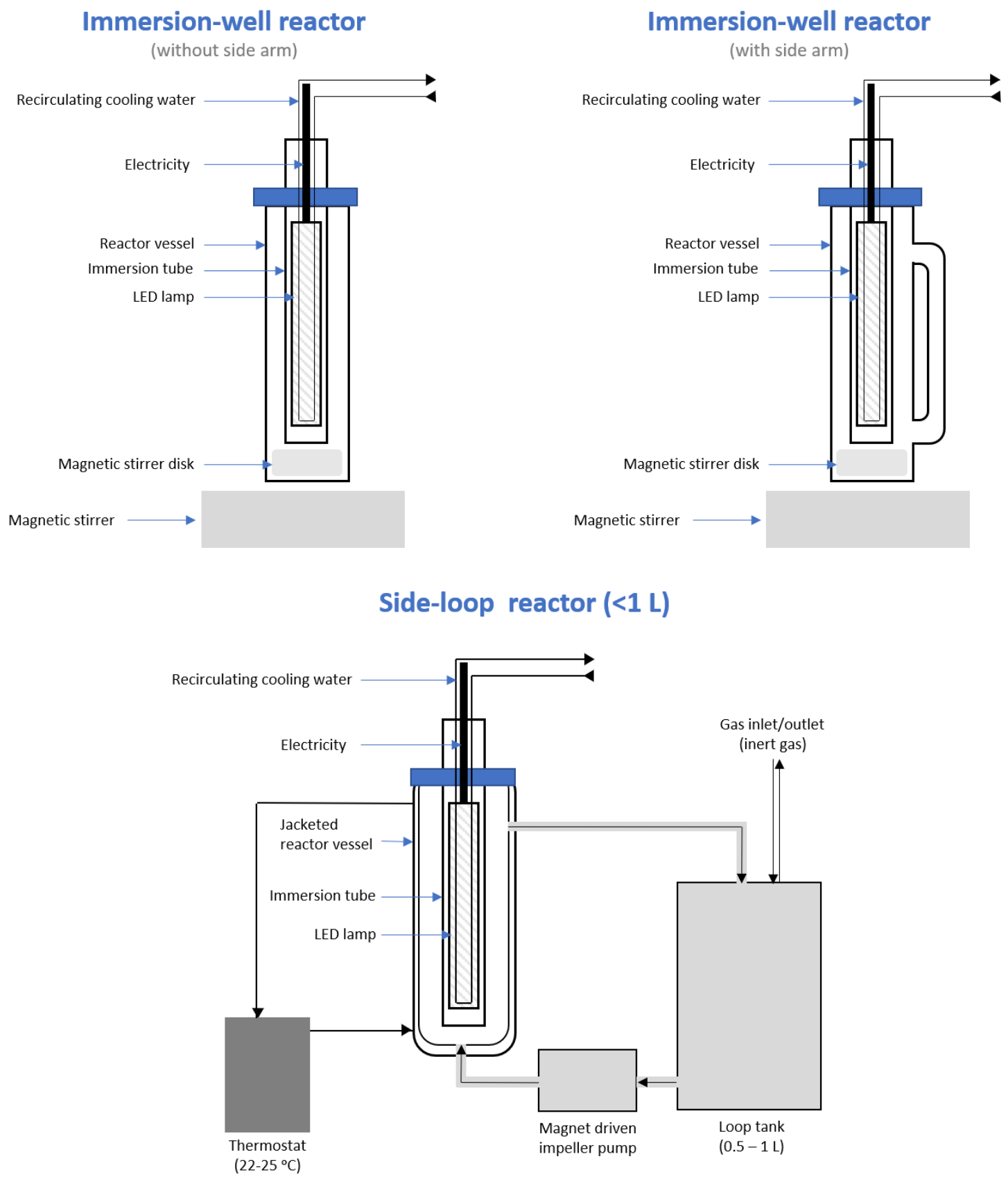

Figure S2: Diagram of different reactors 


\section{Reaction set-up in IW reactors}

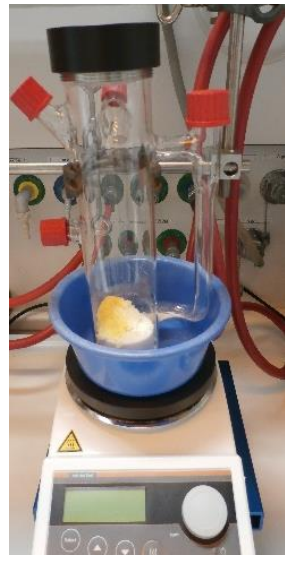

Solids weighed into immersion-well.

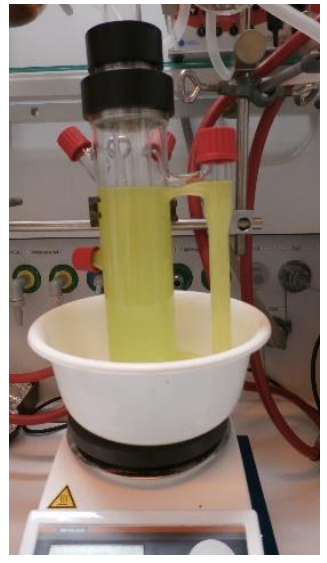

Solvent added, immersion-tube fitted, and reaction degassed by sparging with Ar.

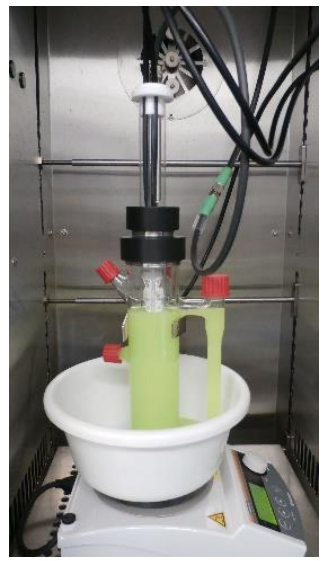

Reaction in PhotoCabinet with LEDs in immersion-

tube.

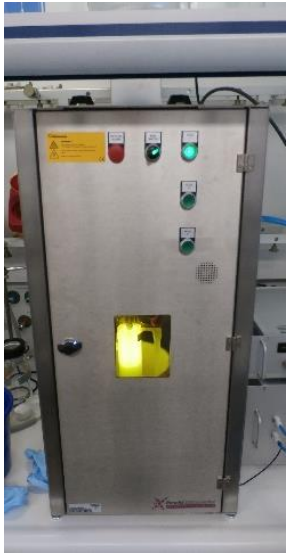

Reaction irradiated in

PhotoCabinet.

Figure S3: Workflow for the set-up of reactions in the IW reactor.

A stirring speed of $300 \mathrm{rpm}$ was used for the reactions. This parameter has not been optimized.

Note: The IW reactor vessel detailed in Figure $\mathrm{S} 1$ has a side-arm ( $50 \mathrm{~mL}$ approximate volume) that is described by the manufacturer as a circulating tube. This, along with a PTFE-magnetic circulation pump, is reported by the manufacturer to ensure thorough mixing of the reaction as, due to the shape of the vessel, the vortex generated in the annular gap does not allow adequate substance transfer. ${ }^{\mathrm{s}}$ We have also achieved comparable yields in reaction vessels that do not have a side-arm, suggesting that sufficient levels of mixing are achieved without the side-arm. 


\section{4. $s p^{2} / s p^{3}$ Deacrboxylative coupling reactions}

\section{tert-Butyl 2-(4-methoxycarbonylphenyl)pyrrolidine-1-carboxylate}
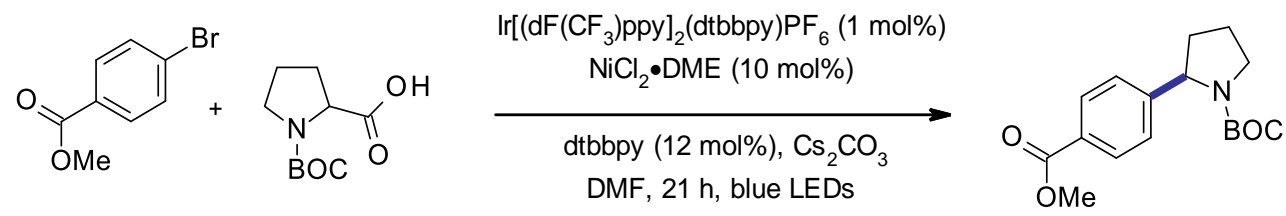

\section{$0.1 \mathrm{mmol}$ scale reaction}

To a microwave flask fitted with stirring magnet was added methyl 4-bromobenzoate $(0.1 \mathrm{mmol}, 21.5 \mathrm{mg}), 1$ tert-butoxycarbonylpyrrolidine-2-carboxylic acid $(0.15 \mathrm{mmol}, 32.3 \mathrm{mg}), \mathrm{Cs}_{2} \mathrm{CO}_{3}(0.15 \mathrm{mmol}, 48.8 \mathrm{mg})$, $\operatorname{Ir}\left[\mathrm{dF}\left(\mathrm{CF}_{3}\right) \mathrm{ppy}_{2}(\mathrm{dtbbpy}) \mathrm{PF}_{6}(0.001 \mathrm{mmol}, 1.12 \mathrm{mg}), \mathrm{NiCl}_{2} \bullet \mathrm{DME}(0.01 \mathrm{mmol}, 2.2 \mathrm{mg})\right.$ and dtbbpy (0.012 $\mathrm{mmol}$, $3.2 \mathrm{mg})$. The reaction vessel was capped and DMF (1.2 mL) was added. The mixture was degassed by bubbling argon through the solution for 5 minutes, then the flask was sealed. The reaction mixture was placed in an EvoluChem ${ }^{\text {TM }}$ DUO box and irradiated with 2 Kessil $^{\circledR}$ lamps (40 W (input), $\lambda_{\max }=427 \mathrm{~nm}$ ) for $21 \mathrm{~h}$. The crude reaction mixture was analyzed by LCMS.

\section{$30 \mathrm{mmol}$ scale reaction}

To the reaction flask fitted with stirring magnet was added methyl 4-bromobenzoate (30 mmol, $6.45 \mathrm{~g}$ ), 1-tertbutoxycarbonylpyrrolidine-2-carboxylic acid $(45 \mathrm{mmol}, 9.69 \mathrm{~g}), \quad \mathrm{Cs}_{2} \mathrm{CO}_{3} \quad\left(\begin{array}{lllll}45 & \mathrm{mmol}, & 14.7 & \mathrm{~g}\end{array}\right)$,

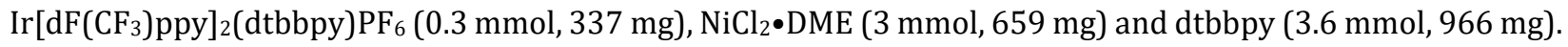
The immersion tube was fitted into the reactor and to the flask was added DMF ( $400 \mathrm{~mL}$ ). The mixture was degassed by bubbling argon through the solution for 20 minutes, then the flask was sealed (Note - this set-up is not gas-tight, the $\mathrm{CO}_{2}$ generated is released through the seals preventing pressure buildup). The reaction was placed in the PhotonCabinet and the lamp was placed inside the immersion tube. The reaction was irradiated with for $21 \mathrm{~h}$, then the crude reaction mixture was analyzed by LCMS (Figure S4).

Following the reaction, water was added to the reaction $(200 \mathrm{~mL})$ and the mixture was extracted with EtOAc (3 x $200 \mathrm{~mL}$ ). The combined organic phases were washed with water and brine, dried with $\mathrm{Na}_{2} \mathrm{SO}_{4}$ and filtered. The reaction mixture was concentrated and purified by silica gel column chromatography gradient column to provide the pure product $(8.0 \mathrm{~g}, 88 \%)$

The data was in accordance with those previously reported. ${ }^{\mathrm{s} 2}$ 

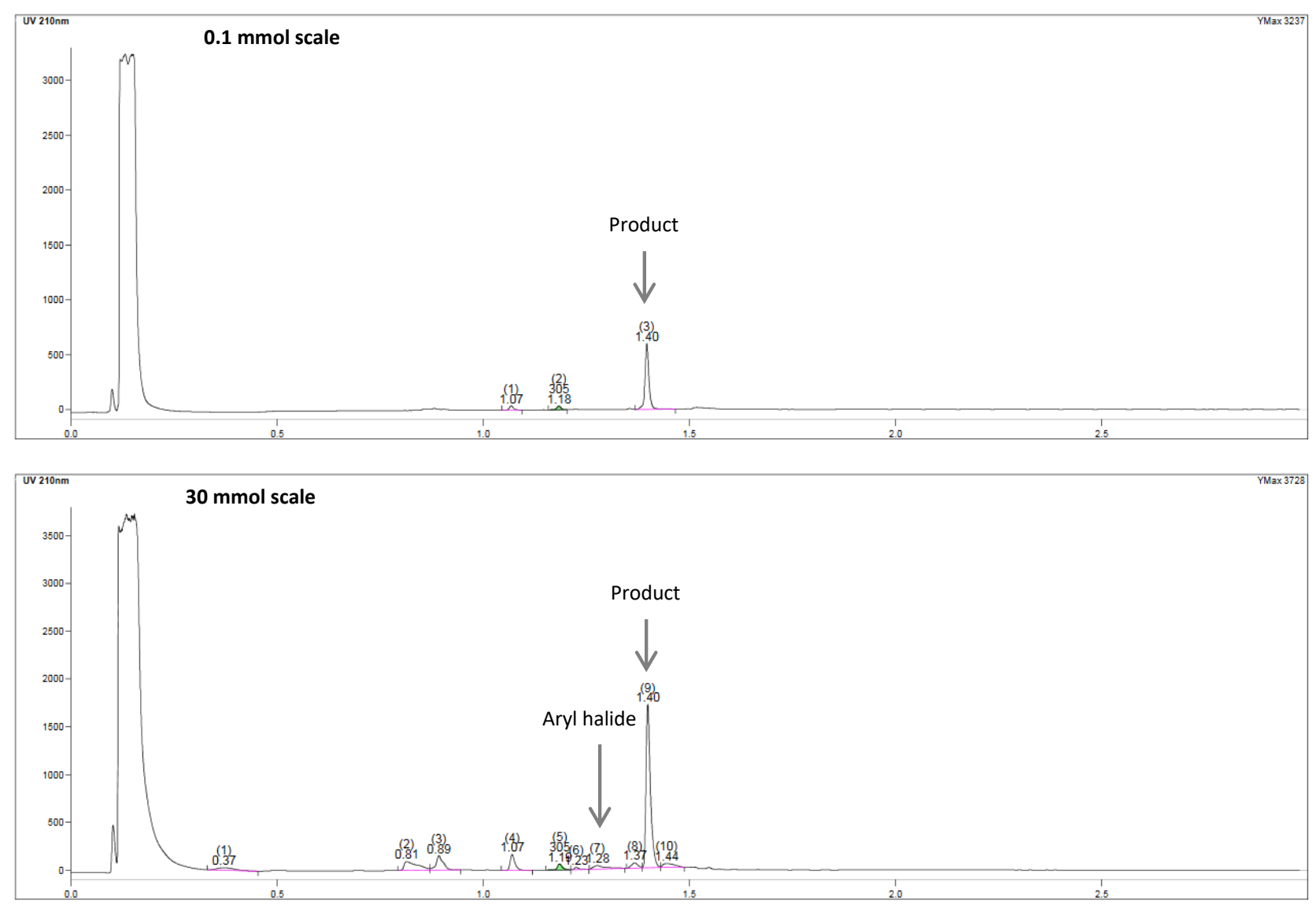

Figure S4: LCMS of crude reaction mixture of 0.1 and $30 \mathrm{mmol}$ scale reaction. 
Ethyl 6-(1-tert-butoxycarbonylpyrrolidin-2-yl)imidazo[1,2-a]pyridine-2-carboxylate

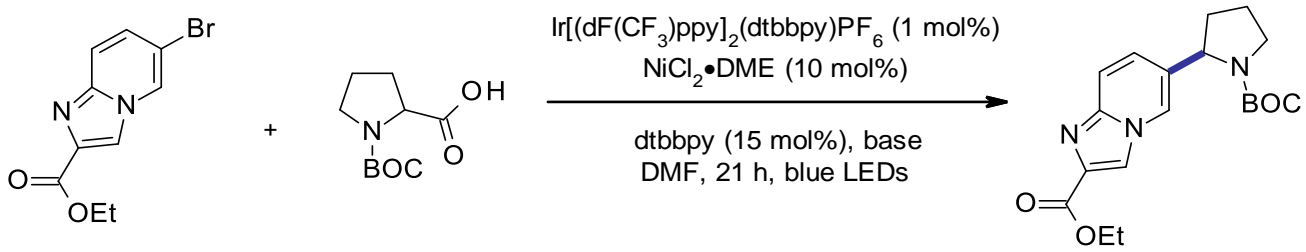

\section{Base screen - $0.1 \mathrm{mmol}$ scale}

To a microwave flask fitted with stirring magnet was added ethyl 6-bromoimidazo[1,2-a]pyridine-2carboxylate $(0.1 \mathrm{mmol}, 26.9 \mathrm{mg}), 1$-tert-butoxycarbonylpyrrolidine-2-carboxylic acid $(0.15 \mathrm{mmol}, 32.3 \mathrm{mg})$,

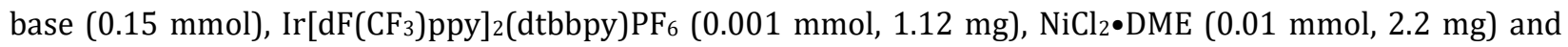
dtbbpy (0.015 mmol, $4.0 \mathrm{mg}$ ). The reaction vessel was capped and DMF (1.0 mL) was added. The mixture was degassed by bubbling argon through the solution for 5 minutes then the flask was sealed. The reaction mixture was placed in an EvoluChem ${ }^{\mathrm{TM}}$ DUO box and irradiated with $2 \mathrm{Kessil}^{\circledR}$ lamps ( $40 \mathrm{~W}$ (input), $\lambda_{\max }=427 \mathrm{~nm}$ ) for $21 \mathrm{~h}$. The crude reaction mixture was analyzed by LCMS.

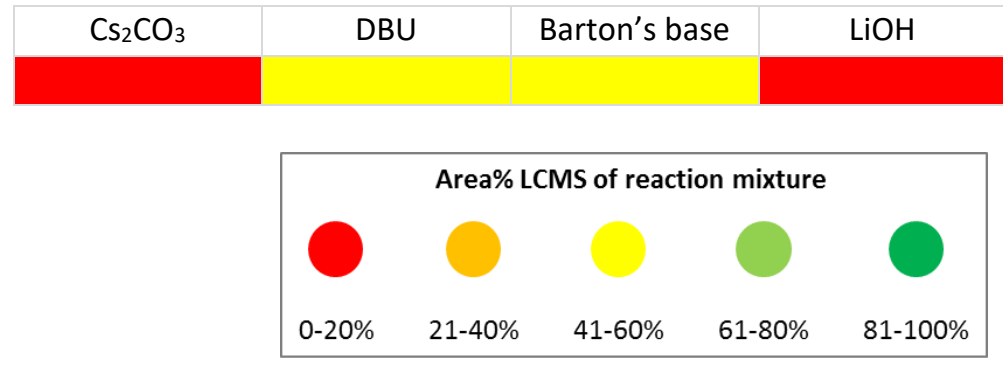

Table S3: Screen results - analysis of area\% of product in LCMS or crude reaction mixture.

\section{$30 \mathrm{mmol}$ scale reaction}

To the reaction flask fitted with stirring magnet was added ethyl 6-bromoimidazo[1,2-a]pyridine-2-carboxylate (30 mmol, $8.07 \mathrm{~g})$, 1-tert-butoxycarbonylpyrrolidine-2-carboxylic acid $(45 \mathrm{mmol}, 9.69 \mathrm{~g})$,

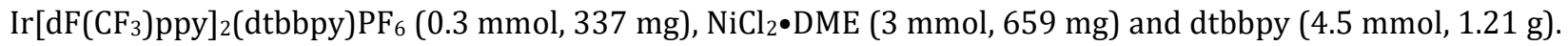
The immersion tube was fitted into the reactor and to the flask was added DMF ( $400 \mathrm{~mL}$ ) followed by TMG (45 mmol, $5.63 \mathrm{~mL}$ ). The mixture was degassed by bubbling argon through the solution for 20 minutes then the flask was sealed (Note - this set-up is not gas-tight, the $\mathrm{CO}_{2}$ generated is released through the seals preventing pressure buildup). The reaction was placed in the PhotonCabinet and the lamp was placed inside the immersion tube The reaction was irradiated with for $21 \mathrm{~h}$, then the crude reaction mixture was analyzed by LCMS (Figure S5).

Following the reaction, water was added to the reaction $(200 \mathrm{~mL})$ and the mixture was extracted with EtOAc (3 x $200 \mathrm{~mL}$ ). The combined organic phases were washed with water and brine, dried with $\mathrm{Na}_{2} \mathrm{SO}_{4}$ and filtered. The reaction mixture was concentrated and purified by silica gel column chromatography gradient column to provide the pure product ( $3.9 \mathrm{~g}, 36 \%$ ) as a mixture of rotamers 1:1 A:B.

${ }^{1}$ H NMR $\left(600 \mathrm{MHz}\right.$, DMSO- $\left.d_{6}\right) \delta$ ppm 8.68 - $8.63(\mathrm{~m}, 1 \mathrm{H}), 7.63$ - $7.54(\mathrm{~m}, 1 \mathrm{H}), 7.47-7.38(\mathrm{~m}, 1 \mathrm{H}), 6.82$ - 6.70 $(\mathrm{m}, 1 \mathrm{H}), 5.40$ - $5.29(\mathrm{~m}, 1 \mathrm{H}), 4.41-4.34(\mathrm{~m}, 2 \mathrm{H}), 3.66$ - $3.63(\mathrm{~m}, 1 \mathrm{H}), 3.49$ - $3.46(\mathrm{~m}, 1 \mathrm{H}), 2.48$ - $2.31(\mathrm{~m}, 1 \mathrm{H})$, $1.98-1.89(\mathrm{~m}, 1 \mathrm{H}), 1.88-1.72(\mathrm{~m}, 2 \mathrm{H}), 1.42(\mathrm{~s}, 9 \mathrm{H}, \mathrm{A}), 1.38$ - $1.31(\mathrm{~m}, 3 \mathrm{H}), 1.04(\mathrm{~m}, 9 \mathrm{H}, \mathrm{B})$ 
${ }^{13}$ C NMR (126 MHz, DMSO-d 6 ) $\delta$ ppm 163.3, 154.0, 153.5, 145.8, 142.1, 141.0, 136.6, 136.5, 127.1, 116.4, 116.3, 115.6, 115.4, 109.5, 109.1, 79.7, 79.1, 60.79, 57.3, 57.0, 47.2, 46.9, 31.3, 30.0, 28.6, 28.1, 23.8, 23.3, 14.8 (5 signals overlapping).

HRMS (ES-TOF) m/z calcd. for $\mathrm{C}_{19} \mathrm{H}_{25} \mathrm{~N}_{3} \mathrm{O}_{4} \mathrm{H}[\mathrm{M}+\mathrm{H}]^{+}$360.1918, found 360.1909.
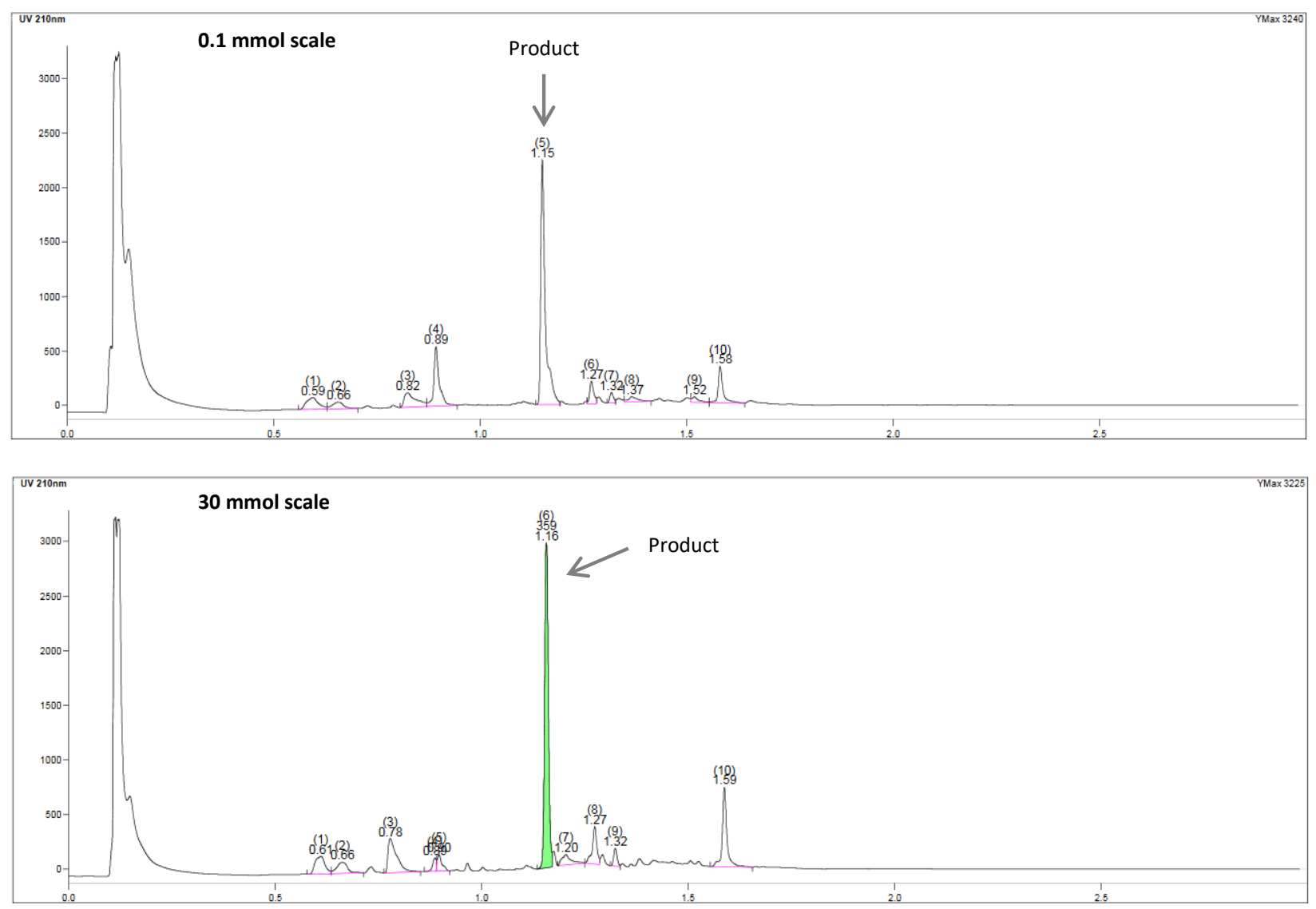

Figure S5: LCMS of crude reaction mixture of 0.1 and $30 \mathrm{mmol}$ scale reaction. 
tert-Butyl 2-[6-(3,5-dimethylpyrazol-1-yl)pyrimidin-4-yl]pyrrolidine-1-carboxylate

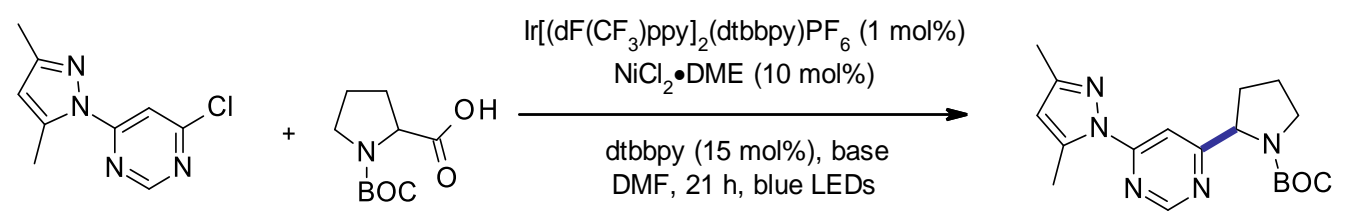

\section{Base screen - $0.1 \mathrm{mmol}$ scale}

To a microwave flask fitted with stirring magnet was added 4-chloro-6-(3,5-dimethylpyrazol-1-yl)pyrimidine (0.1 mmol, $20.9 \mathrm{mg}), 1$-tert-butoxycarbonylpyrrolidine-2-carboxylic acid $(0.15 \mathrm{mmol}, 32.3 \mathrm{mg})$, base $(0.15$ mmol), $\operatorname{Ir}\left[\mathrm{dF}_{\left(\mathrm{CF}_{3}\right) \text { ppy }}\right]_{2}(\mathrm{dtbbpy}) \mathrm{PF}_{6}(0.001 \mathrm{mmol}, 1.12 \mathrm{mg}), \mathrm{NiCl}_{2} \bullet \mathrm{DME}(0.01 \mathrm{mmol}, 2.2 \mathrm{mg})$ and dtbbpy $(0.015$ $\mathrm{mmol}, 4.0 \mathrm{mg})$. The reaction vessel was capped and DMF $(1.0 \mathrm{~mL})$ was added. The mixture was degassed by bubbling argon through the solution for 5 minutes, then the flask was sealed. The reaction mixture was placed in an EvoluChem ${ }^{\mathrm{TM}}$ DUObox and irradiated with 2 Kessil $^{\circledR}$ lamps (40 W (input), $\lambda_{\max }=427 \mathrm{~nm}$ ) for $21 \mathrm{~h}$. The crude reaction mixture was analyzed by LCMS.

\begin{tabular}{|l|l|l|l|}
\hline $\mathrm{Cs}_{2} \mathrm{CO}_{3}$ & DBU & Barton's base & $\mathrm{LiOH}$ \\
\hline
\end{tabular}

Table S4: Screen results - analysis of area\% of product in LCMS or crude reaction mixture.

\section{$30 \mathrm{mmol}$ scale reaction}

To the reaction flask fitted with stirring magnet was added 4-chloro-6-(3,5-dimethylpyrazol-1-yl)pyrimidine (30 mmol, $6.26 \mathrm{~g}$ ), 1-tert-butoxycarbonylpyrrolidine-2-carboxylic acid (45 mmol, $9.69 \mathrm{~g}$ ), LiOH (45 mmol, 1.08 g), $\operatorname{Ir}\left[\mathrm{dF}\left(\mathrm{CF}_{3}\right) \text { ppy }\right]_{2}(\mathrm{dtbbpy}) \mathrm{PF}_{6}(0.3 \mathrm{mmol}, 337 \mathrm{mg}), \mathrm{NiCl}_{2} \bullet \mathrm{DME}$ ( $\left.3 \mathrm{mmol}, 659 \mathrm{mg}\right)$ and dtbbpy (4.5 mmol, 1.21 g). The immersion tube was fitted into the reactor and to the flask was added DMF ( $400 \mathrm{~mL}$ ). The mixture was degassed by bubbling argon through the solution for 20 minutes, then the flask was sealed (Note - this set-up is not gas-tight, the $\mathrm{CO}_{2}$ generated is released through the seals preventing pressure buildup). The reaction was placed in the PhotonCabinet and the lamp was placed inside the immersion tube. The reaction was irradiated with for $21 \mathrm{~h}$, then the crude reaction mixture was analyzed by LCMS (Figure S6).

Following the reaction, water was added to the reaction $(200 \mathrm{~mL})$ and the mixture was extracted with EtOAc (3 x $200 \mathrm{~mL}$ ). The combined organic phases were washed with water and brine, dried with $\mathrm{Na}_{2} \mathrm{SO}_{4}$ and filtered. The reaction mixture was concentrated and purified by silica gel column chromatography gradient column to provide the pure product $(6.4 \mathrm{~g}, 63 \%)$ as a mixture of rotamers 3:2 A:B.

${ }^{1} \mathrm{H}$ NMR (600 MHz, DMSO- $\left.d_{6}\right) \delta$ ppm 8.98 - $8.93(\mathrm{~m}, 1 \mathrm{H}, \mathrm{A}+\mathrm{B}), 7.72(\mathrm{~s}, 1 \mathrm{H}, \mathrm{A}), 7.68(\mathrm{~s}, 1 \mathrm{H}, \mathrm{B}), 6.22(\mathrm{~s}, 1 \mathrm{H}, \mathrm{A}+\mathrm{B})$, 4.86 - $4.75(\mathrm{~m}, 1 \mathrm{H} \mathrm{A}+\mathrm{B}), 3.58-3.44(\mathrm{~m}, 2 \mathrm{H}, \mathrm{A}+\mathrm{B}), 2.67(\mathrm{~s}, 3 \mathrm{H}, \mathrm{A}+\mathrm{B}), 2.44-2.28(\mathrm{~m}, 1 \mathrm{H}, \mathrm{A}+\mathrm{B}), 2.21(\mathrm{~s}, 3 \mathrm{H}, \mathrm{A}+\mathrm{B})$, $1.96-1.81(\mathrm{~m}, 3 \mathrm{H} \mathrm{A}+\mathrm{B}), 1.44-1.36(\mathrm{~m}, 9 \mathrm{H}, \mathrm{B}), 1.14(\mathrm{~m}, 9 \mathrm{H}, \mathrm{A})$

${ }^{13}$ C NMR (126 MHz, DMSO-d 6 ) $\delta$ ppm 173.4 (A), 172.6 (B), 158.8 (A), 158.6 (B), 157.5(0) (B), 157.4(5) (A), 153.6 (B), 153.1 (A), 151.1 (A), 151.0 (B), 142.4 (B), 142.3 (A), 111.0 (B), 110.9 (A), 106.3 (A), 106.2 (B), 78.9 (B), 78.5 (A), 61.5 (A), 61.2 (B), 47.1 (B), 46.9 (A), 33.2 (A), 32.1 (B), 28.0 (B), 27.7 (A), 26.27, 23.4 (B), 22.9 (A), 15.0 (B), 13.4 (A) (one signal overlapping)

HRMS (ES-TOF) m/z calcd. for $\mathrm{C}_{18} \mathrm{H}_{25} \mathrm{~N}_{5} \mathrm{O}_{2} \mathrm{H}(\mathrm{M}+\mathrm{H})^{+} 343.2081$, found 343.2082. 

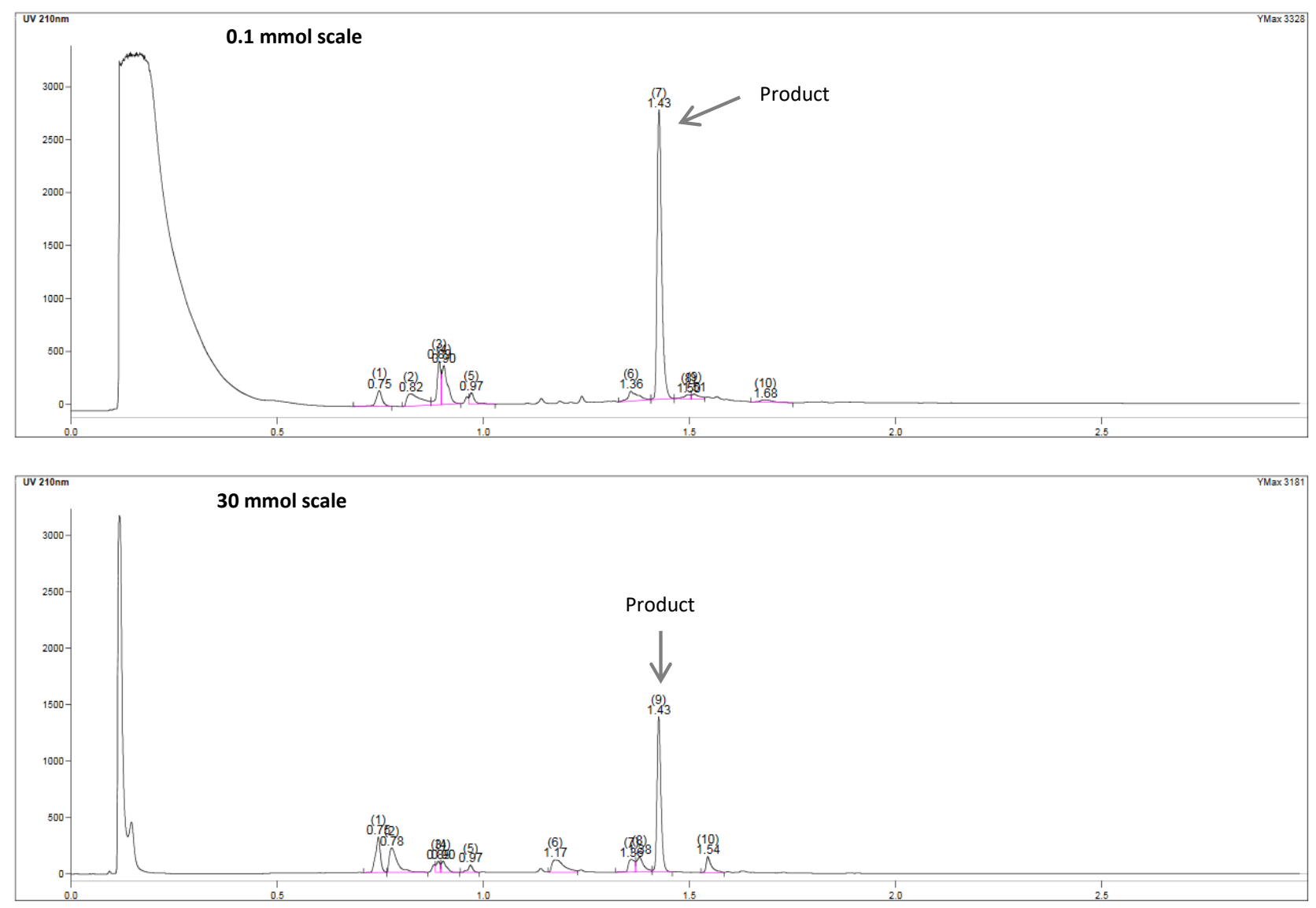

Figure S6: LCMS of crude reaction mixture of 0.1 and $30 \mathrm{mmol}$ scale reaction. 
Methyl 6-[1-(tert-butoxycarbonylamino)-2-phenyl-ethyl]pyridine-2-carboxylate
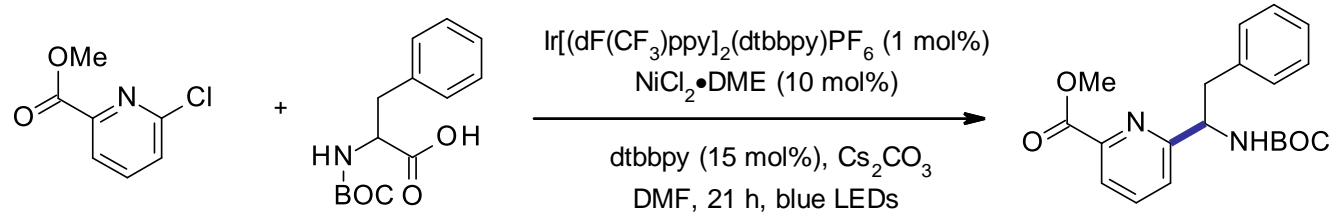

\section{Base screen - 0.1 mmol scale}

To a microwave flask fitted with stirring magnet was added methyl 6-chloropyridine-2-carboxylate $0.1 \mathrm{mmol}$, $17.2 \mathrm{mg}), 2$-(tert-butoxycarbonylamino)-3-phenyl-propanoic acid $(0.15 \mathrm{mmol}, 39.8 \mathrm{mg})$, base $(0.15 \mathrm{mmol})$, $\operatorname{Ir}\left[\mathrm{dF}\left(\mathrm{CF}_{3}\right) \mathrm{ppy}_{2}(\mathrm{dtbbpy}) \mathrm{PF}_{6}(0.001 \mathrm{mmol}, 1.12 \mathrm{mg}), \mathrm{NiCl}_{2} \bullet \mathrm{DME}(0.01 \mathrm{mmol}, 2.2 \mathrm{mg})\right.$ and dtbbpy (0.015 mmol, $4.0 \mathrm{mg})$. The reaction vessel was capped and DMF $(1.0 \mathrm{~mL})$ was added. The mixture was degassed by bubbling argon through the solution for 5 minutes, then the flask was sealed. The reaction mixture was placed in an EvoluChem ${ }^{\mathrm{TM}}$ DUObox and irradiated with $2 \mathrm{Kessil}^{\circledR}$ lamps ( $40 \mathrm{~W}$ (input), $\lambda_{\max }=427 \mathrm{~nm}$ ) for $21 \mathrm{~h}$. The crude reaction mixture was analyzed by LCMS.

\begin{tabular}{l|l}
$\mathrm{Cs}_{2} \mathrm{CO}_{3} \quad$ TMG
\end{tabular}

Table S5: Screen results - analysis of area $\%$ of product in LCMS or crude reaction mixture.

\section{$30 \mathrm{mmol}$ scale reaction}

To the reaction flask fitted with stirring magnet was added methyl 6-chloropyridine-2-carboxylate (30 mmol, $5.15 \mathrm{~g}$ ), 2-(tert-butoxycarbonylamino)-3-phenyl-propanoic acid (45 mmol, $11.9 \mathrm{~g}$ ), $\mathrm{Cs}_{2} \mathrm{CO}_{3}$ (45 mmol, $14.7 \mathrm{~g}$ ), $\operatorname{Ir}\left[\mathrm{dF}\left(\mathrm{CF}_{3}\right) \text { ppy }\right]_{2}(\mathrm{dtbbpy}) \mathrm{PF}_{6}(0.3 \mathrm{mmol}, 337 \mathrm{mg}), \mathrm{NiCl}_{2} \bullet \mathrm{DME}(3 \mathrm{mmol}, 659 \mathrm{mg})$ and dtbbpy $(4.5 \mathrm{mmol}, 1.21 \mathrm{~g})$. The immersion tube was fitted into the reactor and to the flask was added DMF ( $400 \mathrm{~mL}$ ). The mixture was degassed by bubbling argon through the solution for 20 minutes, then the flask was sealed (Note - this set-up is not gas-tight, the $\mathrm{CO}_{2}$ generated is released through the seals preventing pressure buildup). The reaction was placed in the PhotonCabinet and the lamp was placed inside the immersion tube. The reaction was irradiated with for $21 \mathrm{~h}$, then the crude reaction mixture was analyzed by LCMS (Figure S7).

Following the reaction, water was added to the reaction $(200 \mathrm{~mL}$ ) and the mixture was extracted with EtOAc (3 x $200 \mathrm{~mL}$ ). The combined organic phases were washed with water and brine, dried with $\mathrm{Na}_{2} \mathrm{SO}_{4}$ and filtered. The reaction mixture was concentrated and purified by silica gel column chromatography gradient column to provide the pure product $(6.0 \mathrm{~g}, 57 \%)$ as a mixture of rotamers 9:1 A:B.

${ }^{1}$ H NMR (600 MHz, DMSO-d $) \delta$ ppm $8.00-7.93(\mathrm{~m}, 2 \mathrm{H}, \mathrm{A}+\mathrm{B}), 7.64(\mathrm{~d}, J=7.5 \mathrm{~Hz}, 1 \mathrm{H}, \mathrm{A}+\mathrm{B}), 7.51(\mathrm{~d}, J=7.5 \mathrm{~Hz}, 1 \mathrm{H}$, $\mathrm{A}+\mathrm{B}), 7.29-7.24(\mathrm{~m}, 4 \mathrm{H}, \mathrm{A}+\mathrm{B}), 7.19-7.21(\mathrm{~m}, 1 \mathrm{H}, \mathrm{A}+\mathrm{B}), 4.93-4.90(\mathrm{~m}, 1 \mathrm{H}, \mathrm{A}), 4.83-4.77(\mathrm{~m}, 1 \mathrm{H}, \mathrm{B}), 3.91(\mathrm{~s}$, $3 \mathrm{H}, \mathrm{A}+\mathrm{B}), 3.13$ (dd, J=13.7, $4.9 \mathrm{~Hz}, 1 \mathrm{H}, \mathrm{A}+\mathrm{B}), 2.95$ (dd, J=13.7, $10.4 \mathrm{~Hz}, 1 \mathrm{H}, \mathrm{A}+\mathrm{B}), 1.30$ (s, 9H, A), 1.12 (s, 9H, B).

${ }^{13}$ C NMR (151 MHz, DMSO-d $)$ ) $\delta$ ppm 165.3, 162.7, 155.2, 146.7, 138.5, 138.1, 129.2, 128.1, 126.2, 124.5, 123.3, $78.0,57.3,52.4,40.5,28.2$

HRMS (ES-TOF) m/z calcd. for $\mathrm{C}_{20} \mathrm{H}_{24} \mathrm{~N}_{2} \mathrm{O}_{4} \mathrm{H}(\mathrm{M}+\mathrm{H})^{+} 357.1809$, found 357.1811. 

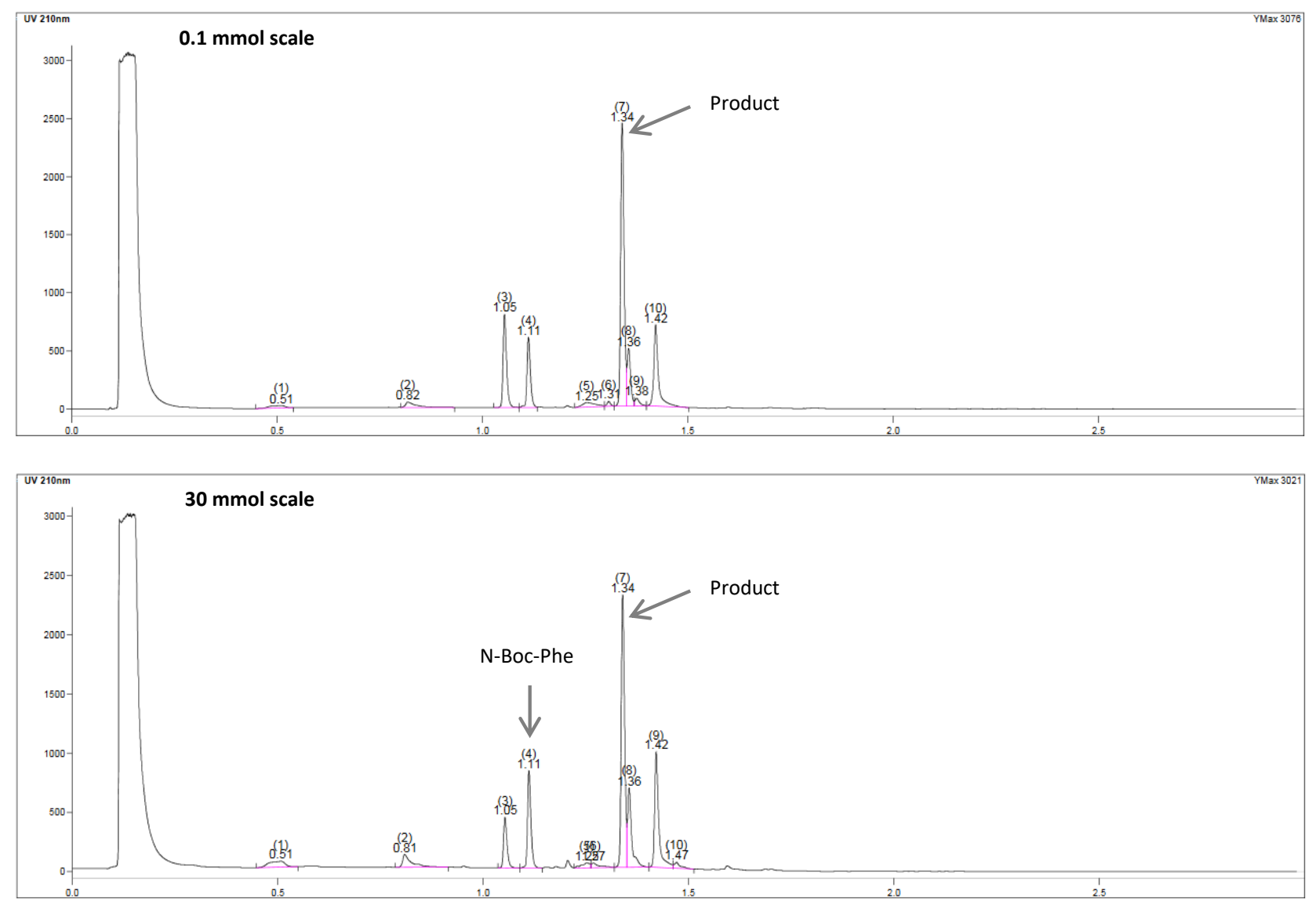

Figure S7: LCMS of crude reaction mixture of 0.1 and $30 \mathrm{mmol}$ scale reaction. 
tert-Butyl 2-[3-hydroxy-4-[methyl(phenyl)sulfamoyl]phenyl]piperidine-1-carboxylate
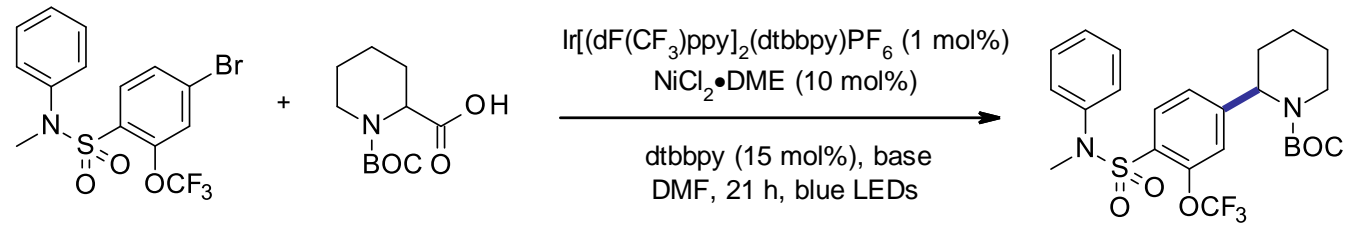

\section{Base screen - $0.1 \mathrm{mmol}$ scale}

To a microwave flask fitted with stirring magnet was added 4-bromo-2-hydroxy- $N$-methyl- $N$-phenylbenzenesulfonamide $(0.1 \mathrm{mmol}, 41.0 \mathrm{mg})$, 1-tert-butoxycarbonylpiperidine-2-carboxylic acid $(0.15 \mathrm{mmol}, 34.4$ $\mathrm{mg})$, base $(0.15 \mathrm{mmol}), \operatorname{Ir}\left[\mathrm{dF}\left(\mathrm{CF}_{3}\right) \text { ppy }\right]_{2}(\mathrm{dtbbpy}) \mathrm{PF}_{6}(0.001 \mathrm{mmol}, 1.12 \mathrm{mg}), \mathrm{NiCl}_{2} \bullet \mathrm{DME}(0.01 \mathrm{mmol}, 2.2 \mathrm{mg})$ and dtbbpy $(0.015 \mathrm{mmol}, 4.0 \mathrm{mg})$. The reaction vessel was capped and DMF $(1.0 \mathrm{~mL})$ was added. The mixture was degassed by bubbling argon through the solution for 5 minutes, then the flask was sealed. The reaction mixture was placed in an EvoluChem ${ }^{\mathrm{TM}}$ DUObox and irradiated with 2 Kessil $^{\circledR}$ lamps ( $40 \mathrm{~W}$ (input), $\lambda_{\max }=427$ $\mathrm{nm}$ ) for $21 \mathrm{~h}$. The crude reaction mixture was analyzed by LCMS.

\begin{tabular}{|l|l|l|l|}
\hline $\mathrm{Cs}_{2} \mathrm{CO}_{3}$ & DBU & Barton's base & $\mathrm{LiOH}$ \\
\hline
\end{tabular}

Table S6: Screen results - analysis of area\% of product in LCMS or crude reaction mixture.

\section{$30 \mathrm{mmol}$ scale reaction}

To the reaction flask fitted with stirring magnet was added 4-bromo-2-hydroxy- $N$-methyl- $N$-phenylbenzenesulfonamide (30 mmol, $12.3 \mathrm{~g}$ ), 1-tert-butoxycarbonylpiperidine-2-carboxylic acid (45 mmol, $10.3 \mathrm{~g}$ ), $\mathrm{Cs}_{2} \mathrm{CO}_{3}\left(45 \mathrm{mmol}, 14.7 \mathrm{~g}\right.$ ), $\operatorname{Ir}\left[\mathrm{dF}\left(\mathrm{CF}_{3}\right) \text { ppy }\right]_{2}(\mathrm{dtbbpy}) \mathrm{PF}_{6}(0.3 \mathrm{mmol}, 337 \mathrm{mg}), \mathrm{NiCl}_{2} \bullet \mathrm{DME}$ (3 mmol, $\left.659 \mathrm{mg}\right)$ and dtbbpy ( $4.5 \mathrm{mmol}, 1.21 \mathrm{~g}$ ). The immersion tube was fitted into the reactor and to the flask was added DMF ( 400 $\mathrm{mL}$ ). The mixture was degassed by bubbling argon through the solution for 20 minutes, then the flask was sealed (Note - this set-up is not gas-tight, the $\mathrm{CO}_{2}$ generated is released through the seals preventing pressure buildup). The reaction was placed in the PhotonCabinet and the lamp was placed inside the immersion tube. The reaction was irradiated with for $21 \mathrm{~h}$, then the crude reaction mixture was analyzed by LCMS (Figure S8).

Following the reaction, water was added to the reaction $(200 \mathrm{~mL})$ and the mixture was extracted with EtOAc (3 x $200 \mathrm{~mL}$ ). The combined organic phases were washed with water and brine, dried with $\mathrm{Na}_{2} \mathrm{SO}_{4}$ and filtered. The Reaction mixture was concentrated and purified by silica gel column chromatography gradient column to provide the pure product $(8.8 \mathrm{~g}, 57 \%)$.

${ }^{1}$ H-NMR (500 MHz, DMSO-d6) $\boldsymbol{\delta} 7.75$ (d, J=8.2, 1H), 7.40 - 7.37 (m, 1H), 7.34 - 7.30(m, 2H), 7.28 - $7.25(\mathrm{~m}, 1 \mathrm{H})$, $7.21(\mathrm{~s}, 1 \mathrm{H}), 7.19-7.17(\mathrm{~m}, 2 \mathrm{H}), 5.31-5.28(\mathrm{~m}, 1 \mathrm{H}), 3.95-3.91(\mathrm{~m}, 1 \mathrm{H}), 3.28(\mathrm{~s}, 3 \mathrm{H}), 2.70(\mathrm{t}, J=3.3 \mathrm{~Hz}, 1 \mathrm{H}), 2.23$ - $2.19(\mathrm{~m}, 1 \mathrm{H}), 1.87-1.79(\mathrm{~m}, 1 \mathrm{H}), 1.60-1.53(\mathrm{~m}, 2 \mathrm{H}), 1.47$ - $1.39(\mathrm{~m}, 1 \mathrm{H}), 1.36(\mathrm{~s}, 9 \mathrm{H}), 1.19-1.14(\mathrm{~m}, 1 \mathrm{H})$.

${ }^{13}$ C NMR (126 MHz, DMSO-d6) $\delta$ 154.5, 149.9, 145.4, 140.5, 132.0, 129.0, 128.0, 127.2, 126.1, 125.2, 118.6, 120.2 (q, J=261.00 Hz), 79.3, 53.0, 38.2, 28.0, 27.8, 24.3, 18.7 (one signal overlapping).

HRMS (ESI-TOF) m/z calcd. for $\mathrm{C}_{24} \mathrm{H}_{29} \mathrm{~F}_{3} \mathrm{~N}_{2} \mathrm{O}_{5} \mathrm{SH}(\mathrm{M}+\mathrm{H})^{+} 515,1822$, found 515,1822. 

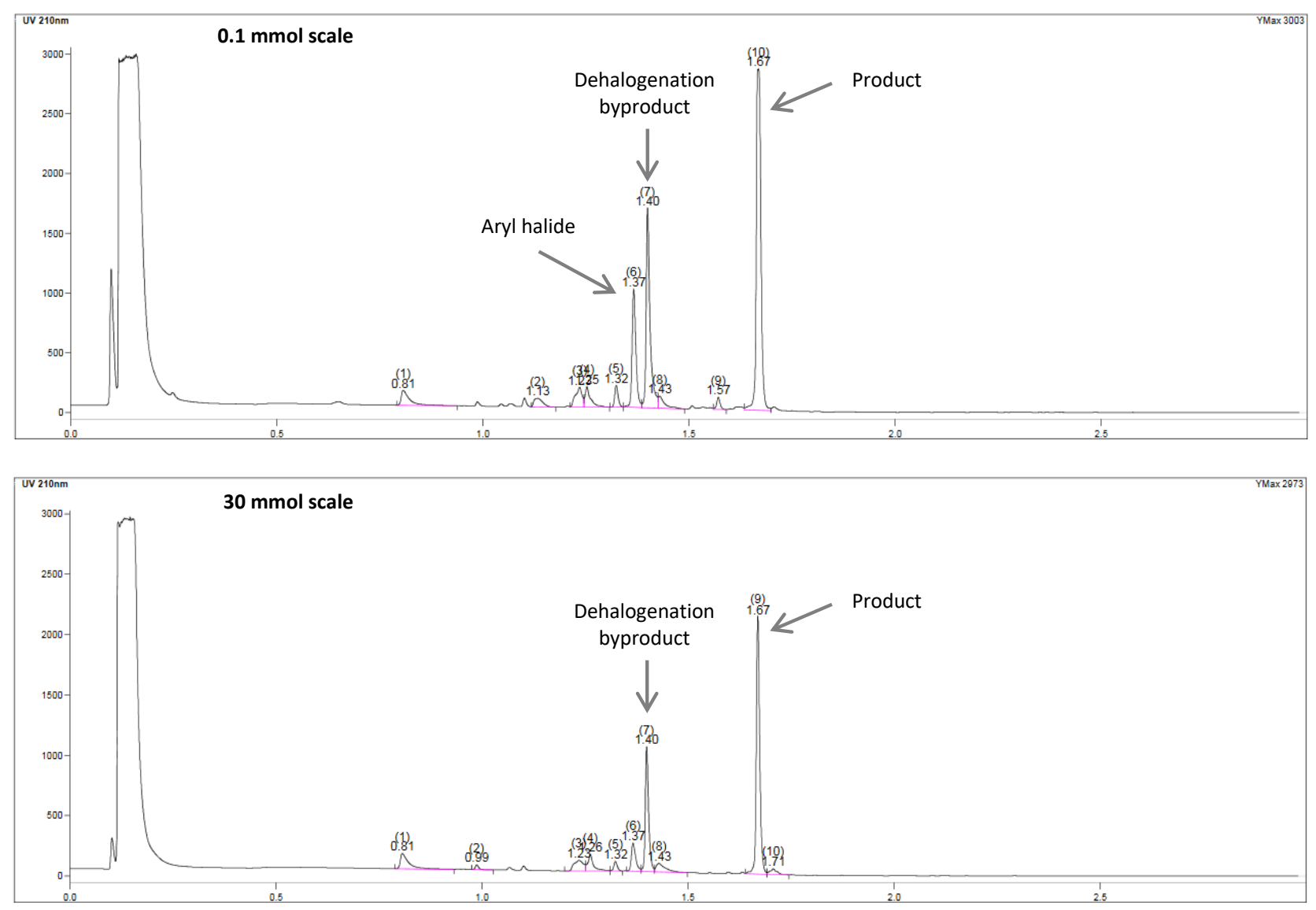

Figure S8: LCMS of crude reaction mixture of 0.1 and $30 \mathrm{mmol}$ scale reaction. 


\section{5. $s p^{2} / s p^{3}$ Reductive coupling reactions}

\section{Methyl 4-(2-cyanoethyl)benzoate}

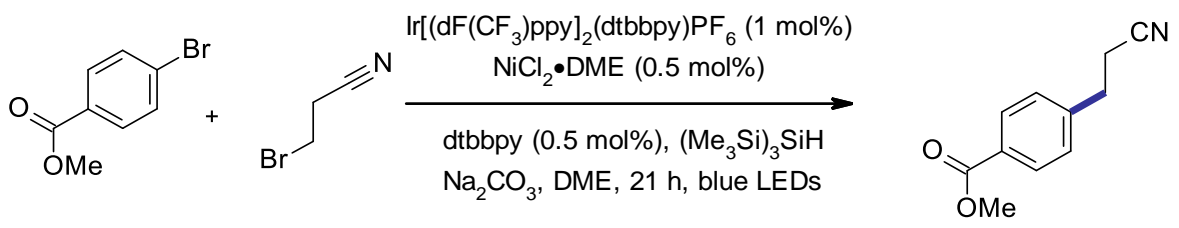

\section{1 mmol scale reaction}

To a microwave flask fitted with stirring magnet was added methyl 4-bromobenzoate ( $0.1 \mathrm{mmol}, 21.5 \mathrm{mg})$, $\mathrm{Na}_{2} \mathrm{CO}_{3}(0.15 \mathrm{mmol}, 21.2 \mathrm{mg})$ and $\operatorname{Ir}\left[\mathrm{dF}\left(\mathrm{CF}_{3}\right) \text { ppy }\right]_{2}(\mathrm{dtbbpy}) \mathrm{PF}_{6}(1 \mu \mathrm{mol}, 1.12 \mathrm{mg})$, followed by DME $(0.8 \mathrm{~mL}) . \mathrm{A}$ stock solution of $\mathrm{NiCl}_{2} \bullet \mathrm{DME}$ ( $5 \mu \mathrm{mol}, 1.1 \mathrm{mg}$ ) and dtbbpy ( $5 \mu \mathrm{mol}, 1.3 \mathrm{mg}$ ) in DME ( $2 \mathrm{~mL}$ ) was prepared and 0.2 $\mathrm{mL}$ of this stock was added to the reaction mixture. 3-Bromopropanenitrile $(0.2 \mathrm{mmol}, 16.3 \mu \mathrm{L})$ was added to the reaction mixture and the vessel was capped and the mixture was degassed by bubbling argon through the solution for 5 minutes. After the reaction mixture was degassed TTMSS $(0.1 \mathrm{mmol}, 30.8 \mu \mathrm{L})$ was added to the reaction and the reaction mixture was placed in an EvoluChem ${ }^{\mathrm{TM}}$ DUObox and irradiated with 2 Kessil ${ }^{\circledR}$ lamps ( $40 \mathrm{~W}$ (input), $\lambda_{\max }=427 \mathrm{~nm}$ ) for $21 \mathrm{~h}$. The crude reaction mixture was analyzed by LCMS.

\section{$60 \mathrm{mmol}$ scale reaction}

To the reaction flask fitted with stirring magnet was added methyl 4-bromobenzoate $(60.0 \mathrm{mmol}, 12.9 \mathrm{~g})$, $\mathrm{Na}_{2} \mathrm{CO}_{3}(120 \mathrm{mmol}, 12.7 \mathrm{~g})$ and $\operatorname{Ir}\left[\mathrm{dF}\left(\mathrm{CF}_{3}\right) \text { ppy }\right]_{2}$ (dtbbpy)PF 6 (0.6 mmol, $673 \mathrm{mg}$ ), followed by DME (600 mL). A stock solution of $\mathrm{NiCl}_{2} \bullet$ DME $(0.3 \mathrm{mmol}, 65.9 \mathrm{mg})$ and dtbbpy $(0.3 \mathrm{mmol}, 80.5 \mathrm{mg})$ in DME $(20 \mathrm{~mL})$ was prepared and was added to the reaction mixture. 3-Bromopropanenitrile $(120 \mathrm{mmol}, 9.92 \mathrm{~mL})$ was added to the reaction mixture and the mixture was degassed by bubbling argon through the solution for 20 minutes. After the reaction mixture was degassed TTMSS $(60 \mathrm{mmol}, 18.5 \mathrm{~mL})$ and the flask was sealed (Note - this set-up is not gas-tight, the $\mathrm{CO}_{2}$ generated is released through the seals preventing pressure buildup). The reaction was placed in the PhotonCabinet and the lamp was placed inside the immersion tube. The reaction was irradiated with for $21 \mathrm{~h}$, then the crude reaction mixture was analyzed by LCMS (Figure S9).

Following the reaction, water was added to the reaction $(200 \mathrm{~mL}$ ) and the mixture was extracted with EtOAc (3 x $200 \mathrm{~mL}$ ). The combined organic phases were washed with water and brine, dried with $\mathrm{Na}_{2} \mathrm{SO}_{4}$ and filtered. The reaction mixture was concentrated and purified by silica gel column chromatography gradient column to provide the pure product $(8.7 \mathrm{~g}, 77 \%)$.

The data was in accordance with those previously reported.s3 

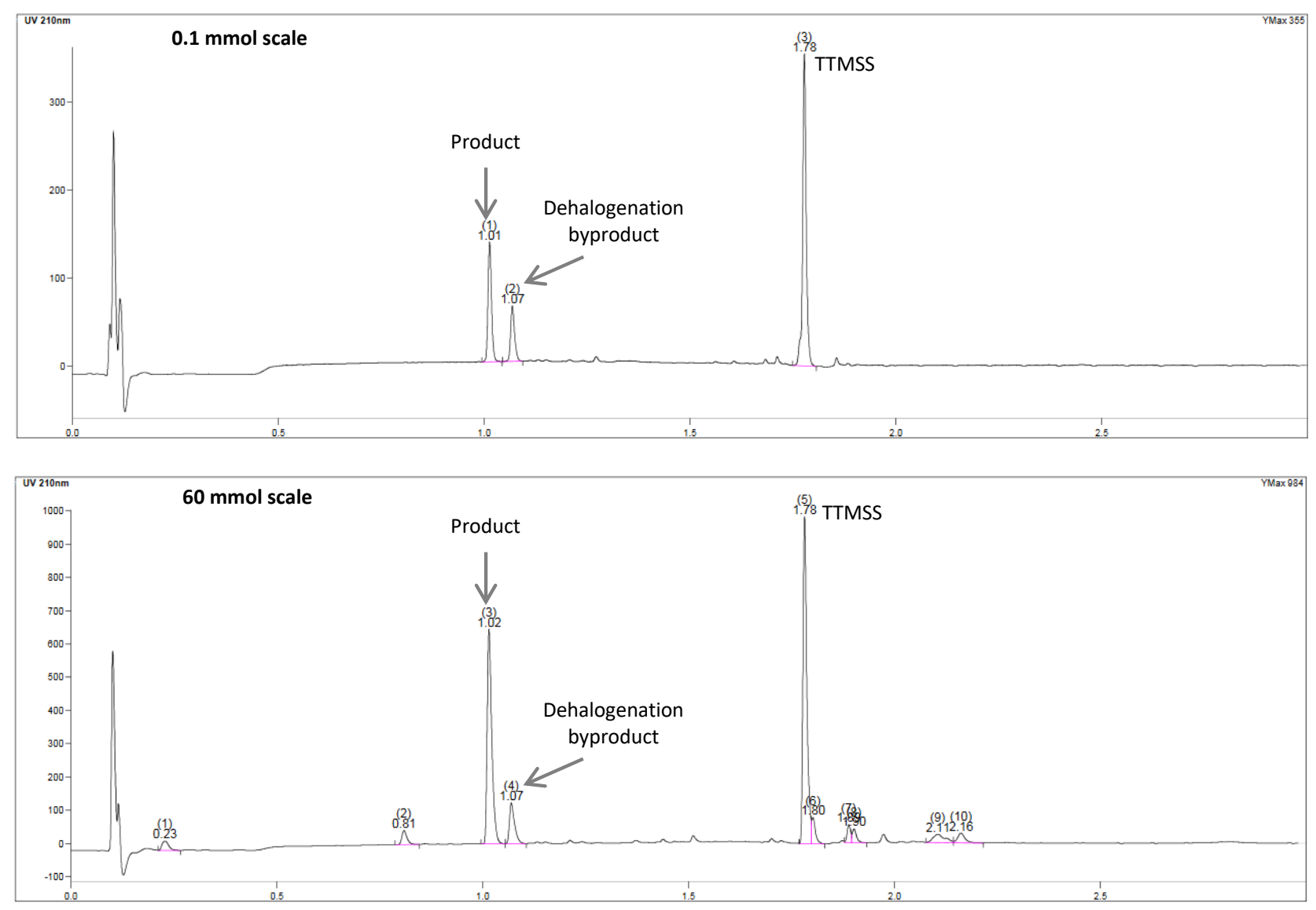

Figure S9: LCMS of crude reaction mixture of 0.1 and $60 \mathrm{mmol}$ scale reaction. 
tert-Butyl 4-cyano-4-(4-isobutylphenyl)piperidine-1-carboxylate
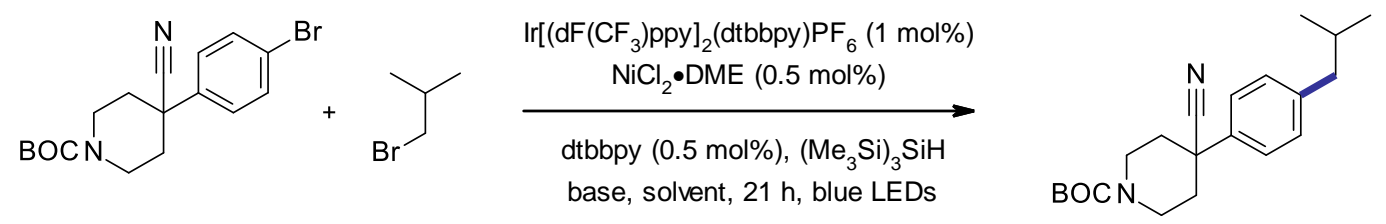

\section{Conditions screen - $0.1 \mathrm{mmol}$ scale reaction}

To a microwave flask fitted with stirring magnet was added tert-butyl 4-(4-bromophenyl)-4-cyano-piperidine1-carboxylate $(0.1 \mathrm{mmol}, 36.5 \mathrm{mg})$, base $(0.15 \mathrm{mmol})$ and $\operatorname{Ir}\left[\mathrm{dF}_{(\mathrm{CF}}\right)$ ppy $]_{2}(\mathrm{dtbbpy}) \mathrm{PF}_{6}(1 \mu \mathrm{mol}, 1.12 \mathrm{mg})$, followed by solvent $(0.8 \mathrm{~mL})$. A stock solution of $\mathrm{NiCl}_{2} \bullet \operatorname{DME}(5 \mu \mathrm{mol}, 1.1 \mathrm{mg})$ and dtbbpy $(5 \mu \mathrm{mol}, 1.3 \mathrm{mg})$ in solvent $(2 \mathrm{~mL})$ was prepared and $0.2 \mathrm{~mL}$ of this stock was added to the reaction mixture. 1-Bromo-2-methylpropane $(0.2 \mathrm{mmol}, 32.4 \mu \mathrm{L})$ was added to the reaction mixture and the vessel was capped and the mixture was degassed by bubbling argon through the solution for 5 minutes. After the reaction mixture was degassed TTMSS $(0.1 \mathrm{mmol}, 30.8 \mu \mathrm{L})$ was added to the reaction and the reaction mixture was placed in an EvoluChem ${ }^{\mathrm{TM}}$ DUObox and irradiated with 2 Kessil ${ }^{\circledR}$ lamps ( $40 \mathrm{~W}$ (input), $\lambda_{\max }=427 \mathrm{~nm}$ ) for $21 \mathrm{~h}$. The crude reaction mixture was analyzed by LCMS.

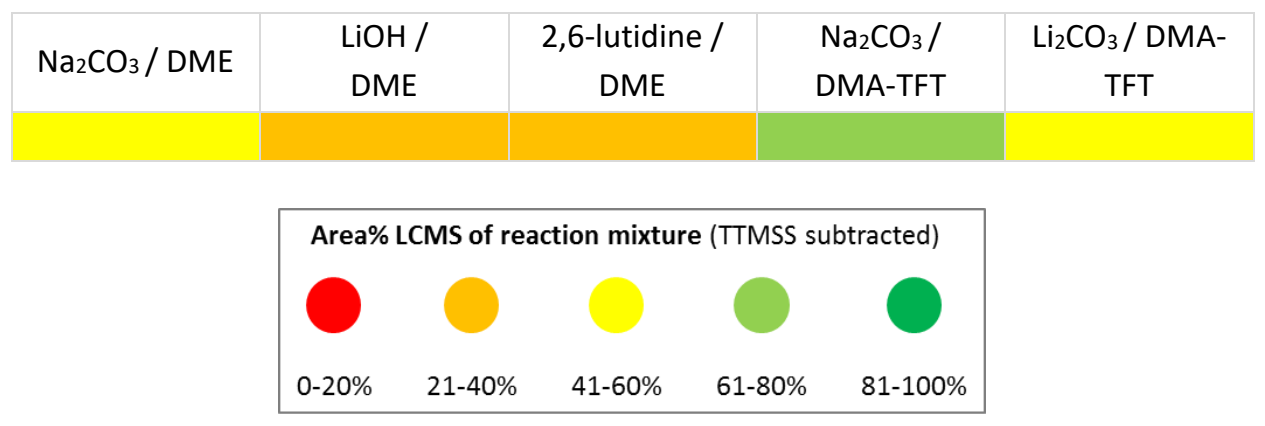

Table S7: Screen results - analysis of area \% of product in LCMS or crude reaction mixture - area of TTMSS subtracted from calculation

\section{5 mmol scale reaction}

To the reaction flask fitted with stirring magnet was added tert-butyl 4-(4-bromophenyl)-4-cyano-piperidine1-carboxylate (25.0 mmol, $9.13 \mathrm{~g}$ ), $\mathrm{Na}_{2} \mathrm{CO}_{3}(50 \mathrm{mmol}, 5.30 \mathrm{~g})$ and $\mathrm{Ir}\left[\mathrm{dF}\left(\mathrm{CF}_{3}\right) \text { ppy }\right]_{2}$ (dtbbpy)PF $6.25 \mathrm{mmol}, 280$ $\mathrm{mg}$ ), followed by $\alpha, \alpha, \alpha$-trifluorotoluene $(240 \mathrm{~mL})$ and DMA $(40 \mathrm{~mL})$. A stock solution of $\mathrm{NiCl}_{2} \bullet \mathrm{DME}(0.125 \mathrm{mmol}$, $27.5 \mathrm{mg})$ and dtbbpy $(0.125 \mathrm{mmol}, 33.6 \mathrm{mg})$ in DMA $(20 \mathrm{~mL})$ was prepared and was added to the reaction mixture. 1-Bromo-2-methyl-propane $(75 \mathrm{mmol}, 8.02 \mathrm{~mL}$ ) was added to the reaction mixture and the mixture was degassed by bubbling argon through the solution for 20 minutes. After the reaction mixture was degassed TTMSS $\left(25 \mathrm{mmol}, 7.71 \mathrm{~mL}\right.$ ) and the flask was sealed (Note - this set-up is not gas-tight, the $\mathrm{CO}_{2}$ generated is released through the seals preventing pressure buildup). The reaction was placed in the PhotonCabinet and the lamp was placed inside the immersion tube. The reaction was irradiated with for $21 \mathrm{~h}$, then the crude reaction mixture was analyzed by LCMS (Figure S10).

Following the reaction, water was added to the reaction $(200 \mathrm{~mL})$ and the mixture was extracted with EtOAc (3 x $200 \mathrm{~mL}$ ). The combined organic phases were washed with water and brine, dried with $\mathrm{Na}_{2} \mathrm{SO}_{4}$ and filtered. The reaction mixture was concentrated and purified by silica gel column chromatography gradient column to provide the pure product $(6.2 \mathrm{~g}, 72 \%)$. 
1H NMR (500 MHz, DMSO-d $) \delta$ ppm $7.44(\mathrm{~d}, J=8.2 \mathrm{~Hz}, 2 \mathrm{H}), 7.23(\mathrm{~d}, J=8.2 \mathrm{~Hz}, 2 \mathrm{H}), 4.20-4.03(\mathrm{~m}, 2 \mathrm{H}), 3.01$ (br s, 2H), $2.47-2.45(\mathrm{~m}, 2 \mathrm{H}), 2.11$ (br d, J=12.3 Hz, 2H), $1.96-1.77$ (m, 3H), $1.42(\mathrm{~s}, 9 \mathrm{H}), 0.86$ (d, J=6.6 Hz, 6H).

${ }^{13}$ C NMR (126 MHz, DMSO-d6) $\delta$ ppm 153.6, 141.1, 137.0, 129.5, 125.3, 121.6, 79.1, 43.9, 41.7, 35.0, 29.5, 28.0, 22.1 (one signal overlapping).

HRMS (ESI-TOF) m/z calcd. for $\mathrm{C}_{21} \mathrm{H}_{30} \mathrm{~N}_{2} \mathrm{O}_{2} \mathrm{Na}(\mathrm{M}+\mathrm{Na})+365.2199$, found 365.2186.
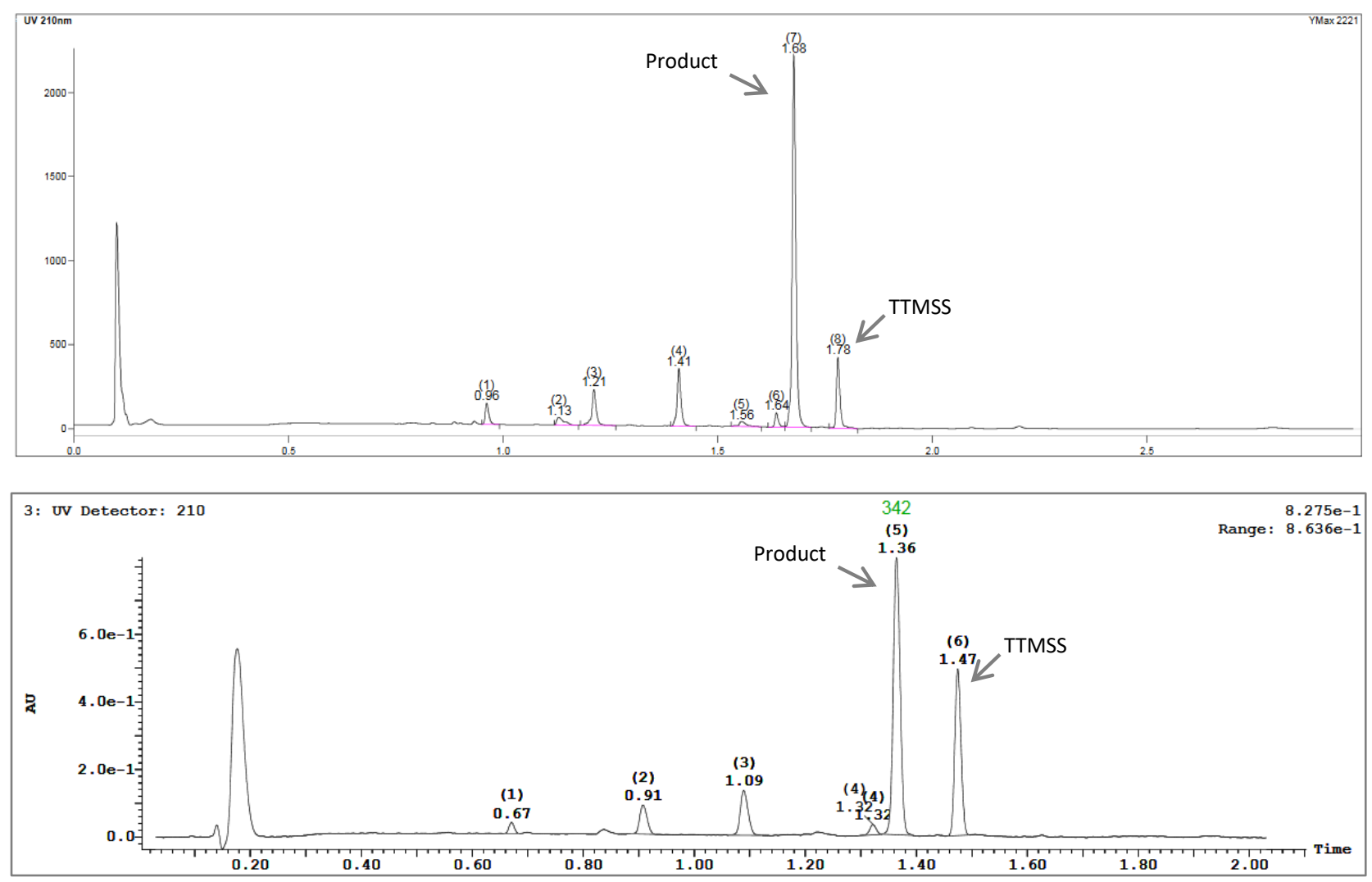

Figure S10: LCMS of crude reaction mixture of 0.1 and $25 \mathrm{mmol}$ scale reaction. 
tert-Butyl 4-[3-hydroxy-4-[methyl(phenyl)sulfamoyl]phenyl]piperidine-1-carboxylate

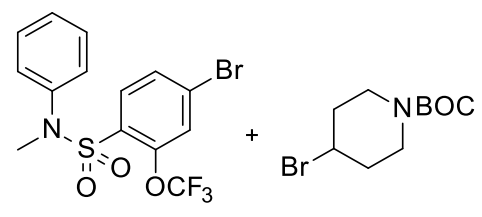

$$
\begin{gathered}
\left.\underset{\operatorname{Ir}\left[\left(\mathrm{dF}\left(\mathrm{CF}_{3}\right) \mathrm{ppy}_{2}(\mathrm{dtbbpy}) \mathrm{PF}_{6}(1 \mathrm{~mol} \%)\right.\right.}{\mathrm{NiCl}_{2} \bullet \mathrm{DME}\left(0.5 \mathrm{~mol}^{\circ}\right)}\right) \\
\underset{\text { dtbbpy }(0.5 \mathrm{~mol} \%),\left(\mathrm{Me}_{3} \mathrm{Si}\right)_{3} \mathrm{SiH}}{2,6-\text { lutidine, DME, } 21 \mathrm{~h} \text {, blue LEDs }}
\end{gathered}
$$

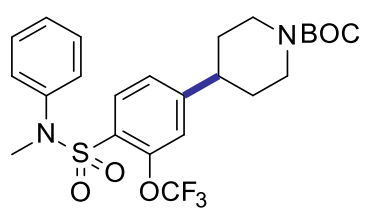

\section{Conditions screen - 0.1 mmol scale reaction}

To a microwave flask fitted with stirring magnet was added 4-bromo-2-hydroxy- $N$-methyl- $N$-phenylbenzenesulfonamide $(0.1 \mathrm{mmol}, 36.5 \mathrm{mg})$, base $(0.15 \mathrm{mmol})$ and $\operatorname{Ir}\left[\mathrm{dF}_{(\mathrm{CF}}\right)$ ppy $]_{2}(\mathrm{dtbbpy}) \mathrm{PF}_{6}(1 \mu \mathrm{mol}, 1.12 \mathrm{mg})$, followed by DME ( $0.8 \mathrm{~mL}$ ). A stock solution of $\mathrm{NiCl}_{2} \bullet \mathrm{DME}$ ( $\left.5 \mu \mathrm{mol}, 1.1 \mathrm{mg}\right)$ and dtbbpy ( $\left.5 \mu \mathrm{mol}, 1.3 \mathrm{mg}\right) \mathrm{in} \mathrm{DME}$ $(2 \mathrm{~mL})$ was prepared and $0.2 \mathrm{~mL}$ of this stock was added to the reaction mixture. tert-Butyl 4-bromopiperidine1-carboxylate $(0.3 \mathrm{mmol}, 79.2 \mathrm{mg})$ was added to the reaction mixture and the vessel was capped and the mixture was degassed by bubbling argon through the solution for 5 minutes. After the reaction mixture was degassed TTMSS $(0.11 \mathrm{mmol}, 33.8 \mu \mathrm{L})$ was added to the reaction and the reaction mixture was placed in an EvoluChem ${ }^{\mathrm{TM}}$ DUObox and irradiated with $2 \mathrm{Kessil}^{\circledR}$ lamps ( $40 \mathrm{~W}$ (input), $\lambda_{\max }=427 \mathrm{~nm}$ ) for $21 \mathrm{~h}$. The crude reaction mixture was analyzed by LCMS.

\begin{tabular}{|l|c|c|}
\hline $\mathrm{Na}_{2} \mathrm{CO}_{3} / \mathrm{DME}$ & $\mathrm{LiOH} /$ & 2,6-lutidine / \\
& DME & DME \\
\hline
\end{tabular}

Table S8: Screen results - analysis of area\% of product in LCMS or crude reaction mixture - area of TTMSS subtracted from calculation

\section{$25 \mathrm{mmol}$ scale reaction}

To the reaction flask fitted with stirring magnet was added 4-bromo-2-hydroxy- $N$-methyl- $N$-phenylbenzenesulfonamide (25.0 mmol, $10.3 \mathrm{~g})$, tert-butyl 4-bromopiperidine-1-carboxylate $(75.0 \mathrm{mmol}, 19.8 \mathrm{~g})$, and $\operatorname{Ir}\left[\mathrm{dF}_{\left(\mathrm{CF}_{3}\right) \text { ppy }}\right]_{2}$ (dtbbpy)PF $6(0.25 \mathrm{mmol}, 280 \mathrm{mg})$, followed by DME $(600 \mathrm{~mL})$ and 2,6-lutidine (50 mmol). A stock solution of $\mathrm{NiCl}_{2} \bullet \mathrm{DME}(0.125 \mathrm{mmol}, 27.5 \mathrm{mg})$ and dtbbpy $(0.125 \mathrm{mmol}, 33.6 \mathrm{mg})$ in DME (20 mL) was prepared and was added to the reaction mixture. The mixture was degassed by bubbling argon through the solution for 20 minutes. After the reaction mixture was degassed TTMSS (25 mmol, $7.71 \mathrm{~mL}$ ) and the flask was sealed. The reaction was placed in the PhotonCabinet and the lamp was placed inside the immersion tube. The reaction was irradiated with for $21 \mathrm{~h}$, then the crude reaction mixture was analyzed by LCMS (Figure S11).

Following the reaction, water was added to the reaction $(200 \mathrm{~mL})$ and the mixture was extracted with EtOAc (3 x $200 \mathrm{~mL}$ ). The combined organic phases were washed with water and brine, dried with $\mathrm{Na}_{2} \mathrm{SO}_{4}$ and filtered. The reaction mixture was concentrated and purified by silica gel column chromatography gradient column to provide the pure product ( $8.8 \mathrm{~g}, 65 \%)$.

${ }^{1}$ H NMR (500 MHz, DMSO-d 6$) \delta 7.69-7.66(\mathrm{~m}, 1 \mathrm{H}), 7.44-7.41(\mathrm{~m}, 2 \mathrm{H}), 7.36$ - $7.31(\mathrm{~m}, 2 \mathrm{H}), 7.28$ - $7.24(\mathrm{~m}, 1 \mathrm{H})$, $7.20-7.16(\mathrm{~m}, 2 \mathrm{H}), 4.12$ - $4.02(\mathrm{~m}, 2 \mathrm{H}), 3.26(\mathrm{~s}, 3 \mathrm{H}), 2.88(\mathrm{tt}, J=12.2,3.4 \mathrm{~Hz}, 1 \mathrm{H}), 2.84-2.71(\mathrm{~m}, 2 \mathrm{H}), 1.79-1.75$ $(\mathrm{m}, 2 \mathrm{H}), 1.49(\mathrm{qd}, J=12.2,4.4 \mathrm{~Hz}, 2 \mathrm{H}), 1.41(\mathrm{~s}, 9 \mathrm{H})$.

${ }^{13}$ C NMR (126 MHz, DMSO-d $) \delta 154.3,153.8,145.1,140.5,131.7,129.0,127.8,127.1,126.0,125.6,119.7,119.6$ (q, J=259.21 Hz), 78.6, 54.9, 41.2, 38.1, 32.0, 28.1. 
HRMS (ESI-TOF) $\mathrm{m} / \mathrm{z}$ calcd. for $\mathrm{C}_{24} \mathrm{H}_{29} \mathrm{~F}_{3} \mathrm{~N}_{2} \mathrm{O}_{5} \mathrm{SNa}(\mathrm{M}+\mathrm{Na})+537.1641$, found 537.1637.
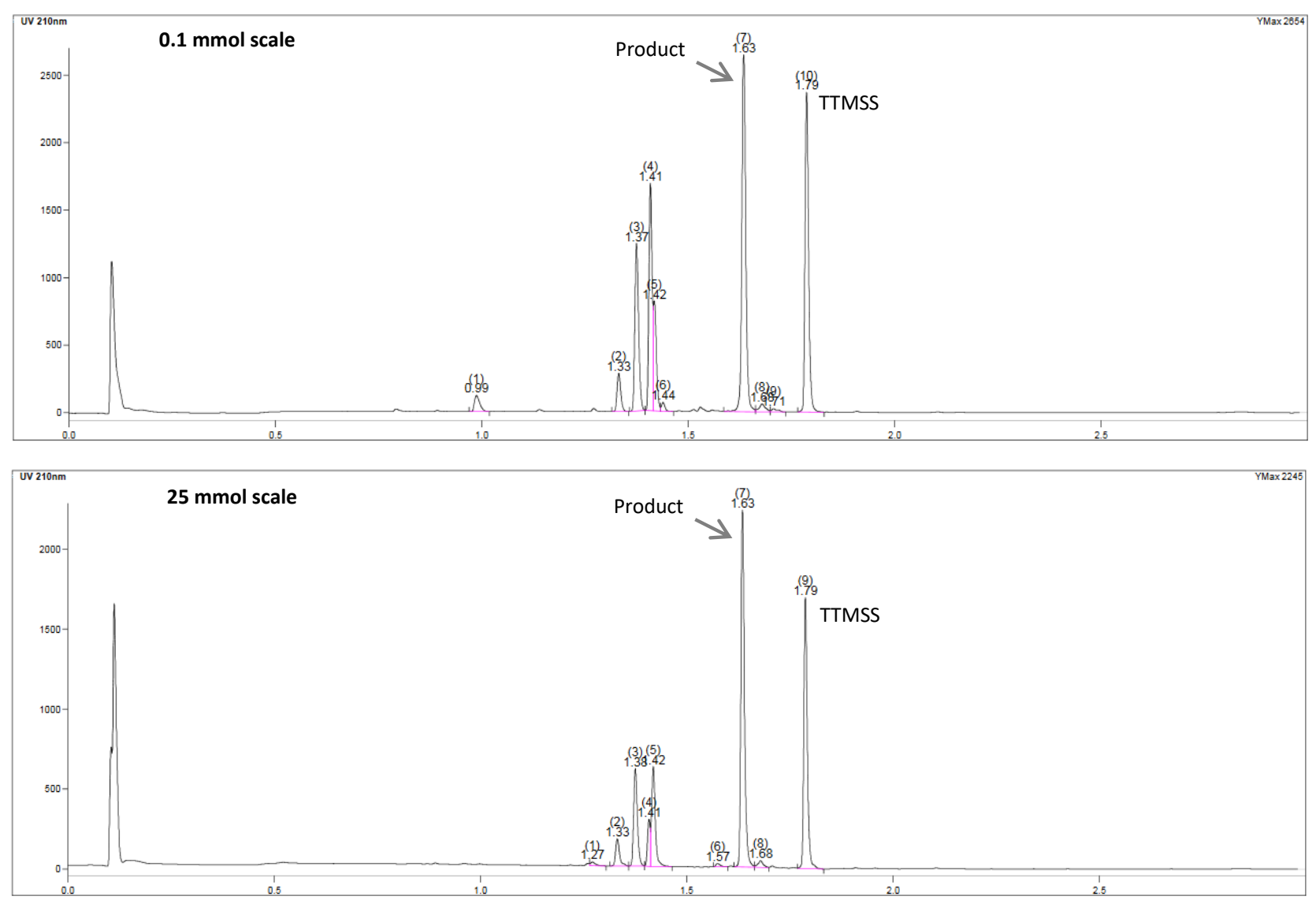

Figure S11: LCMS of crude reaction mixture of 0.1 and $25 \mathrm{mmol}$ scale reaction. 


\section{[5-(4-Cyclohexylphenyl)-2-furyl]-morpholino-methanone}
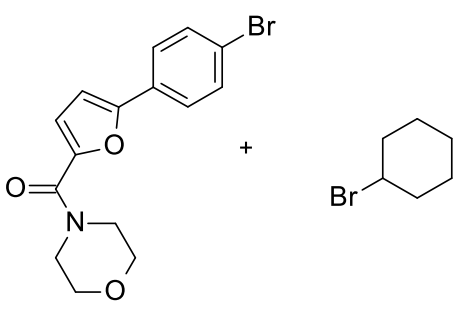

$$
\begin{aligned}
& \operatorname{Ir}\left[\left(\mathrm{dF}\left(\mathrm{CF}_{3}\right) \mathrm{ppy}\right]_{2}(\mathrm{dtbbpy}) \mathrm{PF}_{6}(1 \mathrm{~mol} \%)\right. \\
& \mathrm{NiCl}_{2} \bullet \text { DME (0.5 mol\%) } \\
& \text { dtbbpy (0.5 mol\%), }\left(\mathrm{Me}_{3} \mathrm{Si}\right)_{3} \mathrm{SiH} \\
& \mathrm{Na}_{2} \mathrm{CO}_{3} \text {, DME, } 21 \mathrm{~h} \text {, blue LEDs }
\end{aligned}
$$

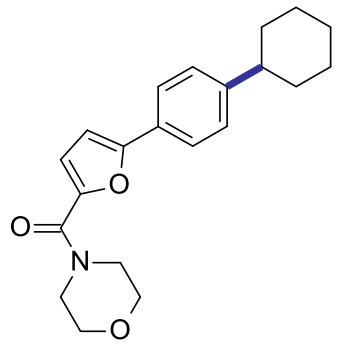

\section{Conditions screen - 0.1 mmol scale reaction}

To a microwave flask fitted with stirring magnet was added [5-(4-bromophenyl)-2-furyl]-morpholinomethanone $(0.1 \mathrm{mmol}, 33.6 \mathrm{mg})$, base $(0.15 \mathrm{mmol})$ and $\operatorname{Ir}\left[\mathrm{dF}_{(\mathrm{CF}}\right)$ ppy $]_{2}(\mathrm{dtbbpy}) \mathrm{PF}_{6}(1 \mu \mathrm{mol}, 1.12 \mathrm{mg})$, followed by solvent $(0.8 \mathrm{~mL})$. A stock solution of $\mathrm{NiCl}_{2} \bullet$ DME $(5 \mu \mathrm{mol}, 1.1 \mathrm{mg})$ and dtbbpy ( $\left.5 \mu \mathrm{mol}, 1.3 \mathrm{mg}\right)$ in solvent ( 2 $\mathrm{mL}$ ) was prepared and $0.2 \mathrm{~mL}$ of this stock was added to the reaction mixture. Bromocyclohexane $(0.3 \mathrm{mmol}$, $36.8 \mu \mathrm{L}$ ) was added to the reaction mixture and the vessel was capped and the mixture was degassed by bubbling argon through the solution for 5 minutes. After the reaction mixture was degassed TTMSS $(0.11 \mathrm{mmol}$, $33.8 \mu \mathrm{L}$ ) was added to the reaction and the reaction mixture was placed in an EvoluChem ${ }^{\mathrm{TM}}$ DUObox and irradiated with $2 \mathrm{Kessil}^{\circledR}$ lamps ( $40 \mathrm{~W}$ (input), $\lambda_{\max }=427 \mathrm{~nm}$ ) for $21 \mathrm{~h}$. The crude reaction mixture was analyzed by LCMS.

\begin{tabular}{|l|c|c|c|c|}
\hline \multirow{2}{*}{$\mathrm{Na}_{2} \mathrm{CO}_{3} / \mathrm{DME}$} & $\mathrm{LiOH} /$ & 2,6-lutidine / & $\mathrm{Na}_{2} \mathrm{CO}_{3} /$ & $\mathrm{Li}_{2} \mathrm{CO}_{3} / \mathrm{DMA}-$ \\
& DME & DME & DMA-TFT & TFT \\
\hline
\end{tabular}

Table S9: Screen results - analysis of area\% of product in LCMS or crude reaction mixture - area of TTMSS subtracted from calculation

\section{5 mmol scale reaction}

To the reaction flask fitted with stirring magnet was added [5-(4-bromophenyl)-2-furyl]-morpholinomethanone (25.0 mmol, $8.41 \mathrm{~g}$ ), bromocyclohexane $(75.0 \mathrm{mmol}, 9.02 \mathrm{~g})$, and $\operatorname{Ir}\left[\mathrm{dF}\left(\mathrm{CF}_{3}\right) \text { ppy }\right]_{2}(\mathrm{dtbbpy}) \mathrm{PF}_{6}(0.25$ mmol, $280 \mathrm{mg})$, followed by DME $(600 \mathrm{~mL})$ and $\mathrm{Na}_{2} \mathrm{CO}_{3}(50 \mathrm{mmol})$. A stock solution of $\mathrm{NiCl}_{2} \bullet \mathrm{DME}(0.125 \mathrm{mmol}$, $27.5 \mathrm{mg})$ and dtbbpy $(0.125 \mathrm{mmol}, 33.6 \mathrm{mg})$ in DME $(20 \mathrm{~mL})$ was prepared and was added to the reaction mixture. The mixture was degassed by bubbling argon through the solution for 20 minutes. After the reaction mixture was degassed TTMSS ( $25 \mathrm{mmol}, 7.71 \mathrm{~mL}$ ) and the flask was sealed (Note - this set-up is not gas-tight, the $\mathrm{CO}_{2}$ generated is released through the seals preventing pressure buildup). The reaction was placed in the PhotonCabinet and the lamp was placed inside the immersion tube. The reaction was irradiated with for $21 \mathrm{~h}$, then the crude reaction mixture was analyzed by LCMS (Figure S12).

Following the reaction, water was added to the reaction $(200 \mathrm{~mL}$ ) and the mixture was extracted with EtOAc (3 x $200 \mathrm{~mL}$ ). The combined organic phases were washed with water and brine, dried with $\mathrm{Na}_{2} \mathrm{SO}_{4}$ and filtered. The reaction mixture was concentrated and purified by silica gel column chromatography gradient column to provide the pure product ( $4.2 \mathrm{~g}, 52 \%)$.

${ }^{1}$ H NMR (500 MHz, DMSO-d $) \delta$ ppm $7.68(\mathrm{~m}, J=8.2 \mathrm{~Hz}, 2 \mathrm{H}), 7.31(\mathrm{~m}, J=8.2 \mathrm{~Hz}, 2 \mathrm{H}), 7.13(\mathrm{~d}, J=3.5 \mathrm{~Hz}, 1 \mathrm{H}), 7.04$ (d, J=3.5 Hz, 1H), $3.87-3.69$ (m, 4H), $3.69-3.63(\mathrm{~m}, 4 \mathrm{H}), 2.56-2.52(\mathrm{~m}, 1 \mathrm{H}), 1.79$ (br d, J=11.3 Hz, 4H), 1.70 (br d, J=12.3 Hz, 1H), $1.46-1.31$ (m, 4H), 1.23 (br d, J=12.3 Hz, 1H) 
13C NMR (126 MHz, DMSO-d6) $\delta$ ppm 158.1, 154.5, 148.1, 145.8, 127.3, 127.0, 124.1, 118.2, 106.4, 66.2, 43.5, $33.7,26.2,25.5$ (one signal overlapping)

HRMS (ESI-TOF) m/z calcd. for $\mathrm{C}_{21} \mathrm{H}_{25} \mathrm{NO}_{3} \mathrm{H}(\mathrm{M}+\mathrm{H})+340.1909$, found 340.1907.
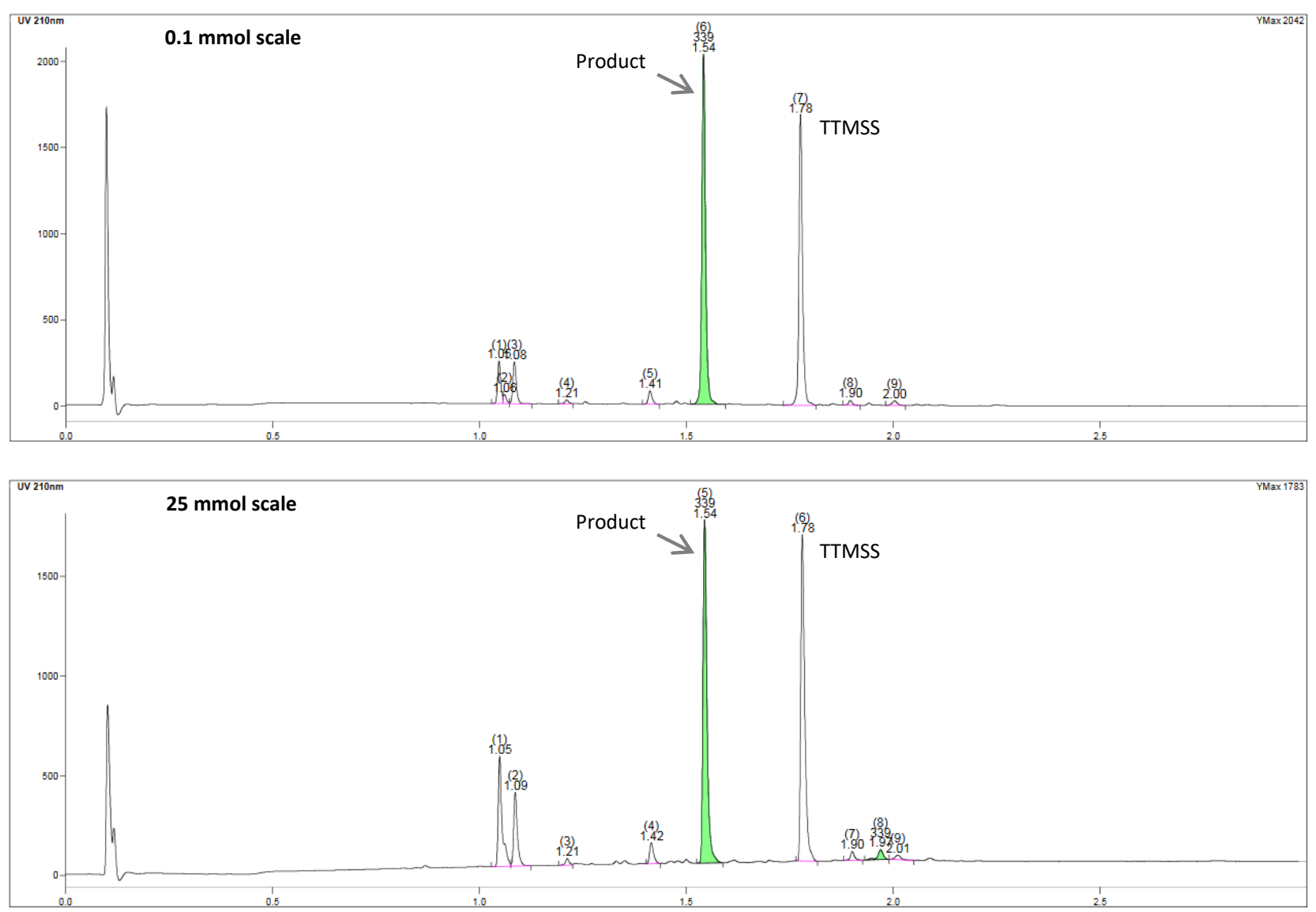

Figure S12: LCMS of crude reaction mixture of 0.1 and $25 \mathrm{mmol}$ scale reaction. 
tert-Butyl 7-cyclohexyl-4-oxo-spiro[chromane-2,4'-piperidine]-1'-carboxylate
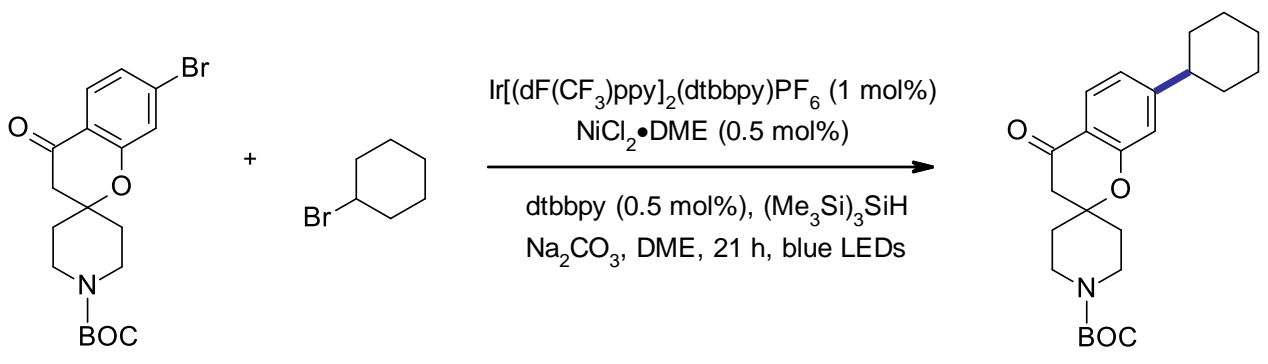

\section{Conditions screen - $0.1 \mathrm{mmol}$ scale reaction}

To a microwave flask fitted with stirring magnet was added tert-butyl 7-cyclohexyl-4-oxo-spiro[chromane-2,4'piperidine $]-1^{\prime}$-carboxylate $(0.1 \mathrm{mmol}, 39.6 \mathrm{mg})$, base $(0.15 \mathrm{mmol})$ and $\operatorname{Ir}\left[\mathrm{dF}\left(\mathrm{CF}_{3}\right) \text { ppy }\right]_{2}(\mathrm{dtbbpy}) \mathrm{PF}_{6}(1 \mu \mathrm{mol}$, $1.12 \mathrm{mg}$ ), followed by solvent $\left(0.8 \mathrm{~mL}\right.$ ). A stock solution of $\mathrm{NiCl}_{2} \bullet \mathrm{DME}$ ( $5 \mu \mathrm{mol}, 1.1 \mathrm{mg}$ ) and dtbbpy (5 $\mu \mathrm{mol}, 1.3$ $\mathrm{mg}$ ) in solvent $(2 \mathrm{~mL})$ was prepared and $0.2 \mathrm{~mL}$ of this stock was added to the reaction mixture. Bromocyclohexane $(0.3 \mathrm{mmol}, 36.8 \mu \mathrm{L})$ was added to the reaction mixture and the vessel was capped and the mixture was degassed by bubbling argon through the solution for 5 minutes. After the reaction mixture was degassed TTMSS $(0.11 \mathrm{mmol}, 33.8 \mu \mathrm{L})$ was added to the reaction and the reaction mixture was placed in an EvoluChem ${ }^{\mathrm{TM}}$ DUObox and irradiated with $2 \mathrm{Kessil}^{\circledR}$ lamps (40 W (input), $\lambda_{\max }=427 \mathrm{~nm}$ ) for $21 \mathrm{~h}$. The crude reaction mixture was analyzed by LCMS.

\begin{tabular}{|c|c|c|c|c|}
\hline $\mathrm{Na}_{2} \mathrm{CO}_{3} / \mathrm{DME}$ & $\begin{array}{c}\mathrm{LiOH} / \\
\text { DME }\end{array}$ & $\begin{array}{c}\text { 2,6-lutidine / } \\
\text { DME }\end{array}$ & $\begin{array}{c}\mathrm{Na}_{2} \mathrm{CO}_{3} / \\
\text { DMA-TFT }\end{array}$ & $\begin{array}{c}\mathrm{Li}_{2} \mathrm{CO}_{3} / \mathrm{DMA}- \\
\text { TFT }\end{array}$ \\
\hline
\end{tabular}

Table S10: Screen results - analysis of area $\%$ of product in LCMS or crude reaction mixture - area of TTMSS subtracted from calculation

\section{5 mmol scale reaction}

To the reaction flask fitted with stirring magnet was added tert-butyl 7-cyclohexyl-4-oxo-spiro[chromane-2,4'piperidine]-1'-carboxylate $(25.0 \mathrm{mmol}, 9.91 \mathrm{~g})$, bromocyclohexane $(75.0 \mathrm{mmol}, 9.02 \mathrm{~g})$, and $\operatorname{Ir}\left[\mathrm{dF}\left(\mathrm{CF}_{3}\right) \text { ppy }\right]_{2}(\mathrm{dtbbpy}) \mathrm{PF}_{6}(0.25 \mathrm{mmol}, 280 \mathrm{mg})$, followed by DME $(600 \mathrm{~mL})$ and $\mathrm{Na}_{2} \mathrm{CO}_{3}(50 \mathrm{mmol})$. A stock solution of $\mathrm{NiCl}_{2} \bullet$ DME $(0.125 \mathrm{mmol}, 27.5 \mathrm{mg})$ and dtbbpy $(0.125 \mathrm{mmol}, 33.6 \mathrm{mg})$ in DME $(20 \mathrm{~mL})$ was prepared and was added to the reaction mixture. The mixture was degassed by bubbling argon through the solution for 20 minutes. After the reaction mixture was degassed TTMSS $(25 \mathrm{mmol}, 7.71 \mathrm{~mL})$ and the flask was sealed (Note - this set-up is not gas-tight, the $\mathrm{CO}_{2}$ generated is released through the seals preventing pressure buildup). The reaction was placed in the PhotonCabinet and the lamp was placed inside the immersion tube. The reaction was irradiated with for $21 \mathrm{~h}$, then the crude reaction mixture was analyzed by LCMS (Figure S13).

Following the reaction, water was added to the reaction $(200 \mathrm{~mL})$ and the mixture was extracted with EtOAc (3 x $200 \mathrm{~mL}$ ). The combined organic phases were washed with water and brine, dried with $\mathrm{Na}_{2} \mathrm{SO}_{4}$ and filtered. The reaction mixture was concentrated and purified by silica gel column chromatography gradient column to provide the pure product $(5.0 \mathrm{~g}, 53 \%)$.

${ }^{1}$ H NMR (500 MHz, DMSO- $d_{6}$ ) $\delta$ ppm 7.53 (d, J=2.2 Hz, $1 \mathrm{H}$ ), 7.45 (dd, J=8.5, $2.2 \mathrm{~Hz}, 1 \mathrm{H}$ ), 6.99 (d, J=8.5 Hz, $1 \mathrm{H}$ ), 3.78 - 3.63 (m, 2 H), 3.23 - 3.01 (m, 2 H), 2.80 (s, 2 H), 1.85 (br d, J=13.2 Hz, 2 H), 1.80 - 1.73 (m, 4 H), 1.69 (br d, $J=12.3 \mathrm{~Hz}, 1 \mathrm{H}), 1.60(\mathrm{br} \mathrm{t}, J=10.4 \mathrm{~Hz}, 2 \mathrm{H}), 1.42-1.30(\mathrm{~m}, 13 \mathrm{H}), 1.27-1.10(\mathrm{~m}, 1 \mathrm{H})$ 
${ }^{13}$ C NMR (126 MHz, DMSO-d6) $\boldsymbol{\delta}$ ppm 191.5, 156.8, 153.7, 140.2, 135.2, 122.8, 119.9, 118.1, 78.7, 77.6, 46.7, $42.5,33.8,28.0,26.2,25.4$ (two signals overlapping)

HRMS (ESI-TOF) m/z calcd. for $\mathrm{C}_{24} \mathrm{H}_{33} \mathrm{NO}_{4} \mathrm{Na}(\mathrm{M}+\mathrm{Na})^{+} 422.2299$, found 422,2302.
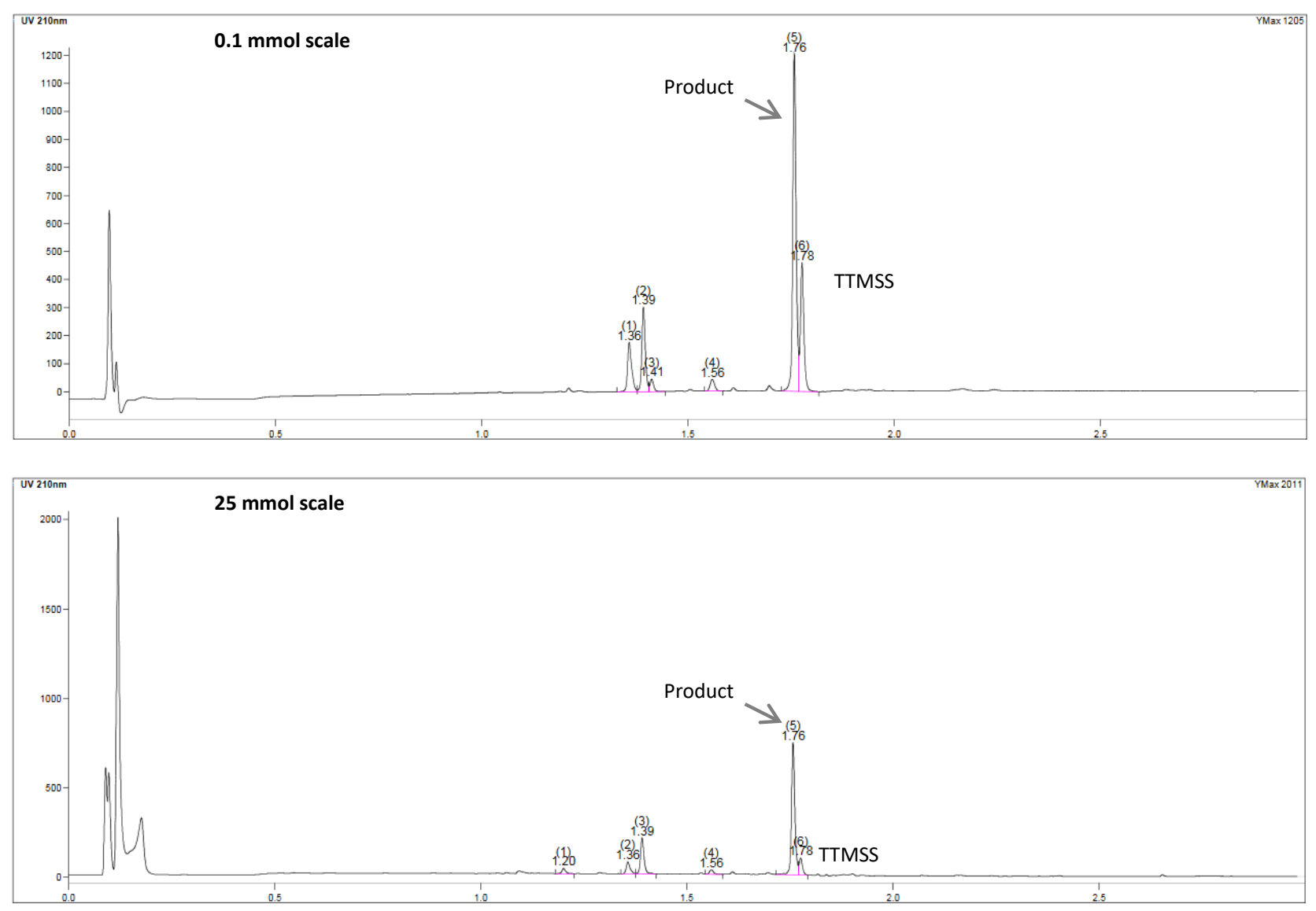

Figure S13: LCMS of crude reaction mixture of 0.1 and $25 \mathrm{mmol}$ scale reaction. 


\section{6. $s p^{3} / s p^{3}$ Decarboxylative coupling reaction}

\section{tert-Butyl 2-benzylpyrrolidine-1-carboxylate}

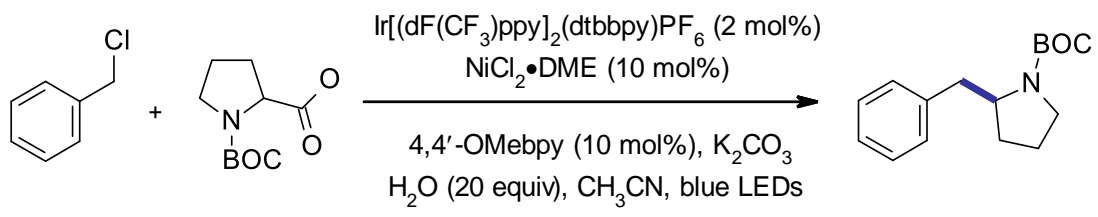

\section{$0.5 \mathrm{mmol}$ scale reaction}

To a microwave flask fitted with stirring magnet was added 1-tert-butoxycarbonylpyrrolidine-2-carboxylic acid (0.75 mmol, $161.4 \mathrm{mg}), \mathrm{K}_{2} \mathrm{CO}_{3}(1.0 \mathrm{mmol}, 138.2 \mathrm{mg}), \operatorname{Ir}\left[\mathrm{dF}_{(\mathrm{CF}}\right)$ ppy $]_{2}(\mathrm{dtbbpy}) \mathrm{PF}_{6}(10 \mu \mathrm{mol}, 11.2 \mathrm{mg})$, $\mathrm{NiCl}_{2} \bullet$ DME (50 $\mu \mathrm{mol}, 11.0 \mathrm{mg}$ ) and 4,4'-dimethoxy-2,2'-bipyridine ( $\left.10 \mu \mathrm{mol}, 10.8 \mathrm{mg}\right)$. The reaction vessel was capped and acetonitrile $(5 \mathrm{~mL})$ was added, followed by chloromethylbenzene $(0.5 \mathrm{mmol}, 57.5 \mu \mathrm{L})$, and the mixture was degassed by bubbling argon through the solution for 5 minutes. Degassed water $(10 \mathrm{mmol}, 108$ $\mu \mathrm{L}$ ) was added to the degassed mixture and the reaction mixture was placed in an EvoluChem ${ }^{\mathrm{TM}}$ DUObox and irradiated with $2 \mathrm{Kessil}^{\circledR}$ lamps ( $40 \mathrm{~W}$ (input), $\lambda_{\max }=427 \mathrm{~nm}$ ) for $21 \mathrm{~h}$. The crude reaction mixture was analyzed by LCMS.

\section{$30 \mathrm{mmol}$ scale reaction}

To the reaction flask fitted with stirring magnet was added 1-tert-butoxycarbonylpyrrolidine-2-carboxylic acid

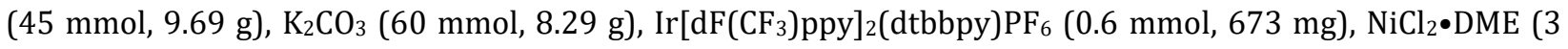
$\mathrm{mmol}, 659 \mathrm{mg}$ ) and 4,4'-dimethoxy-2,2'-bipyridine ( $3.0 \mathrm{mmol}, 649 \mathrm{mg}$ ). The immersion tube was fitted into the reactor and to the flask was added acetonitrile $(300 \mathrm{~mL})$, followed by chloromethylbenzene $(30 \mathrm{mmol}, 3.45$ $\mathrm{mL}$ ). The mixture was degassed by bubbling argon through the solution for 20 minutes then degassed water $\left(600 \mathrm{mmol}, 10.8 \mathrm{~mL}\right.$ ) was added and the flask was sealed (Note - this set-up is not gas-tight, the $\mathrm{CO}_{2}$ generated is released through the seals preventing pressure buildup). The reaction was placed in the PhotonCabinet and the lamp was placed inside the immersion tube. The reaction was irradiated with for $21 \mathrm{~h}$, then the crude reaction mixture was analyzed by LCMS (Figure S14).

Following the reaction, water was added to the reaction $(200 \mathrm{~mL})$ and the mixture was extracted with EtOAc (3 x $200 \mathrm{~mL}$ ). The combined organic phases were washed with water and brine, dried with $\mathrm{Na}_{2} \mathrm{SO}_{4}$ and filtered. The reaction mixture was concentrated and purified by silica gel column chromatography gradient column to provide the pure product ( $4.5 \mathrm{~g}, 57 \%$ ).

The data was in accordance with those previously reported. ${ }^{S 4}$ 

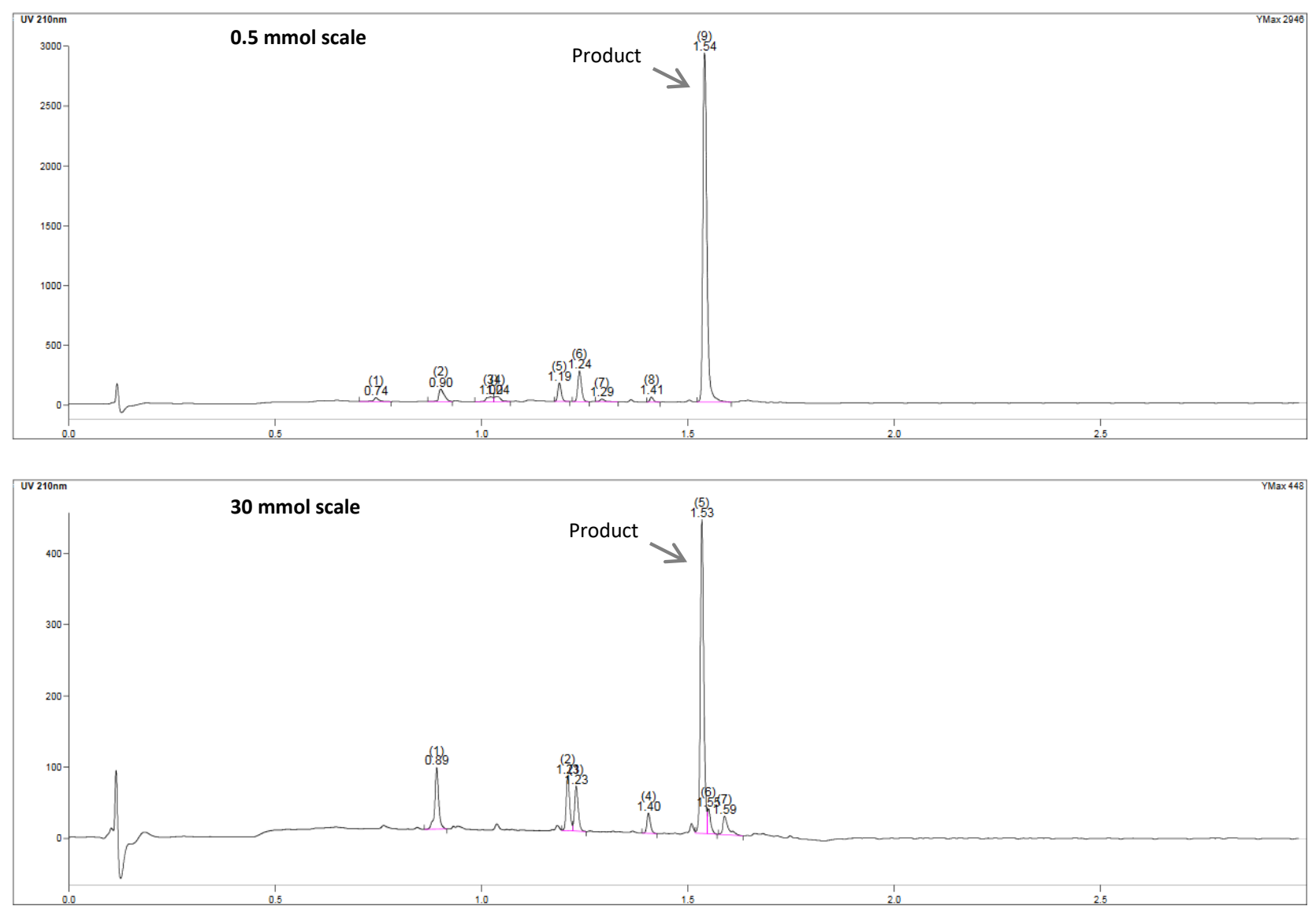

Figure S14: LCMS of crude reaction mixture of 0.5 and $30 \mathrm{mmol}$ scale reaction. 


\section{7. $s p^{2} / s p^{3}$ coupling of benyzl trifluoroborate}

\section{Methyl 4-benzylbenzoate}
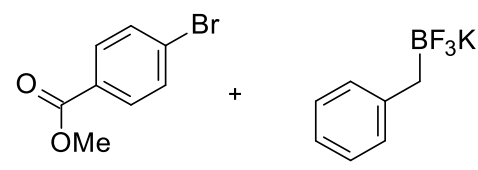
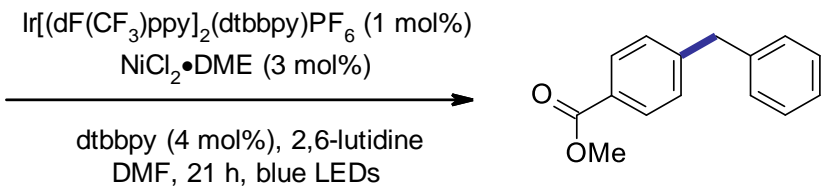

\section{$0.25 \mathrm{mmol}$ scale reaction}

To a microwave flask fitted with stirring magnet was added methyl 4-bromobenzoate $(0.25 \mathrm{mmol}, 53.8 \mathrm{mg})$, potassium trifluoroborate $(0.31 \mathrm{mmol}, 61.9 \mathrm{mg})$ and $\operatorname{Ir}\left[\mathrm{dF}_{2}\left(\mathrm{CF}_{3}\right) \text { ppy }\right]_{2}(\mathrm{dtbbpy}) \mathrm{PF}_{6}(2.5 \mu \mathrm{mol}, 2.81 \mathrm{mg})$. A solution of $\mathrm{NiCl}_{2} \bullet \operatorname{DME}(7.5 \mu \mathrm{mol}, 1.65 \mathrm{mg})$ and dtbbpy $(10 \mu \mathrm{mol}, 1.65 \mathrm{mg})$ in DMF $(2 \mathrm{~mL}) \mathrm{was}$ prepared and added to the reaction mixture. 2,6-Lutidine $(0.88 \mathrm{mmol}, 102 \mu \mathrm{L})$ was added to the reaction mixture and the vessel was capped and the mixture was degassed by bubbling argon through the solution for 5 minutes. After the reaction mixture was placed in an EvoluChem ${ }^{\mathrm{TM}}$ DUObox and irradiated with 2 Kessil $^{\circledR}$ lamps (40 W (input), $\lambda_{\max }=427 \mathrm{~nm}$ ) for $21 \mathrm{~h}$. The crude reaction mixture was analyzed by LCMS.

\section{$40 \mathrm{mmol}$ scale reaction}

To the reaction flask fitted with stirring magnet was added methyl 4-bromobenzoate $(40 \mathrm{mmol}, 8.60 \mathrm{~g})$, potassium trifluoroborate $(50 \mathrm{mmol}, 9.90 \mathrm{~g}), \operatorname{Ir}\left[\mathrm{dF}_{(\mathrm{CF}}\right)$ ppy $]_{2}(\mathrm{dtbbpy}) \mathrm{PF}_{6}(0.4 \mathrm{mmol}, 449 \mathrm{mg}), \mathrm{NiCl}_{2} \bullet \mathrm{DME}(1.2$ $\mathrm{mmol}, 264 \mathrm{mg}$ ) and dtbbpy (1.6 mmol, $429 \mathrm{~g}$ ). The immersion tube was fitted into the reactor and to the flask was added DMF ( $400 \mathrm{~mL}$ ) followed by 2,6-lutidine $(140 \mathrm{mmol}, 16.3 \mathrm{~mL})$. The mixture was degassed by bubbling argon through the solution for 20 minutes then the flask was sealed. The reaction was placed in the PhotonCabinet and the lamp was placed inside the immersion tube. The reaction was irradiated with for $21 \mathrm{~h}$, then the crude reaction mixture was analyzed by LCMS (Figure S15).

Following the reaction, water was added to the reaction $(200 \mathrm{~mL})$ and the mixture was extracted with EtOAc (3 x $200 \mathrm{~mL}$ ). The combined organic phases were washed with water and brine, dried with $\mathrm{Na}_{2} \mathrm{SO}_{4}$ and filtered. The reaction mixture was concentrated and purified by silica gel column chromatography gradient column to provide the pure product $(5.1 \mathrm{~g}, 58 \%)$.

The data was in accordance with those previously reported. 55 

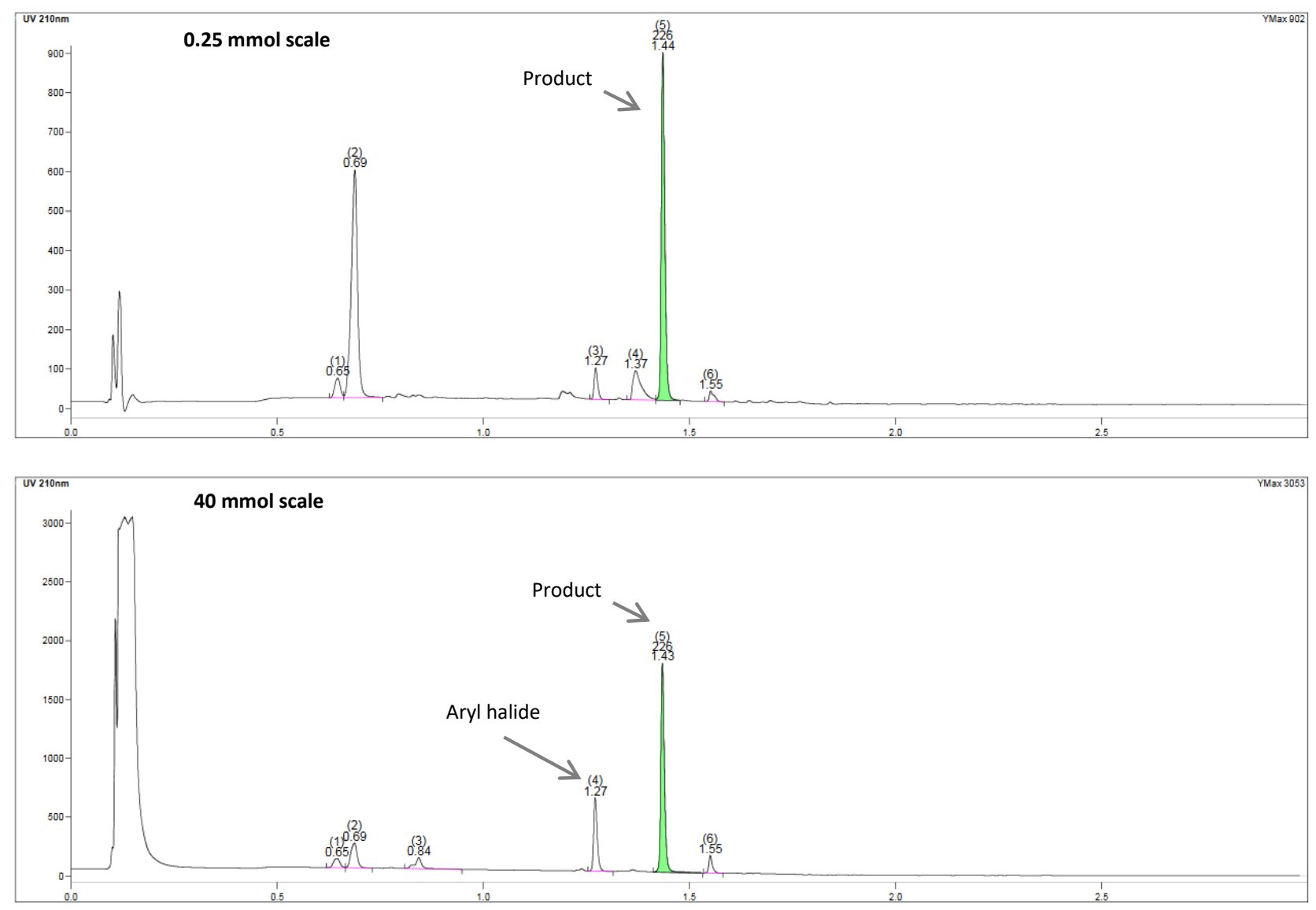

Figure S15: LCMS of crude reaction mixture of 0.25 and $40 \mathrm{mmol}$ scale reaction. 


\section{Scale-up in IW side-loop reactors}

\subsection{Small base screen:}

\section{$1.6 \mathrm{mmol}$ scale reaction}

To a flask fitted with stirring magnet was added methyl 4-bromobenzoate ( $1.6 \mathrm{mmol}, 351 \mathrm{mg})$, base ( $3.26 \mathrm{mmol}$, 2 equiv.) and $\operatorname{Ir}\left[\mathrm{dF}\left(\mathrm{CF}_{3}\right) \text { ppy }\right]_{2}(\mathrm{dtbbpy}) \mathrm{PF}_{6}(16 \mu \mathrm{mol}, 18.3 \mathrm{mg})$ or 4CzIPN $(16 \mu \mathrm{mol}, 13 \mathrm{mg})$, followed by DME $(18 \mathrm{~mL})$. A stock solution of $\mathrm{NiCl}_{2} \bullet \mathrm{DME}(8 \mu \mathrm{mol}, 1.79 \mathrm{mg}$ ) and dtbbpy ( $8 \mu \mathrm{mol}, 2.19 \mathrm{mg})$ in DME (2 mL) was prepared and added to the reaction mixture. 3-Bromopropanenitrile $(3.26 \mathrm{mmol}, 270 \mu \mathrm{L})$ was added to the reaction mixture and the vessel was capped and the mixture was degassed by bubbling argon through the solution for 5 minutes. After the reaction mixture was degassed TTMSS ( $1.63 \mathrm{mmol}, 405 \mathrm{mg}$ ) was added to the reaction and the reaction mixture was irradiated. Initially, the reaction was irradiated for $4 \mathrm{~h}$, then for safety reasons, the reaction was stopped overnight. The reaction was then irradiated for a further $5 \mathrm{~h}$. The reaction was monitored by calibrated LCMS.

The reaction with 2,6-lutidine and $\operatorname{Ir}\left[\mathrm{dF}_{(}\left(\mathrm{CF}_{3}\right) \text { ppy }\right]_{2}(\mathrm{dtbbpy}) \mathrm{PF}_{6}$ had highest conversion (Figure $\mathrm{S} 16$, graph 2), while the reaction with $\mathrm{Na}_{2} \mathrm{CO}_{3}$ did not react further after the overnight break in irradiation (Figure S16, graph 1). ${ }^{\mathrm{S} 6}$ As internal safety requirements prevent irradiation of reactions in the side-loop reactor overnight, the decision was made to proceed with 2,6-lutidine as base.

While 2,6-lutidine is an organic base, the reaction following irradiation is heterogeneous (see Figure S17).

This makes running these reductive couplings in flow challenging.

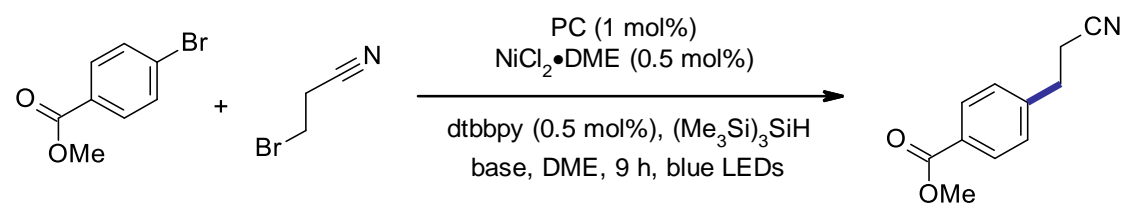

1.

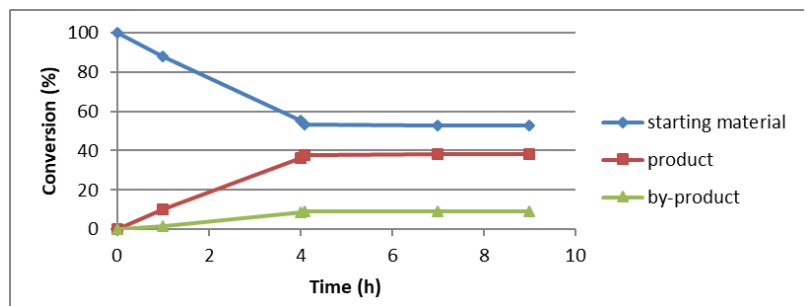

$\mathrm{Na}_{2} \mathrm{CO}_{3}$ with $\operatorname{Ir}\left[\mathrm{dF}\left(\mathrm{CF}_{3}\right) \text { ppy }\right]_{2}(\mathrm{dtbbpy}) \mathrm{PF}_{6}$

3.

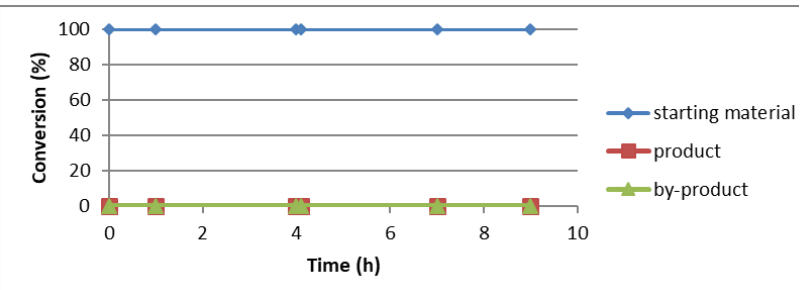

TMG with $\operatorname{Ir}\left[\mathrm{dF}\left(\mathrm{CF}_{3}\right) \text { ppy }\right]_{2}(\mathrm{dtbbpy}) \mathrm{PF}_{6}$
2.

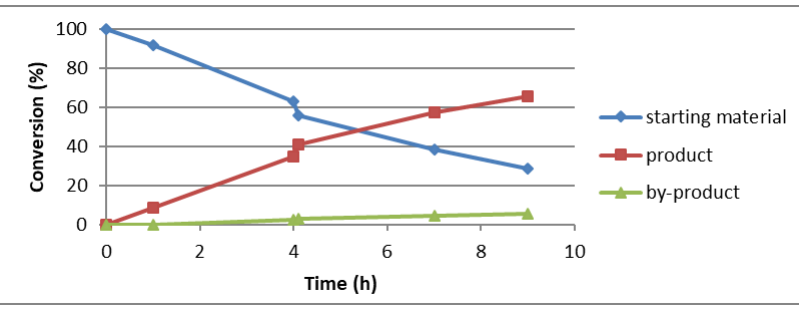

2,6-Lutidine with $\operatorname{Ir}\left[\mathrm{dF}\left(\mathrm{CF}_{3}\right) \text { ppy }\right]_{2}(\mathrm{dtbbpy}) \mathrm{PF}_{6}$

4.

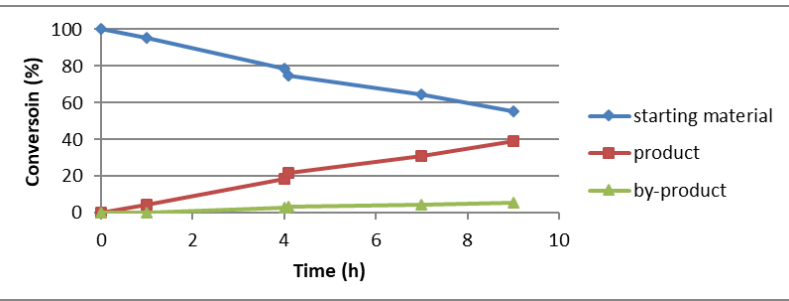

2,6-Lutidine with 4CzIPN

Figure S16: Plot of the (\%) amounts of starting material, by-product and product verses time for each base. Conversion determined by calibrated LCMS. 

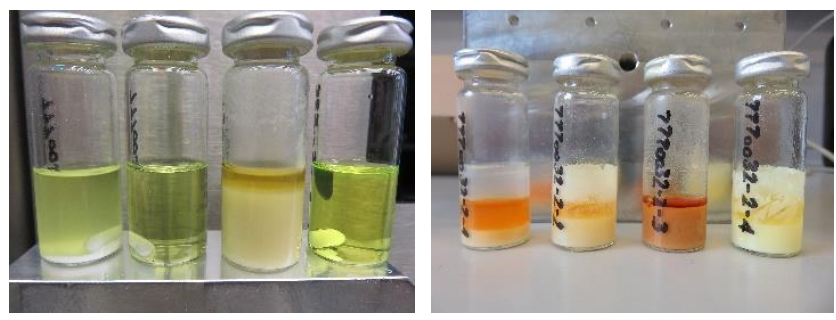

Figure S17: Small scale screen of bases and photocatalysts to determine. Photo on left, prior to irradiation. Photo on right, after irradiation. Vial 1: $\mathrm{Na}_{2} \mathrm{CO}_{3}$, vial 2: 2,6-lutidine, vial 3: TMG, vial 4: 2,6-lutidine with 4CzIPN.

\section{$8.240 \mathrm{mmol}$ scale reaction in side-loop reactor}
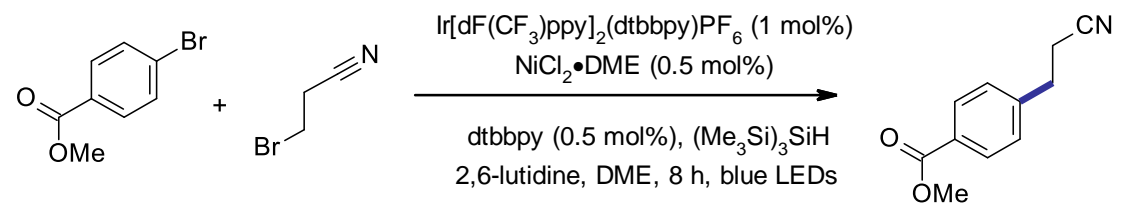

To the reaction flask fitted with immersion tube and connected to the side-loop with PTFE tubing (internal diameter, $4 \mathrm{~mm}$ ) was added methyl 4-bromobenzoate ( $40.0 \mathrm{mmol}, 8.60 \mathrm{~g})$, 2,6-lutidine ( $80 \mathrm{mmol}, 8.57 \mathrm{~g})$ and $\operatorname{Ir}\left[\mathrm{dF}\left(\mathrm{CF}_{3}\right) \mathrm{ppy}_{2}\right.$ (dtbbpy)PF $6(0.4 \mathrm{mmol}, 449 \mathrm{mg})$, followed by DME $(470 \mathrm{~mL})$. A solution of $\mathrm{NiCl}_{2} \bullet \mathrm{DME}(0.2$ $\mathrm{mmol}, 43.9 \mathrm{mg})$ and dtbbpy $(0.2 \mathrm{mmol}, 53.7 \mathrm{mg})$ in DME $(30 \mathrm{~mL})$ was prepared and was added to the reaction mixture. 3-Bromopropanenitrile $(80 \mathrm{mmol}, 6.62 \mathrm{~mL})$ was added to the reaction mixture and the mixture was degassed by bubbling nitrogen through the solution for 45 minutes. After the reaction mixture was degassed TTMSS ( $40 \mathrm{mmol}, 9.94 \mathrm{~g}$ ) was added. The flask was kept under a nitrogen atmosphere throughout the reaction (the $\mathrm{O}_{2}$ level in the reaction mixture was measured to be between $<0.1$ and $2.9 \%$ at different timepoints). The reaction was irradiated for $8 \mathrm{~h}$ and monitored with calibrated LCMS. The reaction mixture was circulated using an IWAKI magnet pump (MD-15F-Z-220N magnet driven impeller pump) with a flow rate of $9 \mathrm{~mL} / \mathrm{min}$.
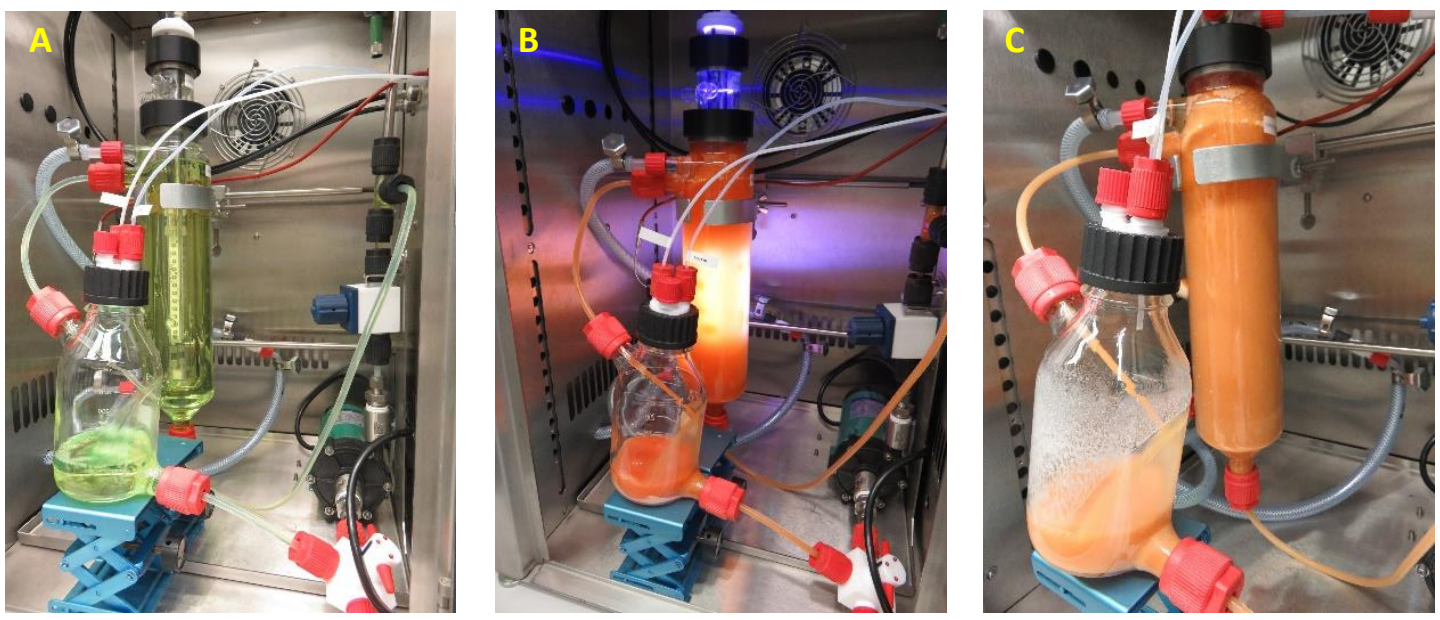

Figure S18: $40 \mathrm{mmol}$ scale reaction in small side loop reactor. A. Prior to irradiation. B. After $1 \mathrm{~h}$ of irradiation. C. At completion of reaction. 


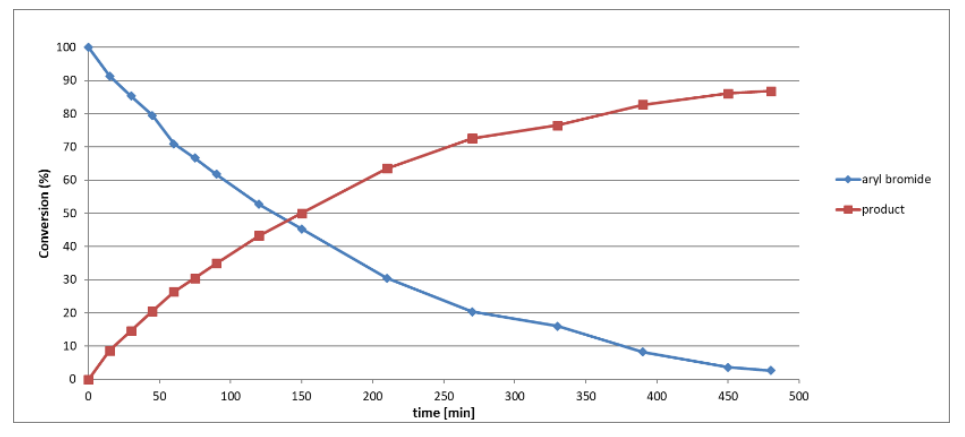

Figure S19: Plot of the conversion of methyl 4-bromobenzoate to product. Conversion determined by calibrated LCMS.

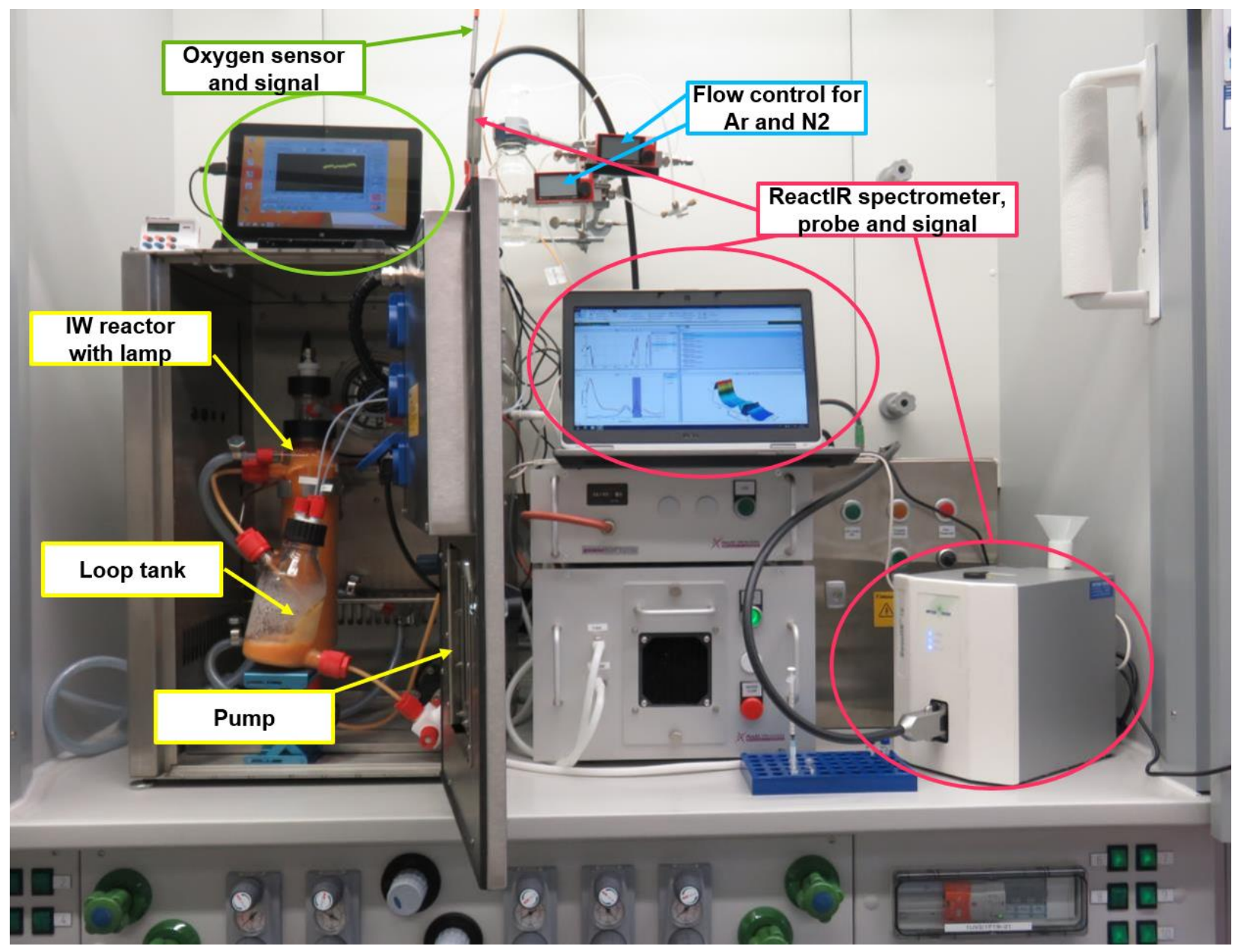

Figure S20: IW side-loop reactor setup running $40 \mathrm{mmol}$ scale reductive coupling with ReactIR monitoring (larger version of Figure 4 from manuscript). 


\section{$8.3400 \mathrm{mmol}$ scale reaction in side-loop reactor}

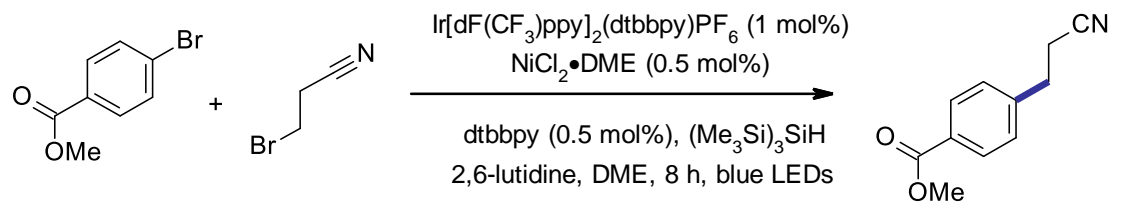

To the reaction flask fitted with immersion tube and the connected side-loop with PTFE tubing (internal diameter, $12 \mathrm{~mm}$ ) was added methyl 4-bromobenzoate ( $400 \mathrm{mmol}, 86.0 \mathrm{~g}$ ), 2,6-lutidine ( $800 \mathrm{mmol}, 85.7 \mathrm{~g}$ ) and $\operatorname{Ir}\left[\mathrm{dF}\left(\mathrm{CF}_{3}\right) \mathrm{ppy}_{2}(\mathrm{dtbbpy}) \mathrm{PF}_{6}(4.0 \mathrm{mmol}, 4.49 \mathrm{~g})\right.$, followed by DME (4.59 L). A solution of $\mathrm{NiCl}_{2} \bullet \mathrm{DME}(2 \mathrm{mmol}$, $439 \mathrm{mg}$ ) and dtbbpy $(2 \mathrm{mmol}, 537 \mathrm{mg})$ in DME $(300 \mathrm{~mL})$ was prepared and was added to the reaction mixture. 3-Bromopropanenitrile ( $800 \mathrm{mmol}, 66.2 \mathrm{~mL})$ was added to the reaction mixture and the mixture was degassed by bubbling nitrogen through the solution for 10 minutes. After the reaction mixture was degassed the pump was started to circulate the reaction mixture and TTMSS $(400 \mathrm{mmol}, 99.4 \mathrm{~g})$ was added and the mixture was degassed for a further 45 mins. The flask was kept under a nitrogen atmosphere throughout the reaction (the $\mathrm{O}_{2}$ level in the reaction mixture was measured to be $<1 \%$ throughout). The reaction was irradiated for $25 \mathrm{~h}$ and monitored with calibrated LCMS. The reaction mixture was circulated using an IWAKI magnet pump (MD-55F$\mathrm{X}$ magnet driven impeller pump) with a flow rate of $10 \mathrm{~mL} / \mathrm{min}$. After $25 \mathrm{~h}$, the product was observed in $76 \%$ yield based on calibrated LCMS analysis.
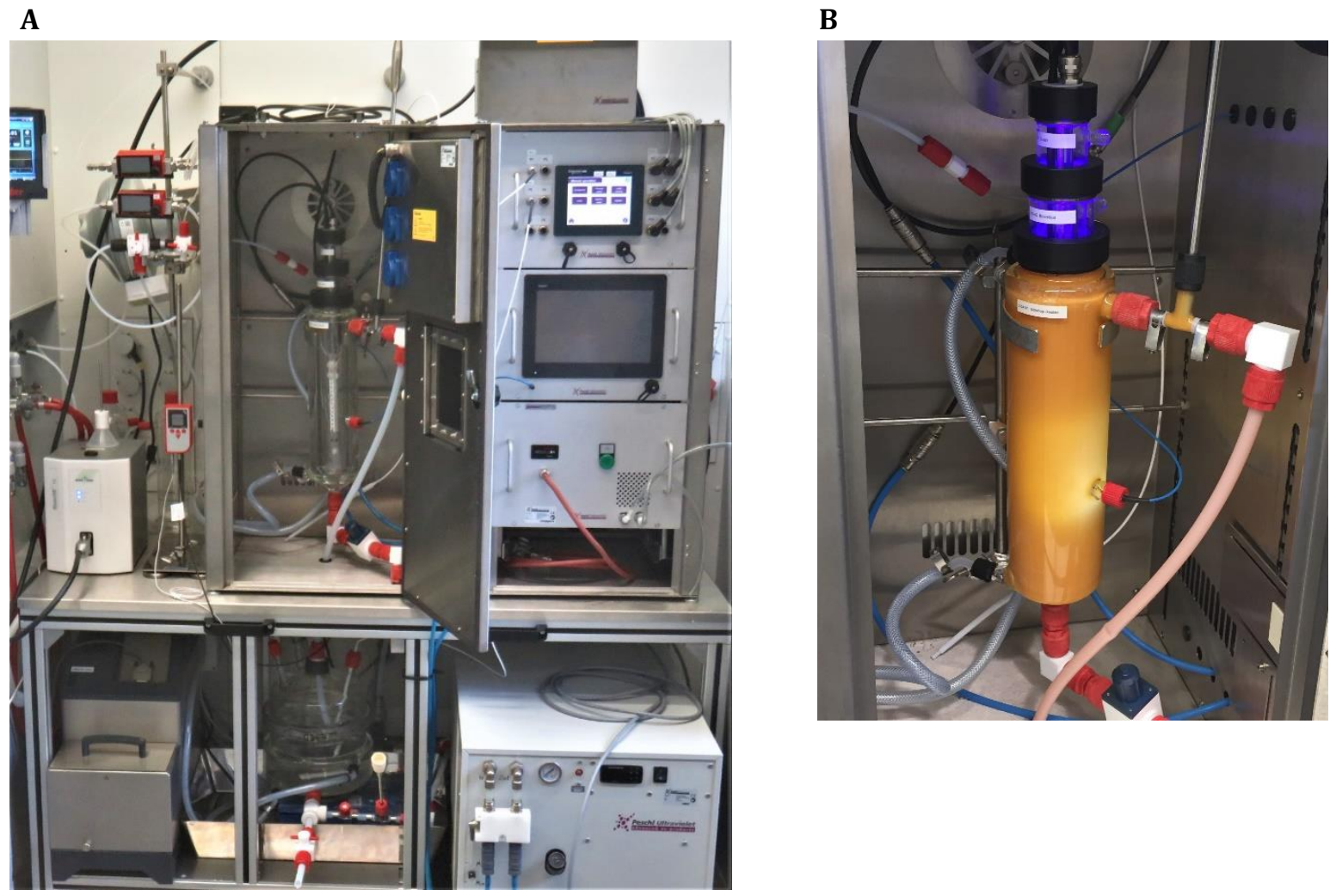

Figure S21: A. Large IW side-loop reactor (above) with $5 \mathrm{~L}$ loop tank (below). B. Irradiation of the $400 \mathrm{mmol}$ scale reaction mixture. 


\section{Reactions up-scaled in round-bottom flasks}

Prior to investigating the use of IW reactors for upscaling carbon $s p^{2}-s p^{3}$ cross coupling reactions, a number of reactions were attempted in round-bottom flasks using 3 high powered Kessil ${ }^{\circledR}\left(40 \mathrm{~W}\right.$ [input], $\left.\lambda_{\max }=427 \mathrm{~nm}\right)$ lamps positioned approximately $5 \mathrm{~cm}$ from the flask with water cooling to maintain the reaction temperature close to room temperature.

The decarboxylative coupling between methyl 4-bromobenzoate and $N$-Boc-proline in a round-bottom flask ( 4 mmol scale) resulted in comparable yields to the reaction performed on a $30 \mathrm{mmol}$ scale in the IW reactor (eq. 1).

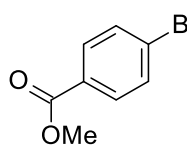<smiles>O=C(O)C1CCCN1C(=O)O</smiles>

$4 \mathrm{mmol}$

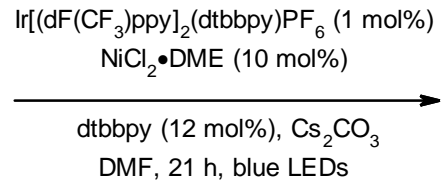

DMF, $21 \mathrm{~h}$, blue LEDs

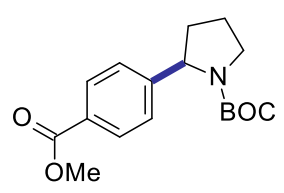

$86 \%(1.06 \mathrm{~g})$

The reductive coupling between methyl 4-bromobenzoate and 3-bromopropanenitrile in a round-bottom flask (30 mmol scale) resulted in nearly comparable yield to the reaction performed on $60 \mathrm{mmol}$ scale in the IW reactor (68\% vs $77 \%$ ), however the reaction in the round bottom flask required extended reaction time. The major by-product of this reaction was methyl benzoate (eq. 2).

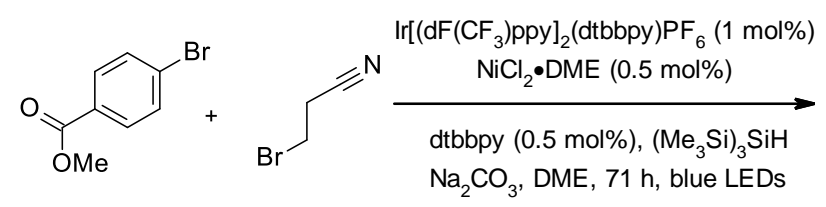

$30 \mathrm{mmol}$

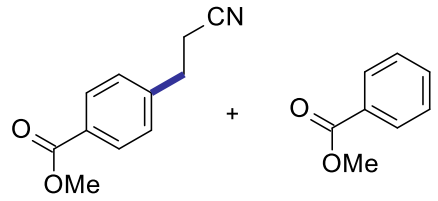

$68 \%$

(major by-product)

The decarboxylative coupling between ethyl 6-bromoimidazo[1,2-a]pyridine-2-carboxylate and $N$-Boc-proline in an round-bottom flask ( $30 \mathrm{mmol}$ scale) provided only trace amounts of product. After $48 \mathrm{~h}$, a lot of starting material remained and the major by-product was ethyl imidazo[1,2-a]pyridine-2-carboxylate (resulting from protodebromination). Using the IW reactor (also on $30 \mathrm{mmol} \mathrm{scale),} \mathrm{the} \mathrm{product} \mathrm{was} \mathrm{isolated} \mathrm{in} 36 \%$ (eq. 3).<smiles>CCOC(=O)c1cn2cc(Br)ccc2n1</smiles>

$30 \mathrm{mmol}$
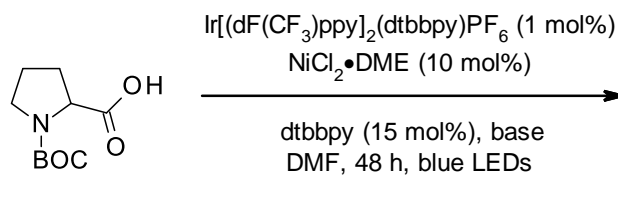

DMF, $48 \mathrm{~h}$, blue LEDs

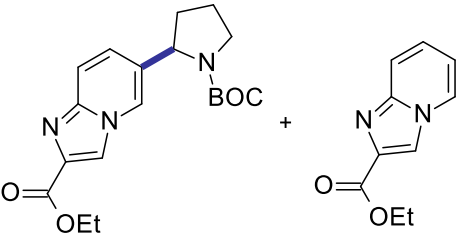

traces

$$
\text { (major by-product) }
$$




\section{References}

[S1] http://peschl-ultraviolet.com/english_n/products/photochemistry/preparativephotochemistry/standard-photoreactor-system/mpdsbasic-standard-laboratory-photoreactors.html [S2] Shaw, M. H.; Shurtleff, V. W.; Terrett, J. A.; Cuthbertson, J. D.; MacMillan, D. W. C. Native functionality in triple catalytic cross-coupling: $\mathrm{sp}^{3} \mathrm{C}-\mathrm{H}$ bonds as latent nucleophiles, Science, 2016, 352, 1304.

[S3] An, X.-D.; Yu, S. Direct Synthesis of Nitriles from Aldehydes Using an $O$-Benzoyl Hydroxylamine (BHA) as the Nitrogen Source, Org. Lett. 2015, 17, 5064.

[S4] Johnston, C. P.; Smith, R. T.; Allmendinger, S.; MacMillan, D. W. C. Nature Metallaphotoredox-catalysed $s p^{3}-$ $s p^{3}$ cross-coupling of carboxylic acids with alkyl halides, 2016, 536, 322.

[S5] Tellis, J. C.; Primer, D. N.; Molander, G. A. Single-electron transmetalation in organoboron cross-coupling by photoredox/nickel dual catalysis, Science, 2014, 345, 433.

[S6] Pomberger, A.; Mo, Y.; Nandiwale, K. Y.; Schultz, V. L.; Duvadie, R.; Robinson, R. I.; Altinoglu, E. I.; Jensen, K. F. A Continuous Stirred-Tank Reactor (CSTR) Cascade for Handling Solid-Containing Photochemical Reactions, Org. Process Res. Dev. 2019, 23, 2699. 

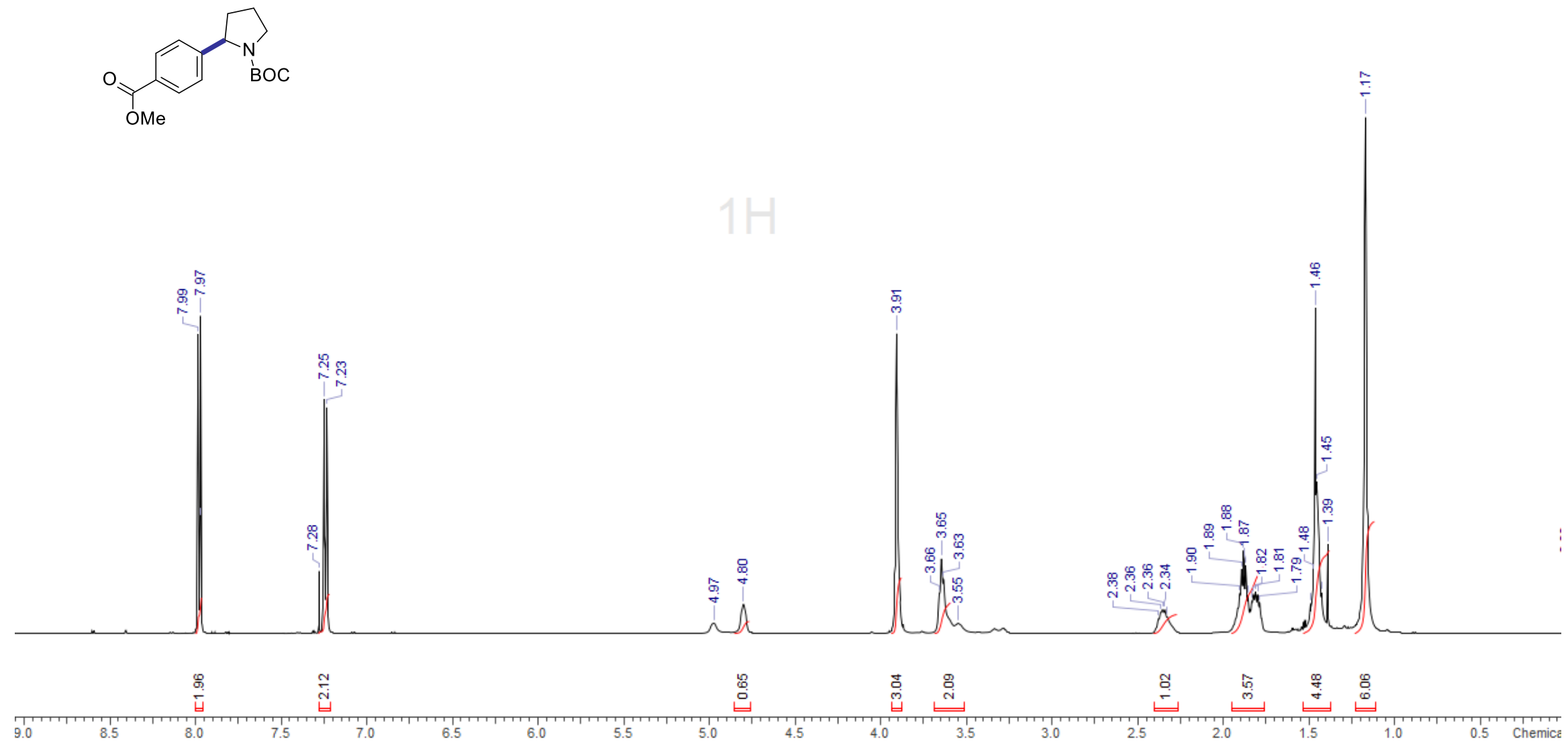
tert-Butyl 2-(4-methoxycarbonylphenyl)pyrrolidine-1-carboxylate ${ }^{13} \mathrm{C} \mathrm{NMR}\left(126 \mathrm{MHz}, \mathrm{CDCl}_{3}\right)$
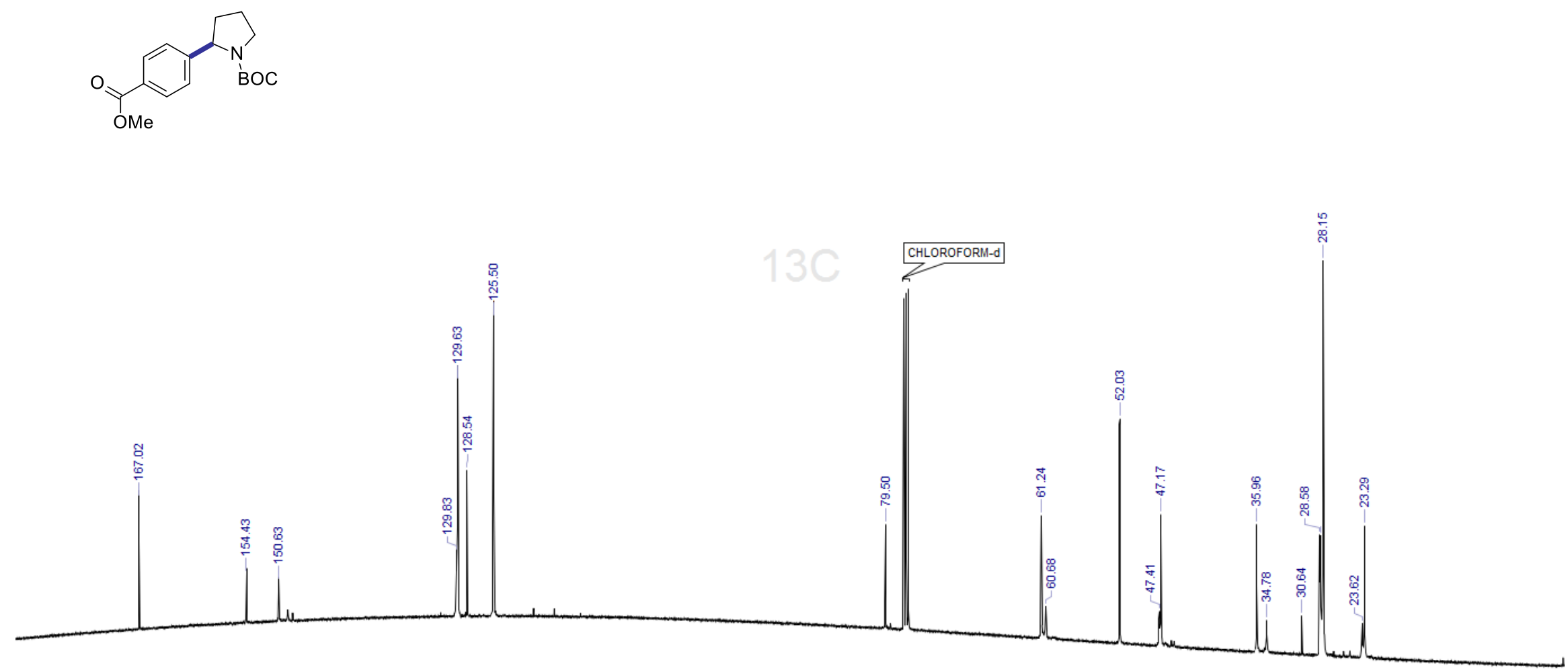

180
185 

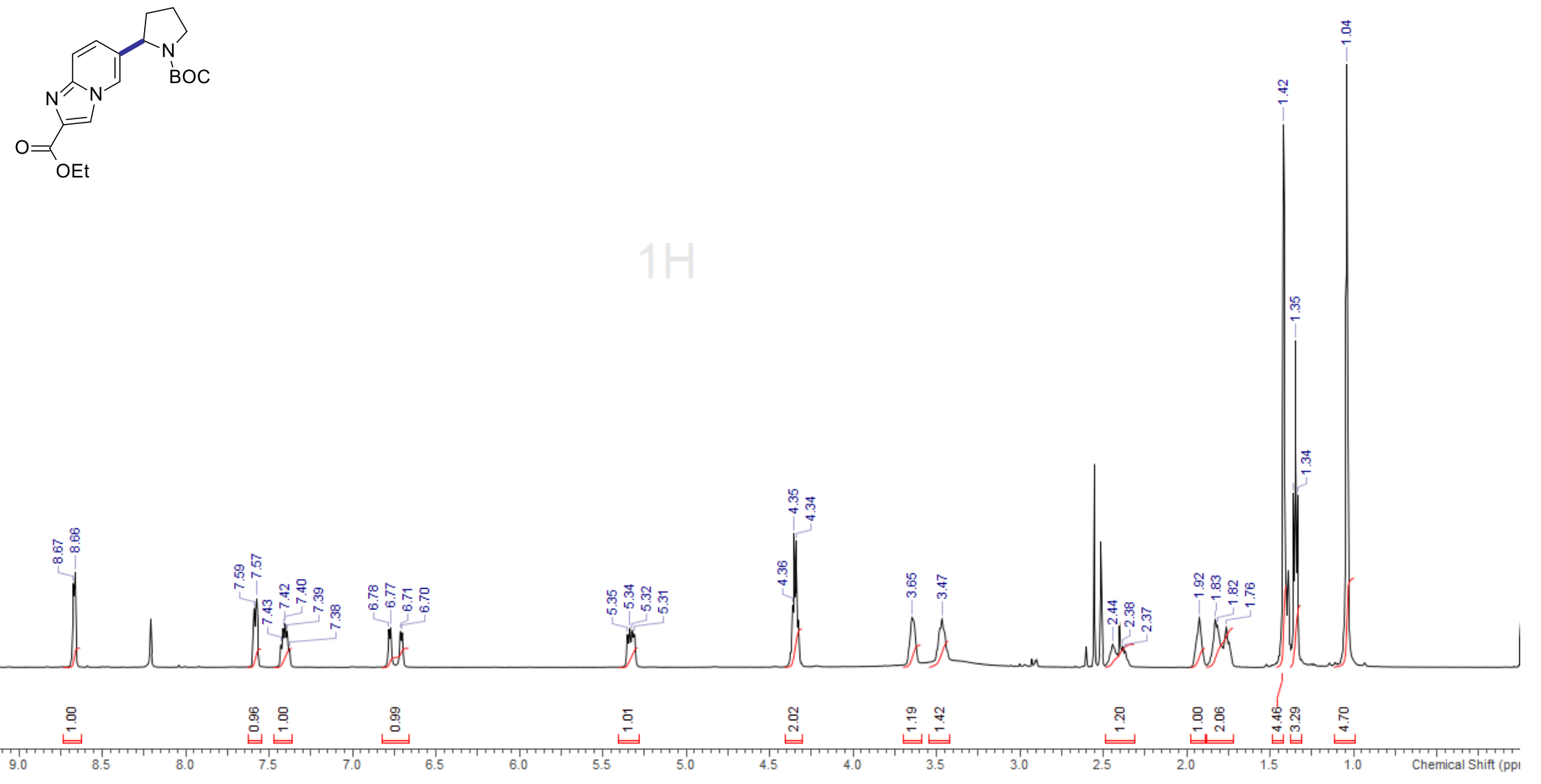
Ethyl 6-(1-tert-butoxycarbonylpyrrolidin-2-yl)imidazo[1,2-a]pyridine-2-carboxylate ${ }^{13} \mathrm{C}$ NMR $\left(126 \mathrm{MHz}, \mathrm{DMSO}-d_{6}\right)$
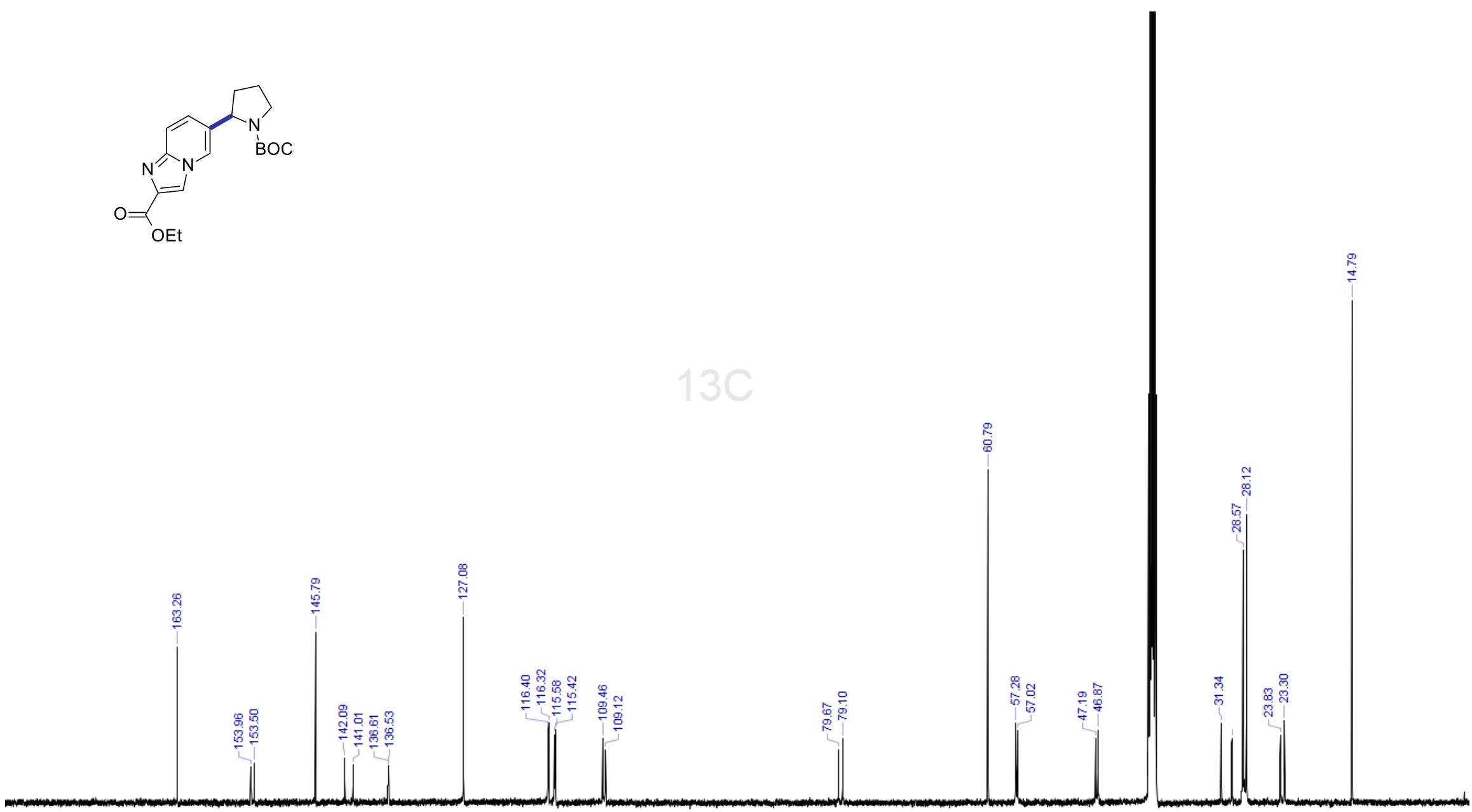

$T_{184}$

$176 \quad 168$

160

$152+144$

128

$120 \quad 112$

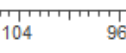

88 

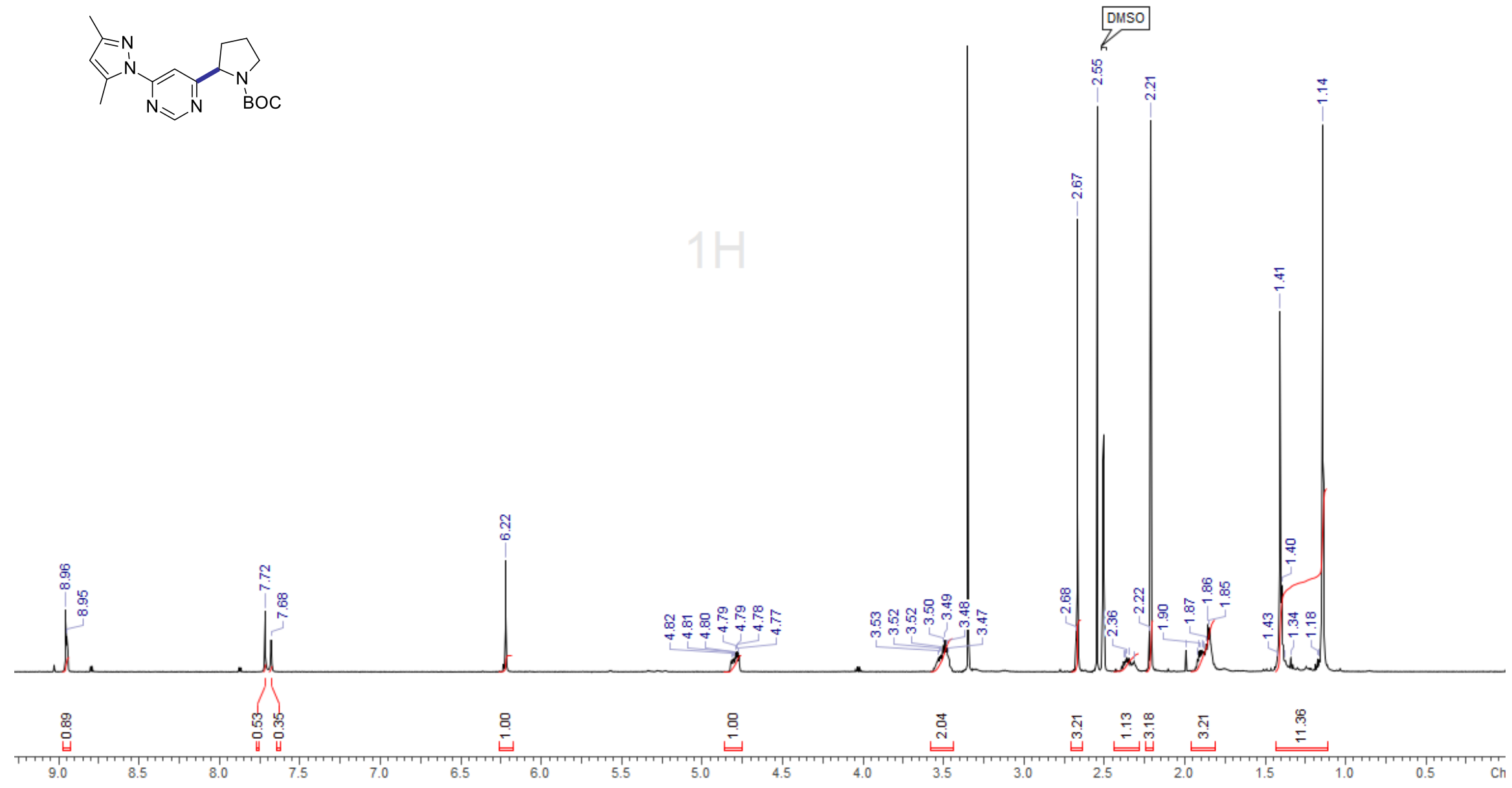
tert-Butyl 2-[6-(3,5-dimethylpyrazol-1-yl)pyrimidin-4-yl]pyrrolidine-1-carboxylate ${ }^{13} \mathrm{C}$ NMR $\left(126 \mathrm{MHz}\right.$, DMSO- $\left.d_{6}\right)$
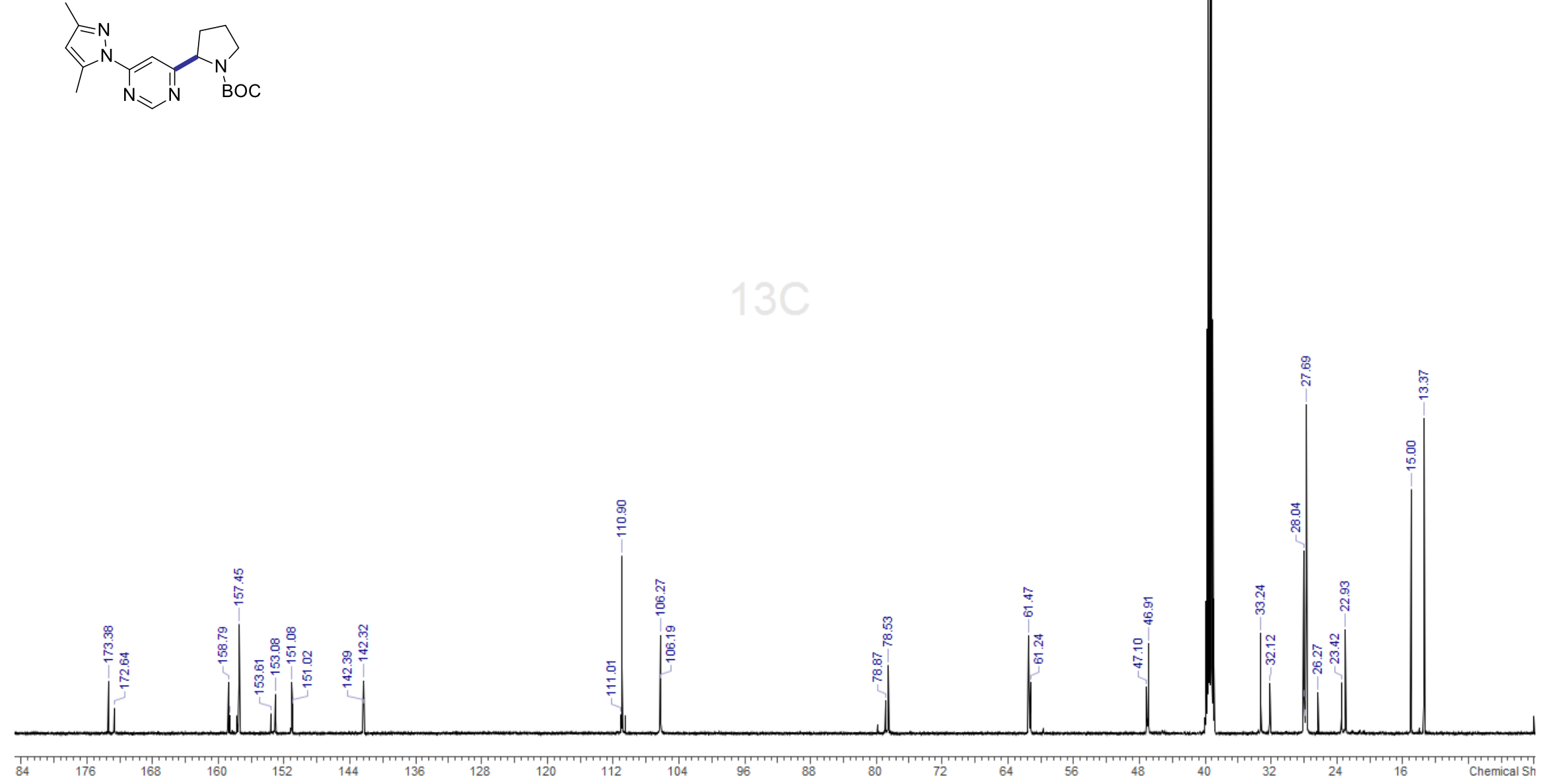
Methyl 6-[1-(tert-butoxycarbonylamino)-2-phenyl-ethyl]pyridine-2-carboxylate ${ }^{1} \mathrm{H}$ NMR $(600 \mathrm{MHz}$, DMSO-d6) (rotamers visible)
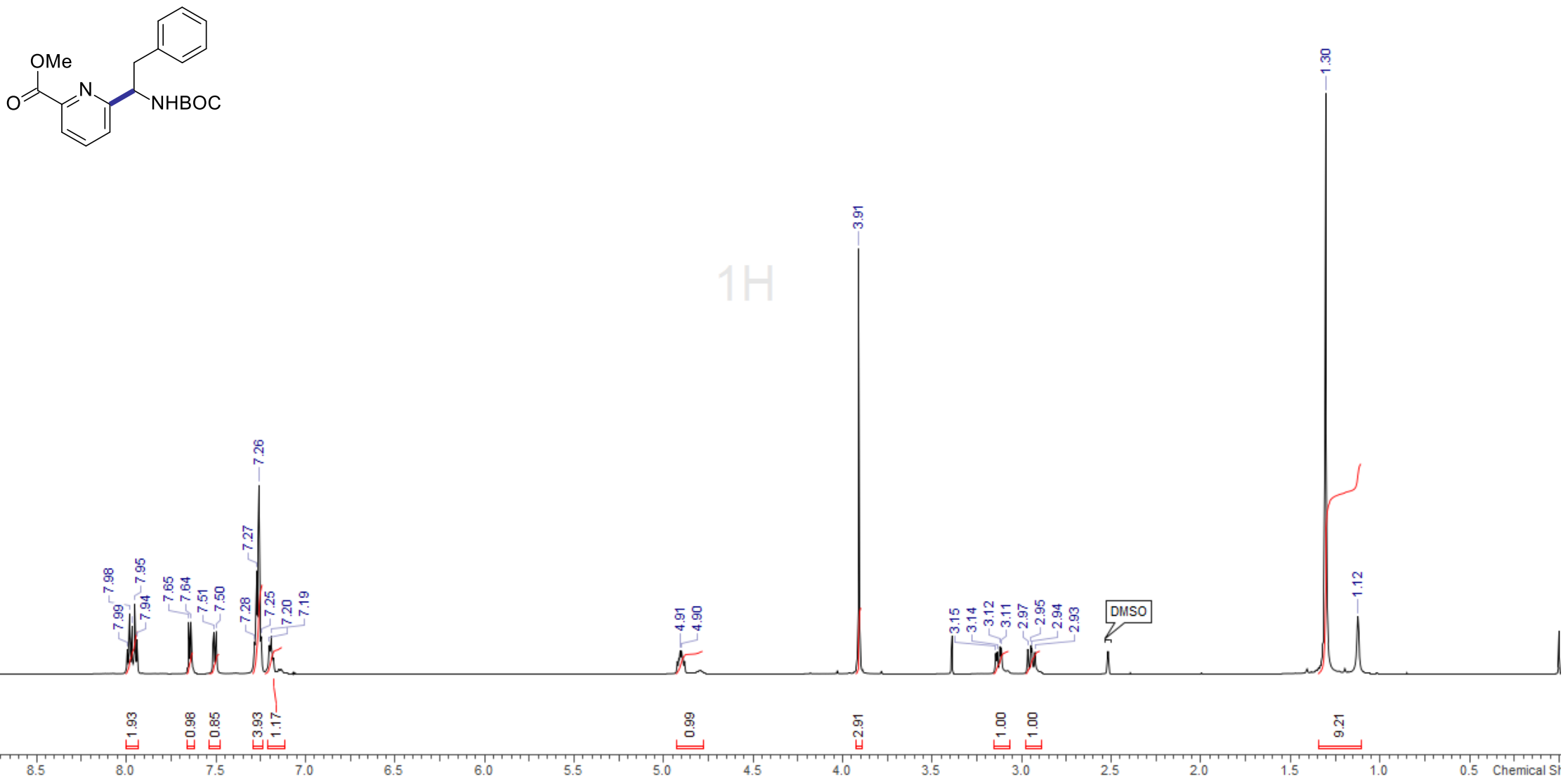
Methyl 6-[1-(tert-butoxycarbonylamino)-2-phenyl-ethyl]pyridine-2-carboxylate ${ }^{13} \mathrm{C}$ NMR $\left(600 \mathrm{MHz}\right.$, DMSO- $\left.d_{6}\right)$
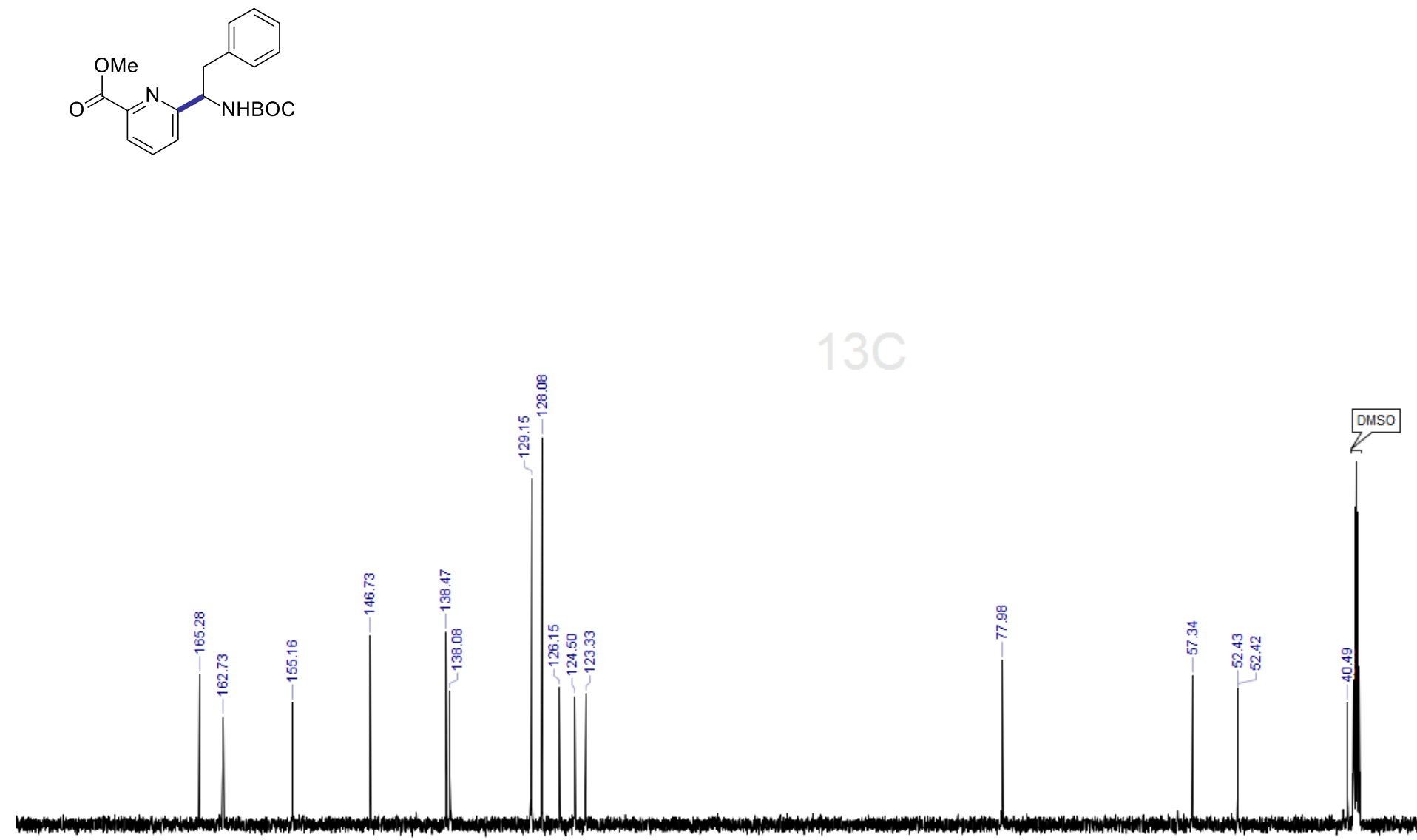
tert-Butyl 2-[3-hydroxy-4-[methyl(phenyl)sulfamoyl]phenyl]piperidine-1-carboxylate ${ }^{1} \mathrm{H}-\mathrm{NMR}$ (500 MHz, DMSO- $\left.d_{6}\right)$
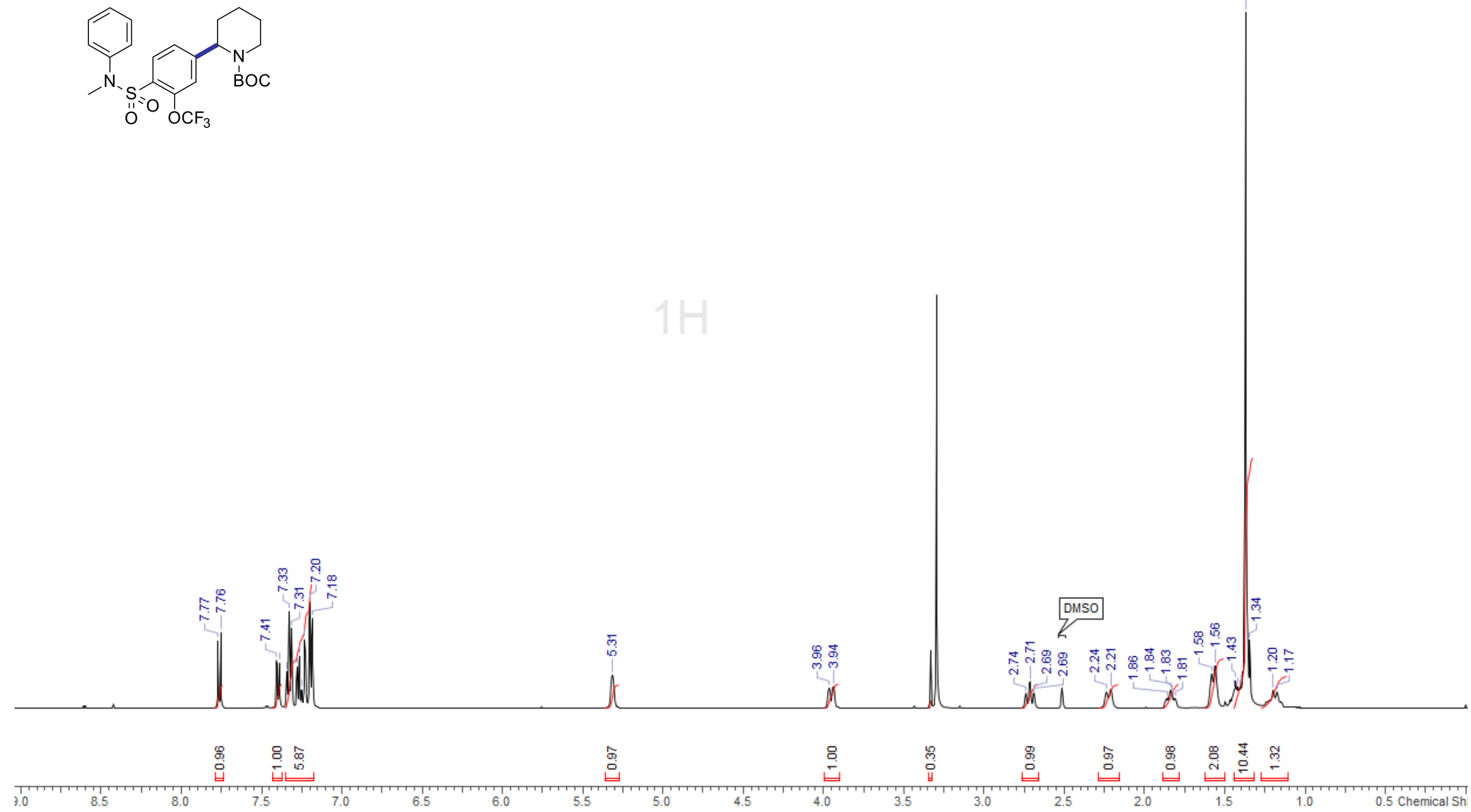
tert-Butyl 2-[3-hydroxy-4-[methyl(phenyl)sulfamoyl]phenyl]piperidine-1-carboxylate ${ }^{1} \mathrm{H}-\mathrm{NMR}\left(126 \mathrm{MHz}\right.$, DMSO- $\left.d_{6}\right)$
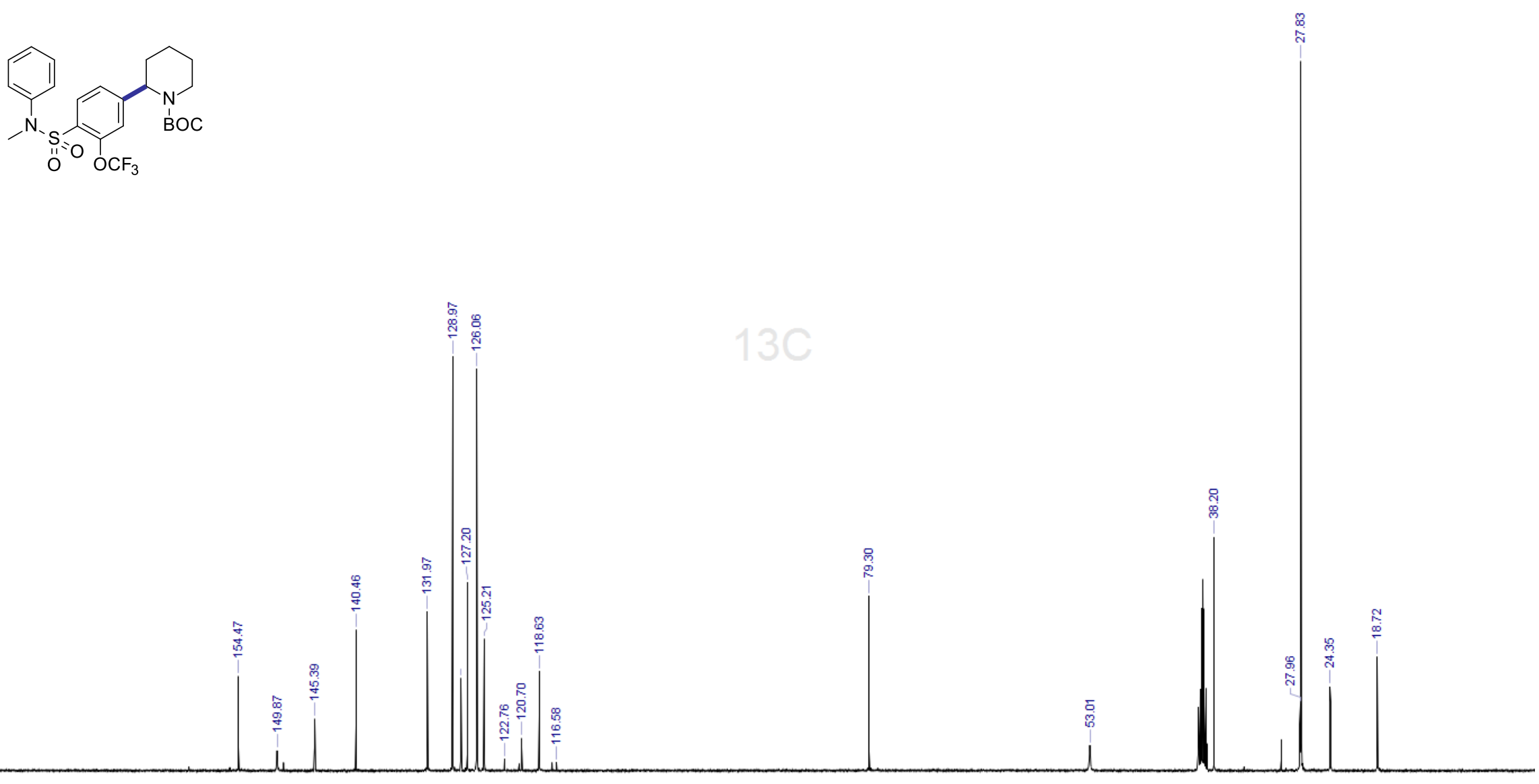

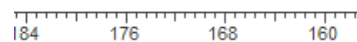
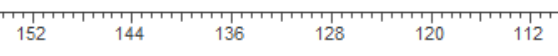
Methyl 4-(2-cyanoethyl)benzoate ${ }^{1} \mathrm{H}-\mathrm{NMR}\left(500 \mathrm{MHz}, \mathrm{CDCl}_{3}\right)$
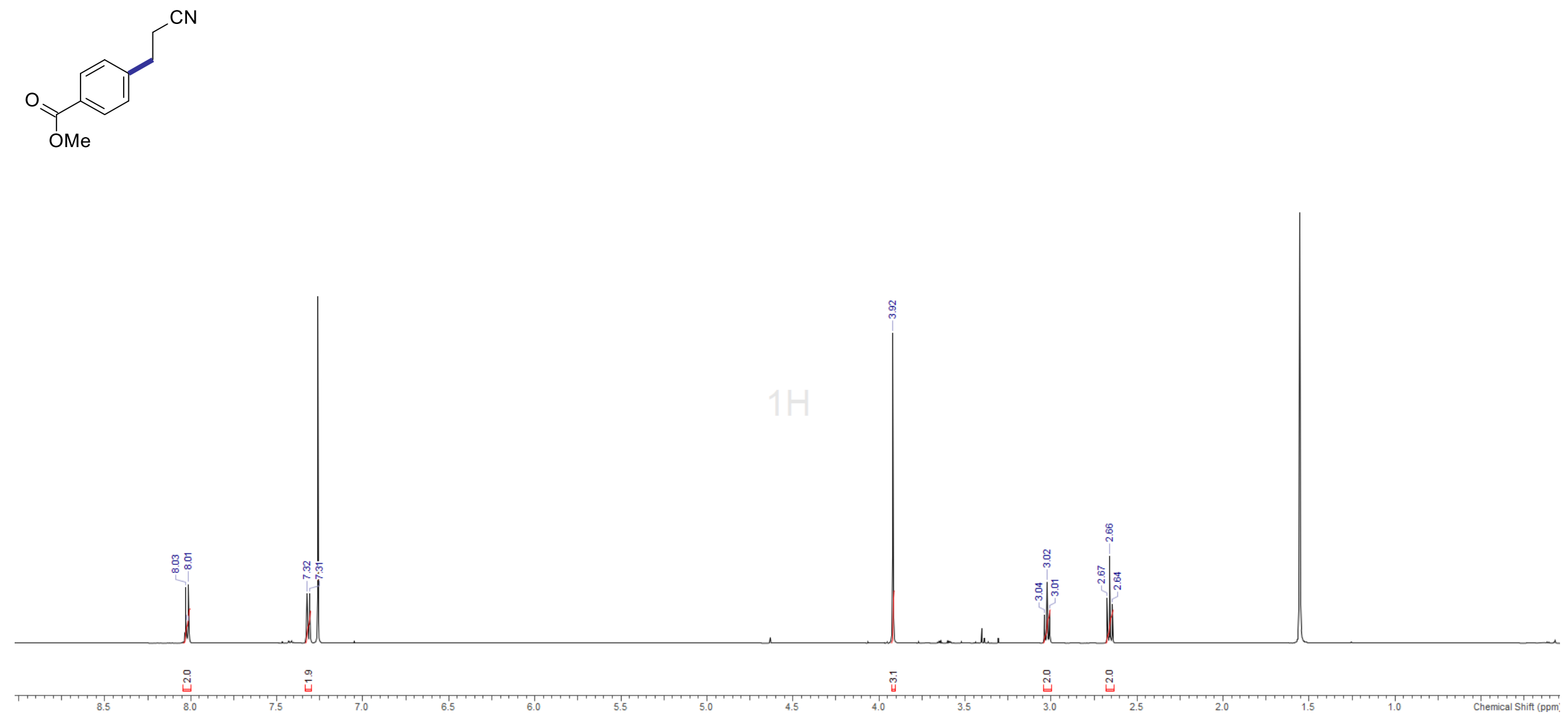
Methyl 4-(2-cyanoethyl)benzoate ${ }^{13} \mathrm{C}-\mathrm{NMR}\left(126 \mathrm{MHz}, \mathrm{CDCl}_{3}\right)$
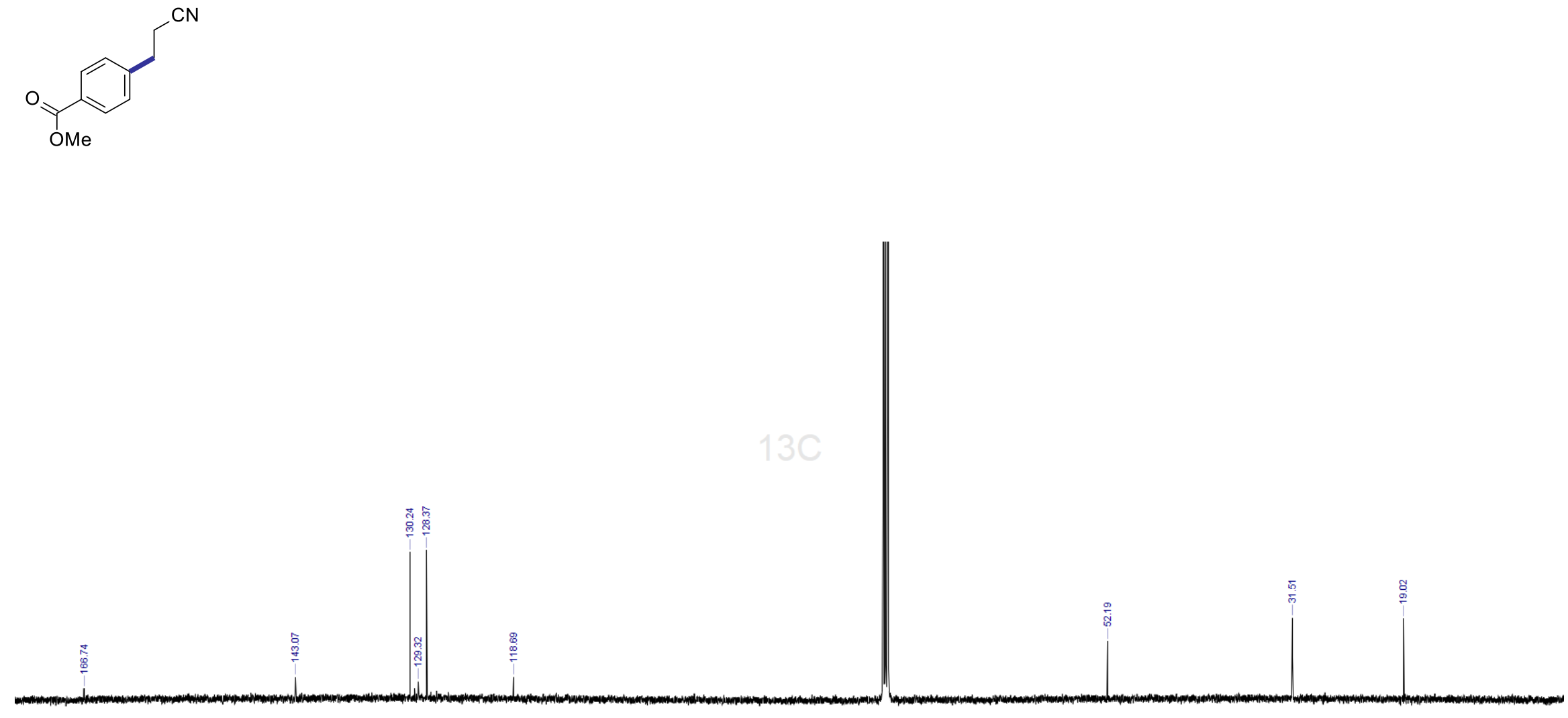
tert-Butyl 4-cyano-4-(4-isobutylphenyl)piperidine-1-carboxylate ${ }^{1} \mathrm{H}$ NMR (500 MHz, DMSO- $\left.d_{6}\right)$

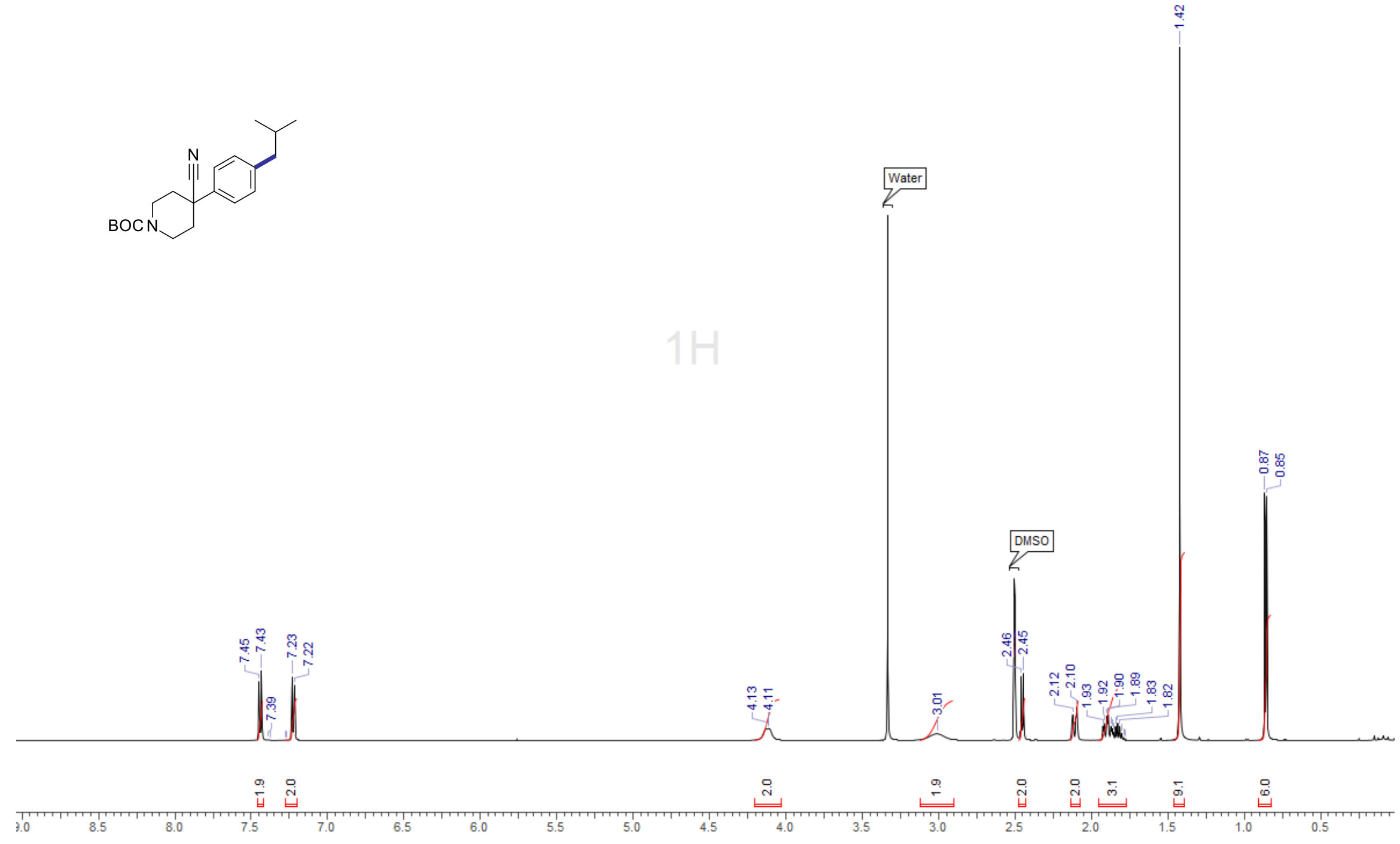


tert-Butyl 4-cyano-4-(4-isobutylphenyl)piperidine-1-carboxylate ${ }^{13} \mathrm{C}$ NMR (126 MHz, DMSO-d6)
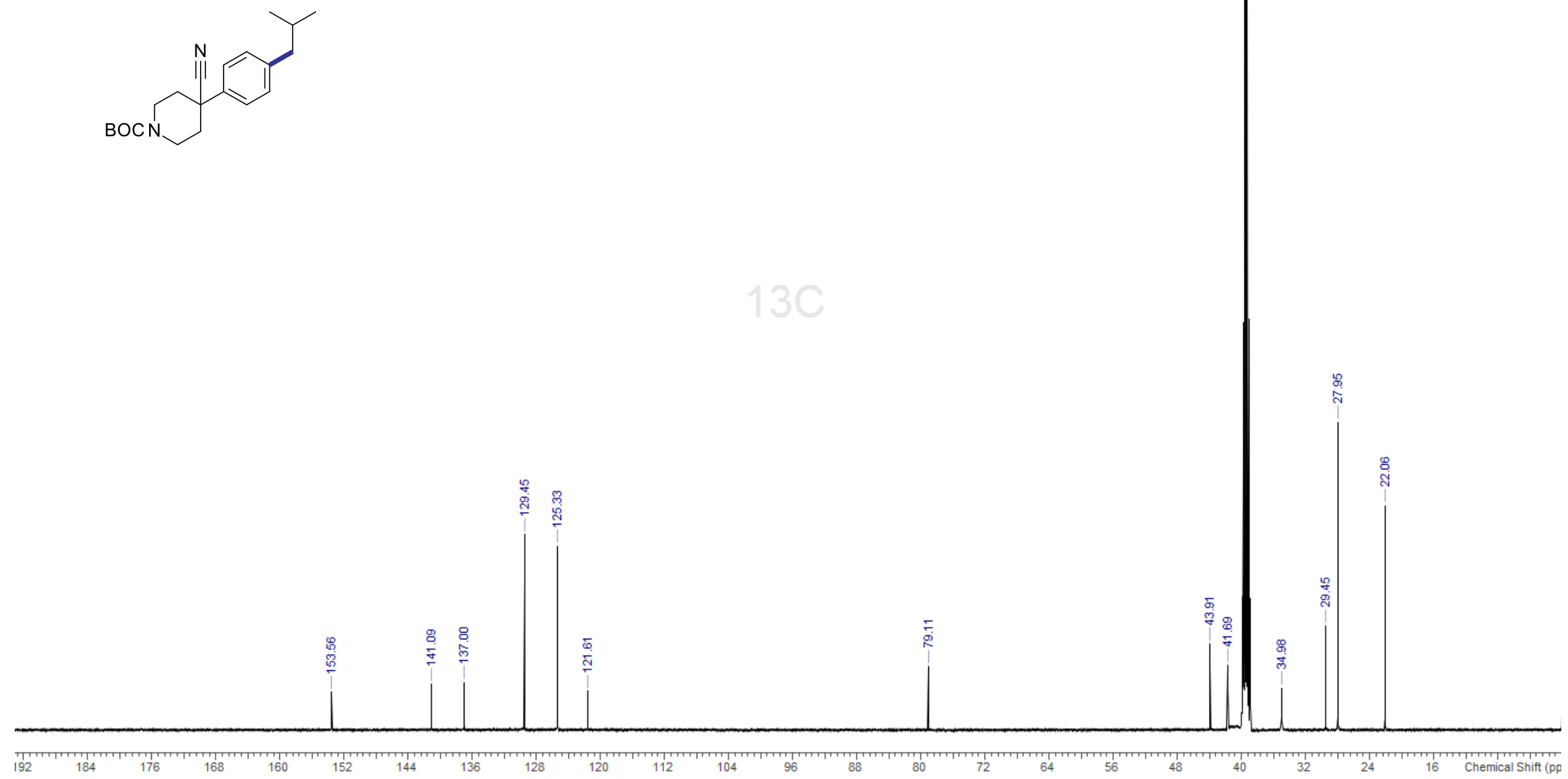
tert-Butyl 4-[3-hydroxy-4-[methyl(phenyl)sulfamoyl]phenyl]piperidine-1-carboxylate ${ }^{1} \mathrm{H}$ NMR (500 MHz, DMSO-d6)
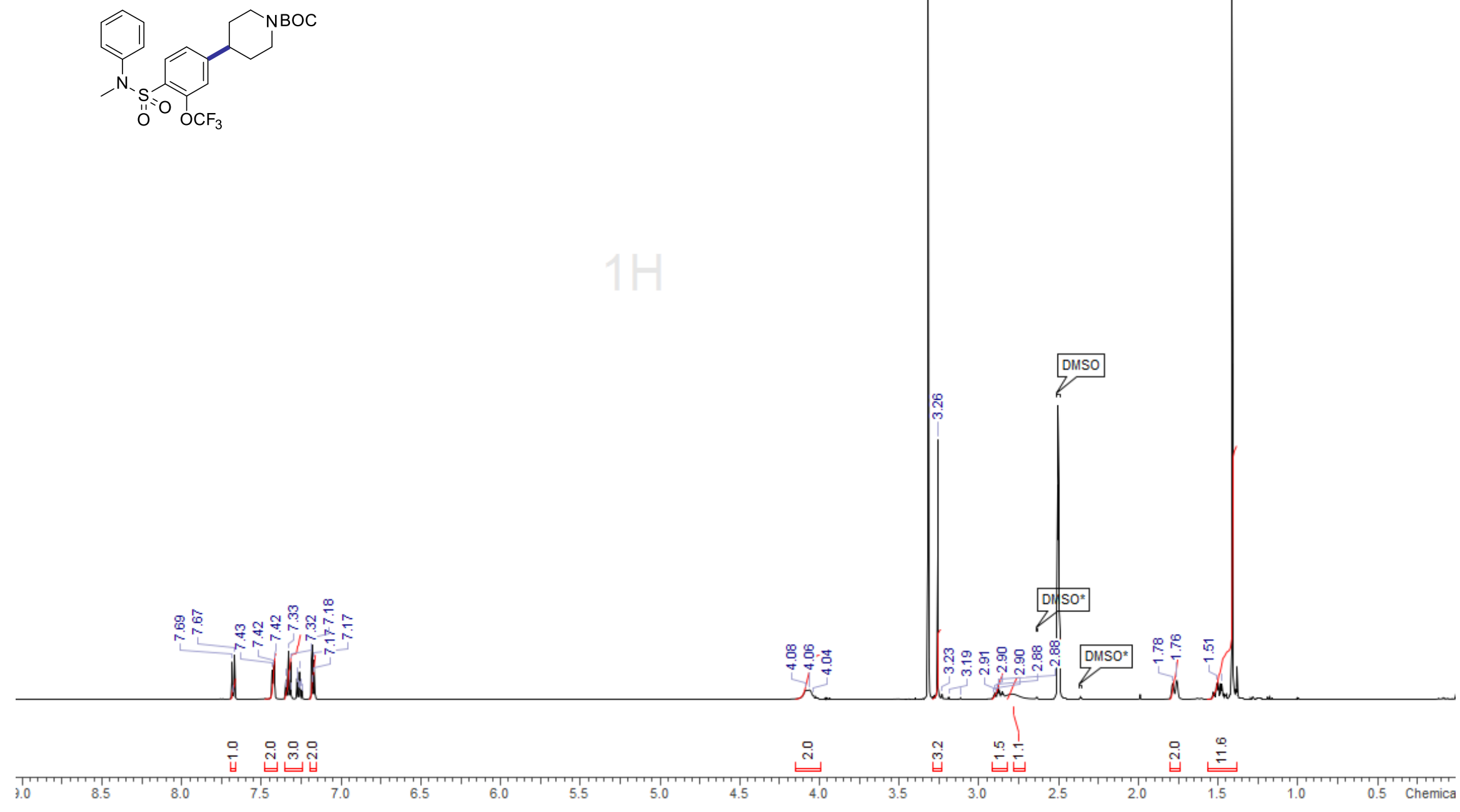
tert-Butyl 4-[3-hydroxy-4-[methyl(phenyl)sulfamoyl]phenyl]piperidine-1-carboxylate ${ }^{13} \mathrm{C}$ NMR $(126 \mathrm{MHz}$, DMSO-d6)
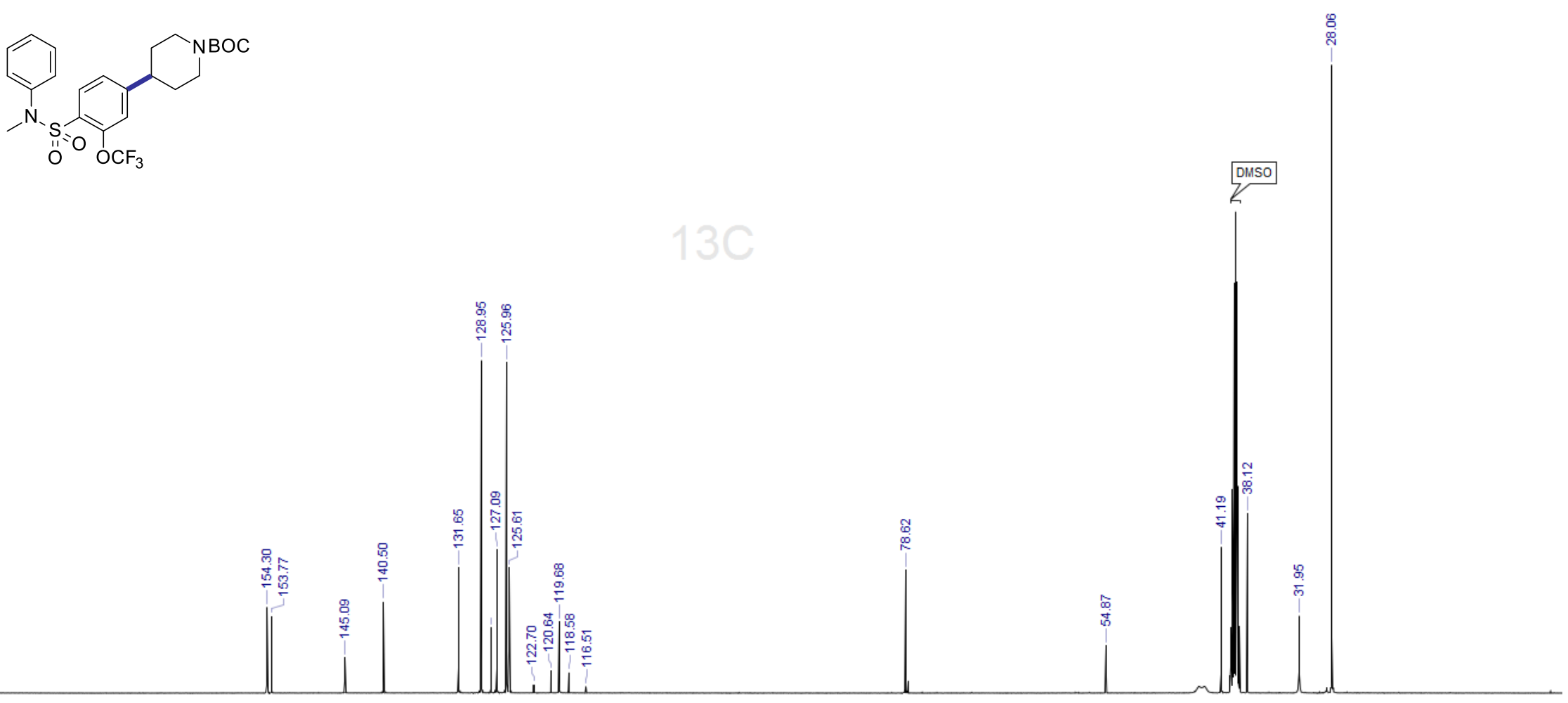

92

$152 \quad 144$

$136 \quad 128$

$104+96$

64

32

16 Chemical Shift (ppm: 


\section{[5-(4-Cyclohexylphenyl)-2-furyl]-morpholino-methanone ${ }^{1} \mathrm{H}$ NMR (500 MHz, DMSO-d6)}

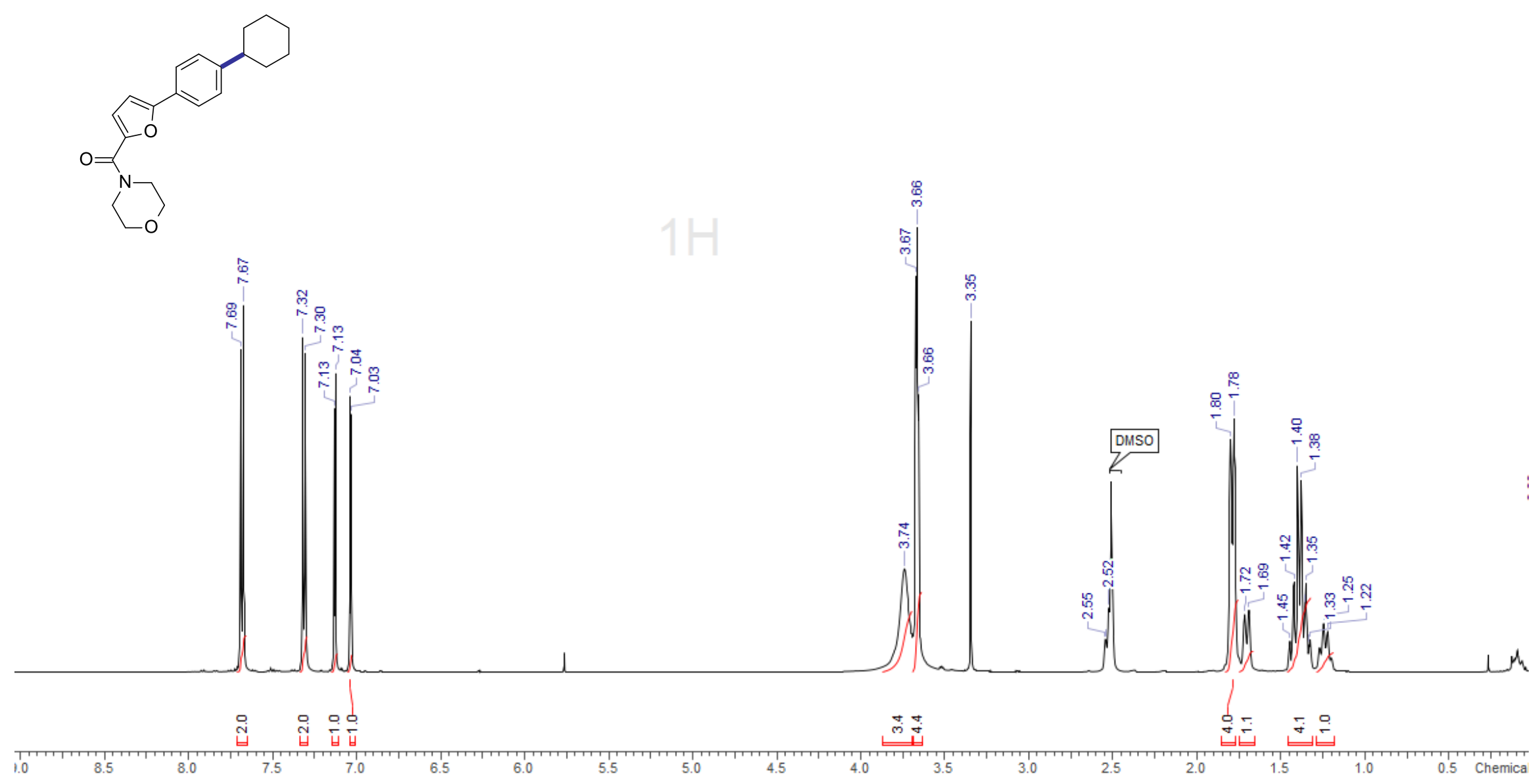




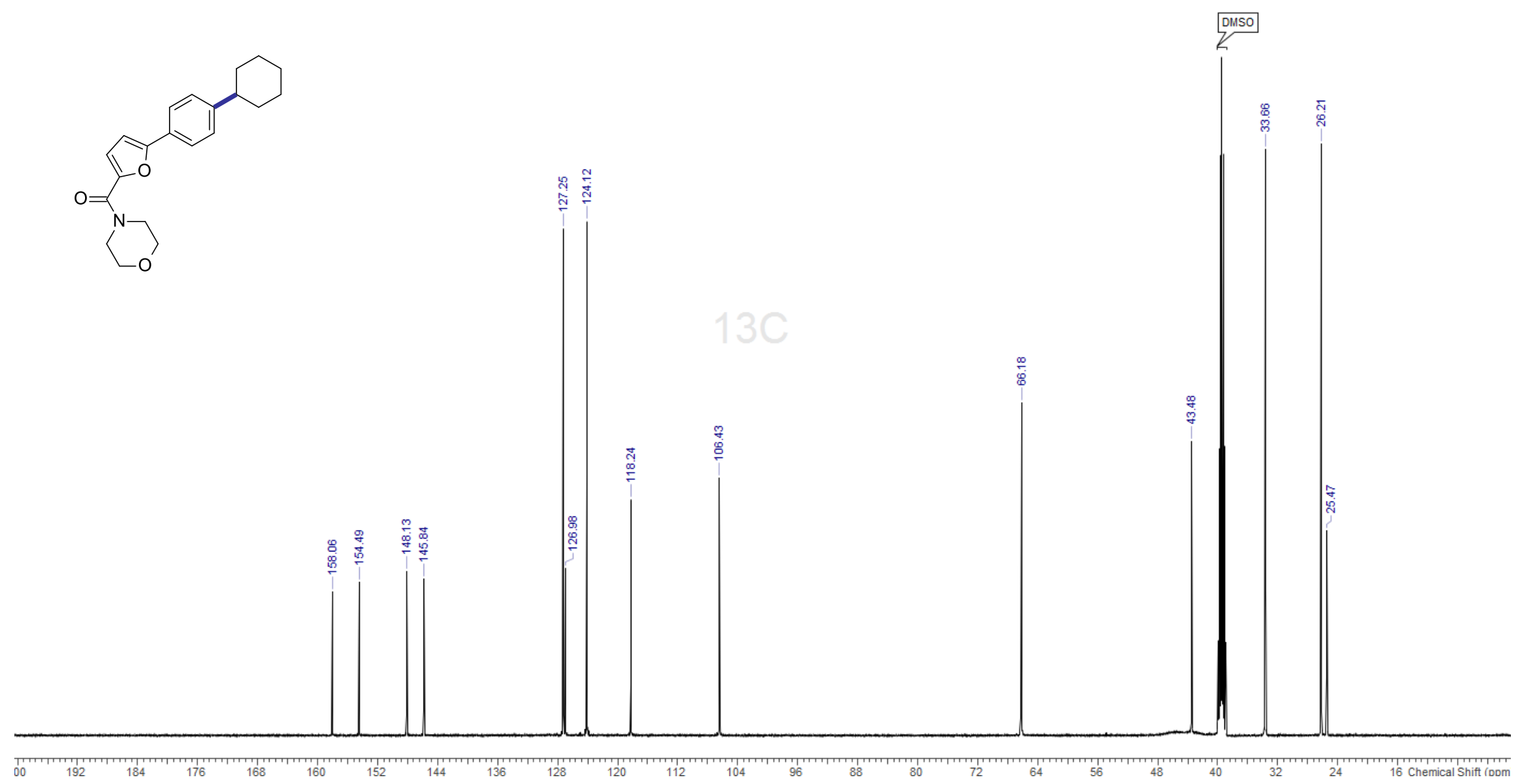


tert-Butyl 7-cyclohexyl-4-oxo-spiro[chromane-2,4'-piperidine]-1'-carboxylate ${ }^{1} \mathrm{H}$ NMR (500 MHz, DMSO-d6)
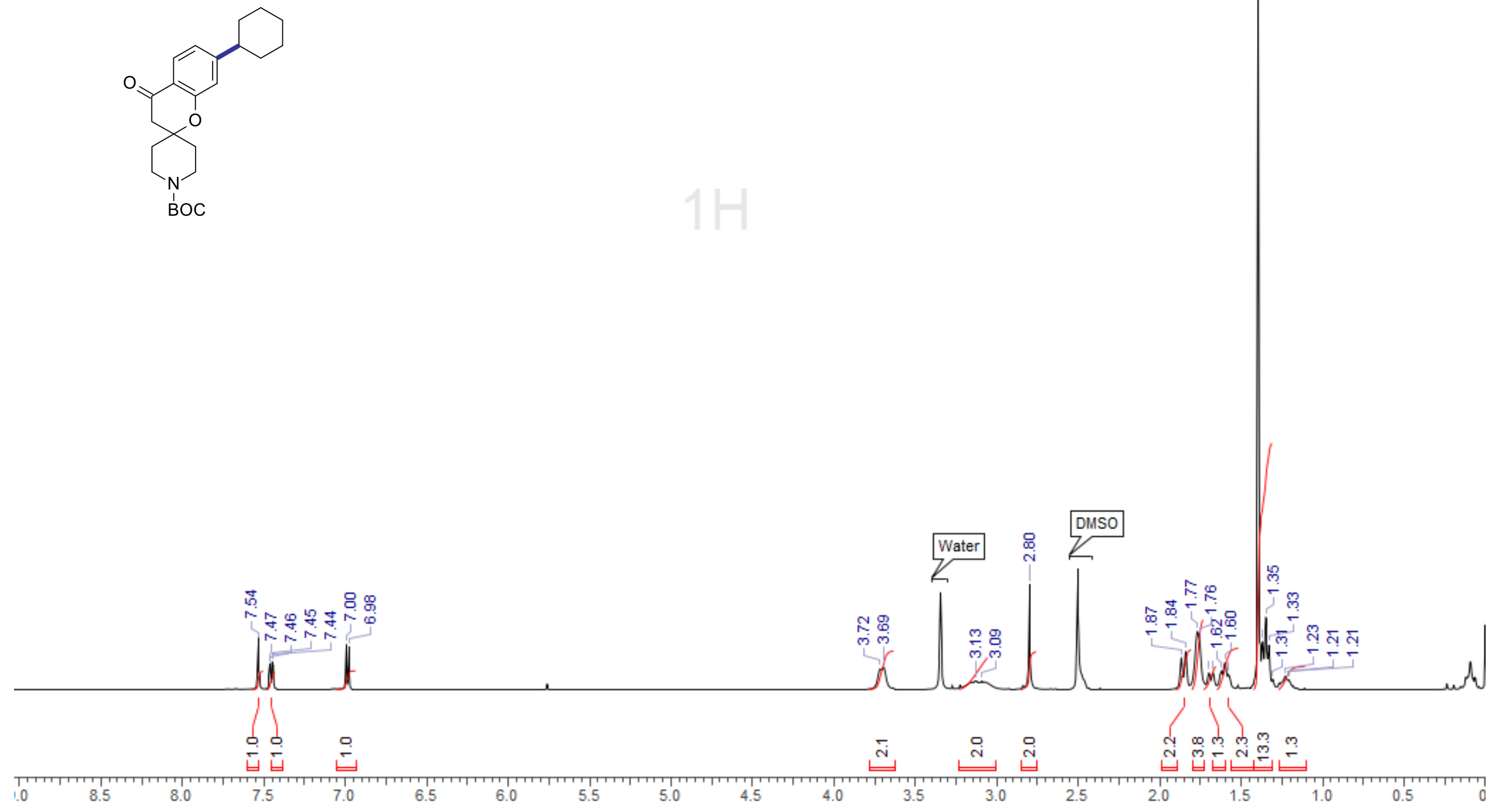
tert-Butyl 7-cyclohexyl-4-oxo-spiro[chromane-2,4'-piperidine]-1'-carboxylate ${ }^{13} \mathrm{C}$ NMR (126 MHz, DMSO-d6)
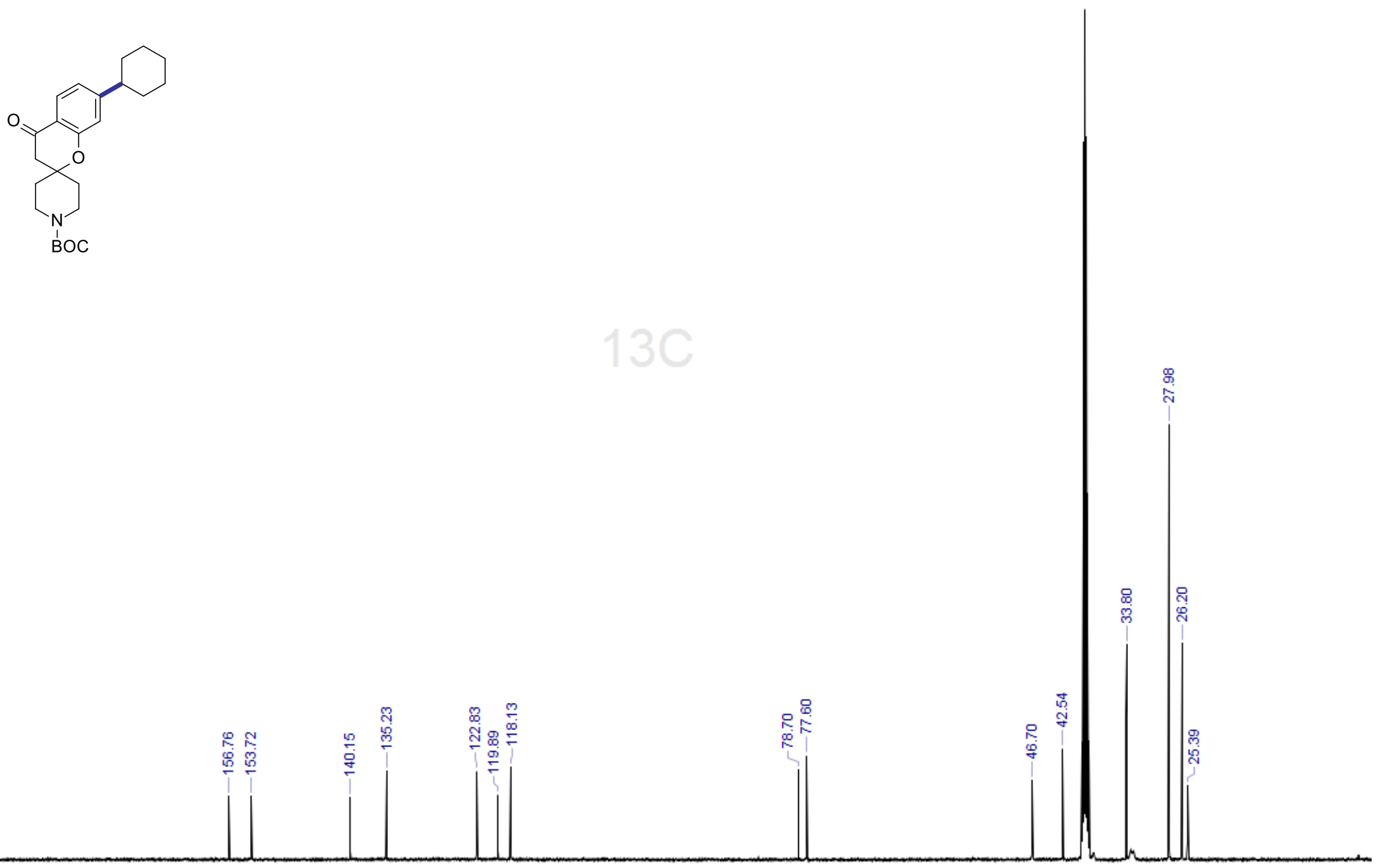

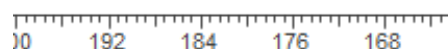
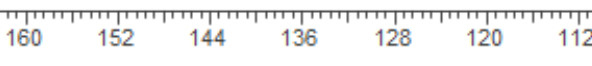

104
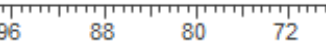
tert-Butyl 2-benzylpyrrolidine-1-carboxylate ${ }^{1} \mathrm{H}-\mathrm{NMR}\left(500 \mathrm{MHz}, \mathrm{CDCl}_{3}\right)$

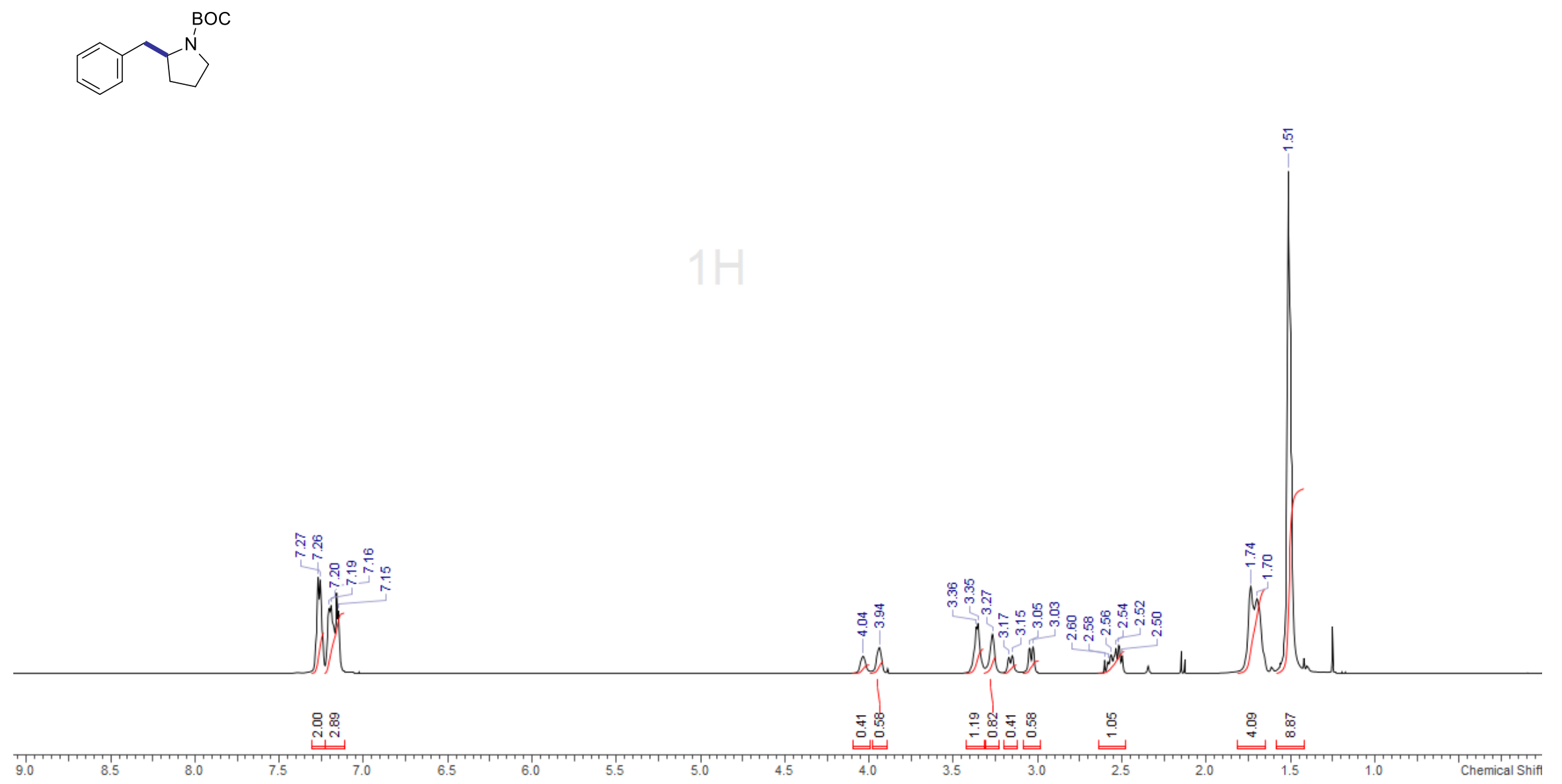


tert-Butyl 2-benzylpyrrolidine-1-carboxylate ${ }^{13} \mathrm{C}-\mathrm{NMR}\left(126 \mathrm{MHz}, \mathrm{CDCl}_{3}\right)$

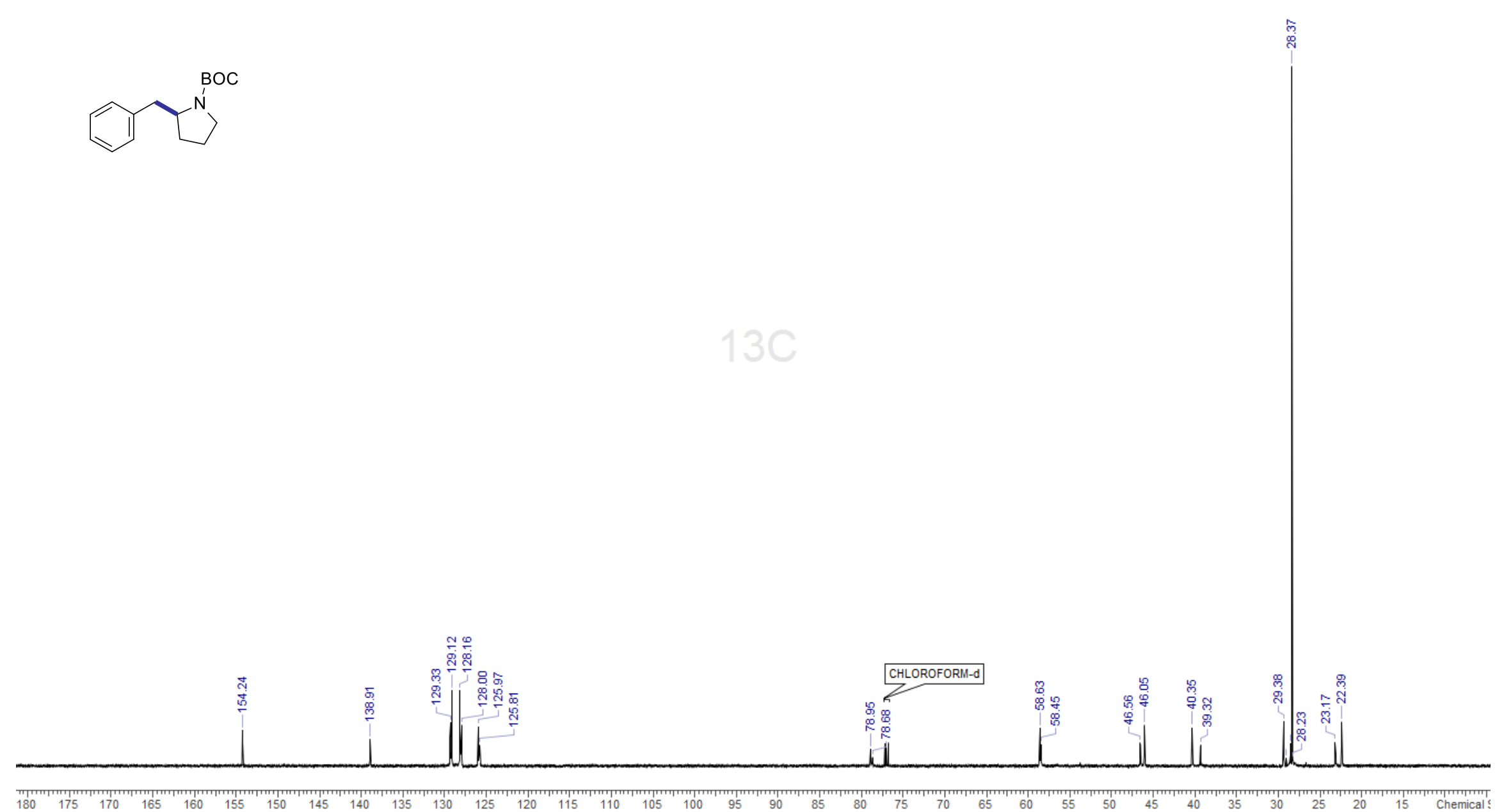


Methyl 4-benzylbenzoate ${ }^{1} \mathrm{H}-\mathrm{NMR}\left(500 \mathrm{MHz}, \mathrm{CDCl}_{3}\right)$
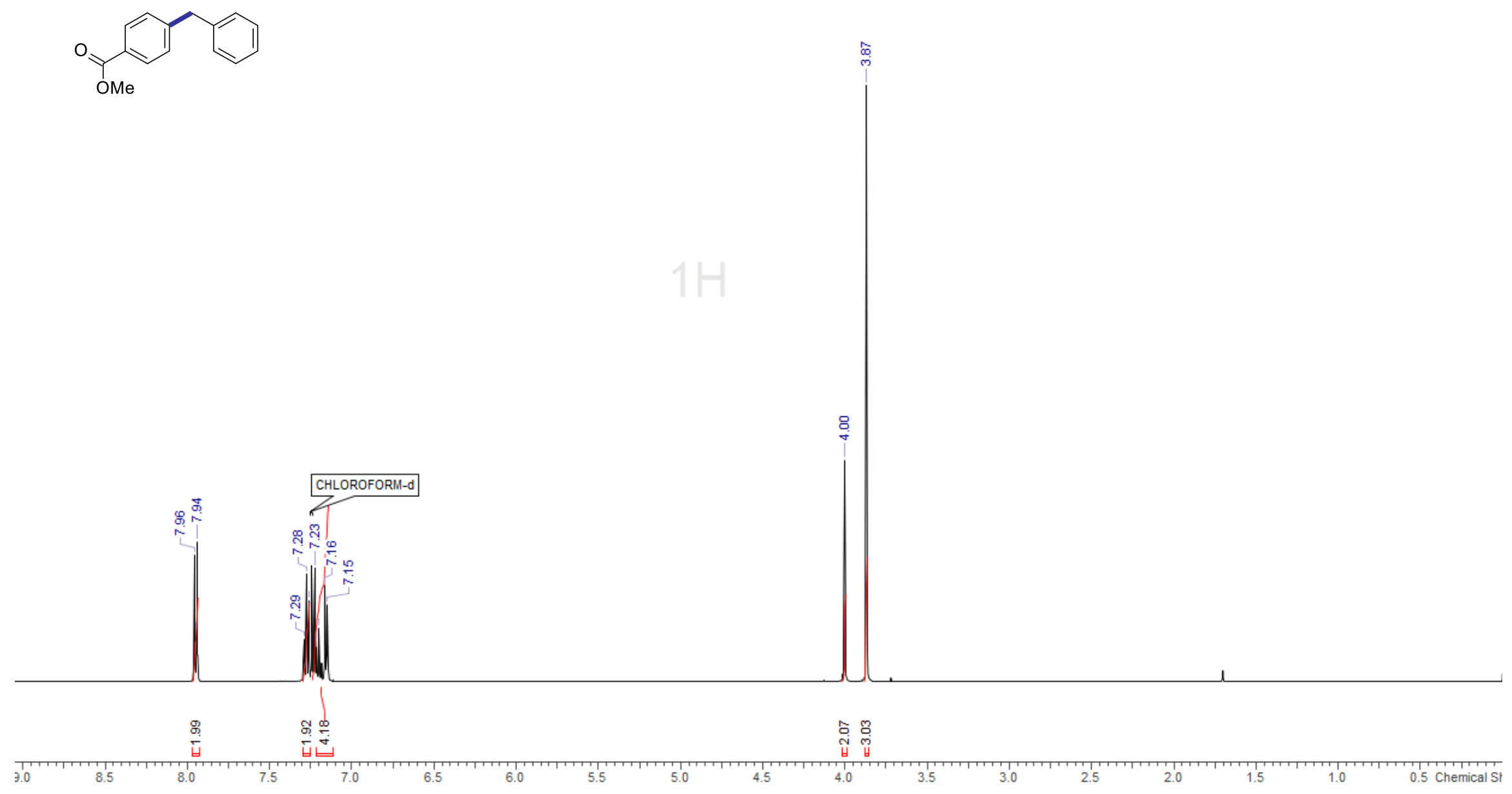

S59 
Methyl 4-benzylbenzoate ${ }^{13} \mathrm{C}-\mathrm{NMR}\left(126 \mathrm{MHz}, \mathrm{CDCl}_{3}\right)$

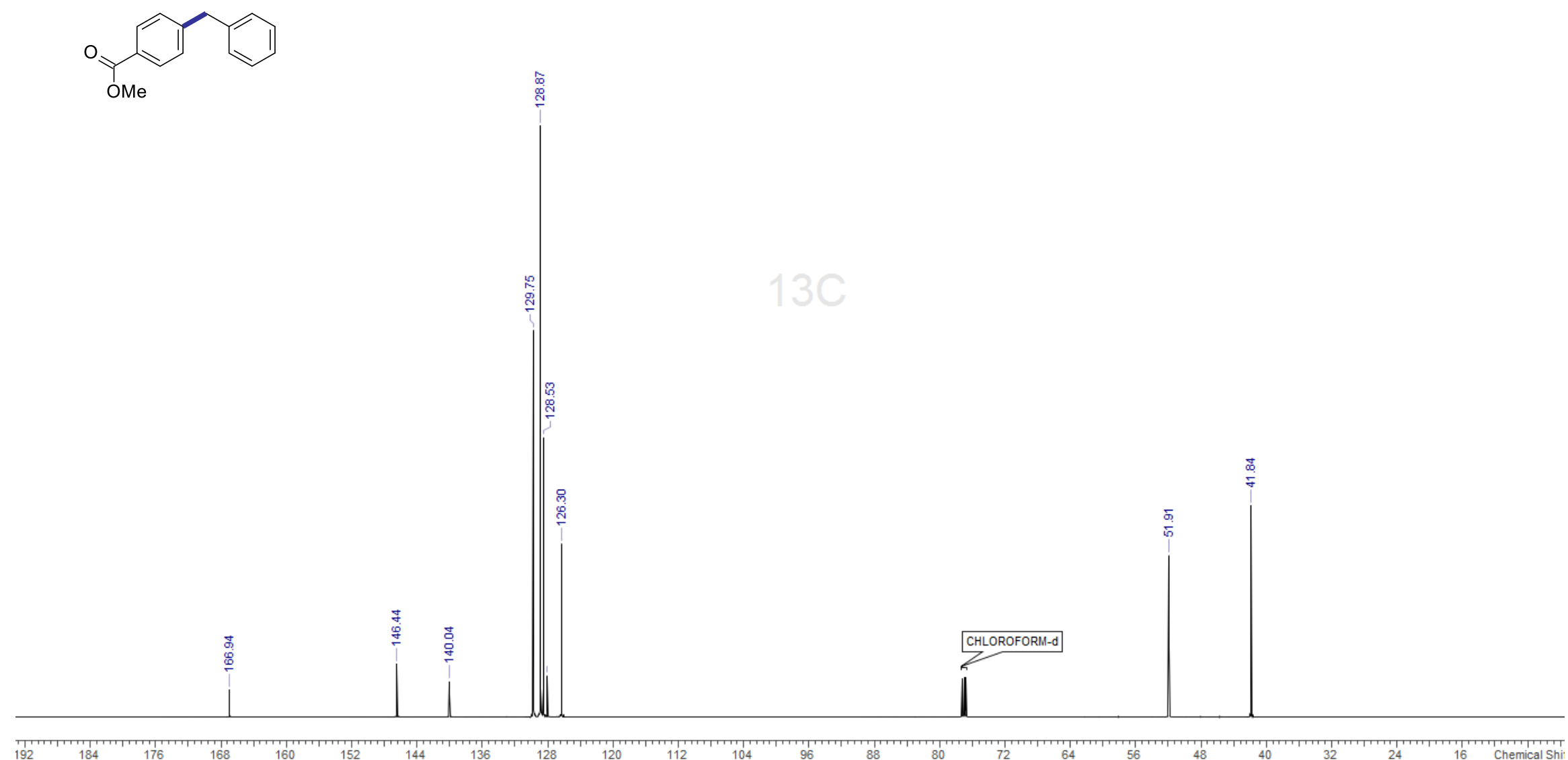

